\title{
DATA DECISION ANALYSIS: Project Shoal
}

\author{
prepared by \\ Greg Pohll, John Tracy, Frank Forsgren
}

submitted to

Nevada Operations Office

U.S. Department of Energy

January 1999 
This report was prepared as an account of work sponsored by the United States Government. Neither the United States nor the United States Department of Energy, nor any of their employees, nor any of their contractors, subcontractors or their employees, makes any warranty, express or implied, or assumes any legal liability or responsibility for the accuracy, completeness, or any third party's use or the results of such use of any information, apparatus, product, or process disclosed, or represents that its use would not infringe privately owned rights. Reference herein to any specific commercial product, process, or service by trade name, trademark, manufacturer, or otherwise, does not necessarily constitute or imply its endorsement, recommendation, or favoring by the United States Government or any agency thereof or its contractors or subcontractors. The views and opinions of authors expressed herein do not necessarily state or reflect those of the United States Government or any agency thereof.

This report has been reproduced directly from the best available copy.

Available to the public from:

U.S. Department of Commerce

National Technical Information Service

5285 Port Royal Rd.

Springfield, VA 22161

(703) $487-4650$

Available electronically at $h t t p: / / w w w . d o e . g o v / b r i d g e$

Available to the U.S. Department of Energy and its contractors from:

U.S. Department of Energy

Office of Scientific and Technical Information

P.O. Box 62

Oak Ridge, TN 37831

(423) 576-8401 


\title{
DATA DECISION ANALYSIS: Project Shoal
}

\author{
prepared by \\ Greg Pohll ${ }^{1}$, John Tracy ${ }^{1}$, Frank Forsgren ${ }^{2}$ \\ Water Resources Center \\ Desert Research Institute \\ University and Community College System of Nevada \\ Publication No. 45166
}

submitted to

Nevada Operations Office

U.S. Department of Energy

Las Vegas, Nevada

January 1999

${ }^{1}$ Desert Research Institute, Water Resources Center

${ }^{2}$ HSI Geotrans/IT Corporation

The work upon which this report is based was supported by the U.S. Department of Energy under Contract \#DE-AC08-95NV11508. Approved for public release; further dissemination unlimited. 


\section{EXECUTIVE SUMMARY}

The purpose of this study was to determine the most appropriate field activities in terms of reducing the uncertainty in the groundwater flow and transport model at the Project Shoal area. The data decision analysis relied on well-known tools of statistics and uncertainty analysis. This procedure identified nine parameters that were deemed uncertain. These included effective porosity, hydraulic head, surface recharge, hydraulic conductivity, fracture correlation scale, fracture orientation, dip angle, dissolution rate of radionuclides from the puddle glass, and the retardation coefficient, which describes the sorption characteristics. The parameter uncertainty was described by assigning prior distributions for each of these parameters. Next, the various field activities were identified that would provide additional information on these parameters. Each of the field activities was evaluated by an expert panel to estimate posterior distribution of the parameters assuming a field activity was performed. The posterior distributions describe the ability of the field activity to estimate the true value of the nine parameters. Monte Carlo techniques were used to determine the current uncertainty, the reduction of uncertainty if a single parameter was known with certainty, and the reduction of uncertainty expected from each field activity on the model predictions. The mean breakthrough time to the downgradient land withdrawal boundary and the peak concentration at the control boundary were used to evaluate the uncertainty reduction. The radionuclide ${ }^{137} \mathrm{Cs}$ was used as the reference solute, as its migration is dependent on all of the parameters. The results indicate that the current uncertainty of the model yields a 95 percent confidence interval between 42 and 1,412 years for the mean breakthrough time and an 18 order-of-magnitude range in peak concentration.

The uncertainty in effective porosity and recharge dominates the uncertainty in the model predictions, while the other parameters are less important. A two-stage process was used to evaluate the optimal field activities. For all of the field activities combined there were five activities that were found to be "optimal" in terms of uncertainty reduction per unit cost: two-well, natural-gradient, energy budget, and single-well tracer tests, and the vadose zone modeling. A subset of the field activities was chosen such that there would be no duplication in parameter characterization. Of this subset, the vadose zone model, barometric test, energy budget, and the two-well tracer test were found to be optimal for the peak breakthrough time metric, while the single-well tracer test and the hydraulic head measurements are also considered optimal for the peak concentration metric. The environmental tracer activity was not found to be optimal, yet this activity may provide additional information on the transport system. Care must be taken in using this analysis to design a field characterization plan, as many assumptions were required in the analysis. First, many subjective assumptions were required to assess the reliability of the field activities in terms of their ability to reduce the uncertainty in the mean parameters. Actual field characterization may not result in the same reduction in model output uncertainty as estimated by this analysis. Second, this analysis focused on the reduction in model uncertainty due to the reduction in the uncertainty in the mean parameters. If the uncertainty in the mean parameters is reduced to zero, there still exists uncertainty in the natural heterogeneity that can never be reduced to zero. Therefore, this analysis should be used in combination with expert judgement when designing a field characterization strategy. 


\section{CONTENTS}

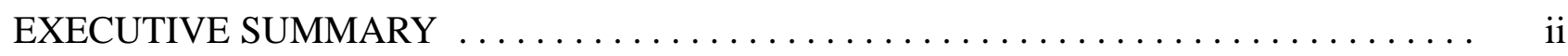

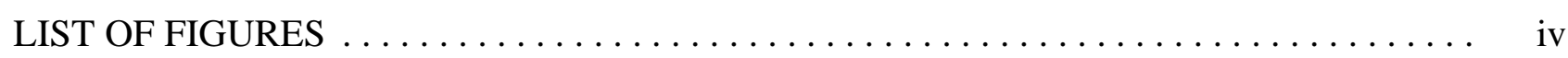

LIST OF TABLES $\ldots \ldots \ldots \ldots \ldots \ldots \ldots \ldots \ldots \ldots \ldots \ldots \ldots \ldots \ldots \ldots \ldots \ldots \ldots \ldots$

INTRODUCTION $\ldots \ldots \ldots \ldots \ldots \ldots \ldots \ldots \ldots \ldots \ldots \ldots \ldots \ldots \ldots \ldots \ldots \ldots$

COST ANALYSIS FOR FIELD ACTIVITIES $\ldots \ldots \ldots \ldots \ldots \ldots \ldots \ldots \ldots \ldots \ldots \ldots$

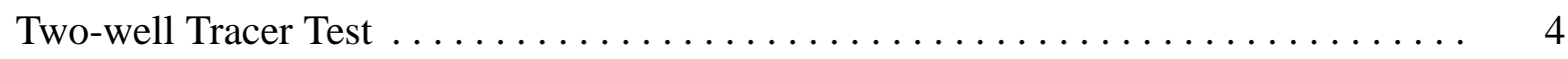

Barometric Tests (Including Vapor Extraction Tests) $\ldots \ldots \ldots \ldots \ldots \ldots \ldots$

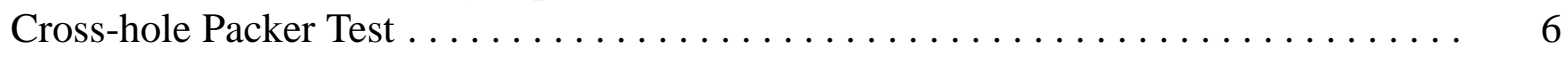

Hydraulic Head Measurements $\ldots \ldots \ldots \ldots \ldots \ldots \ldots \ldots \ldots \ldots \ldots \ldots \ldots$

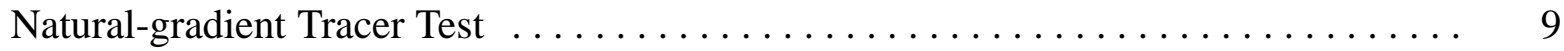

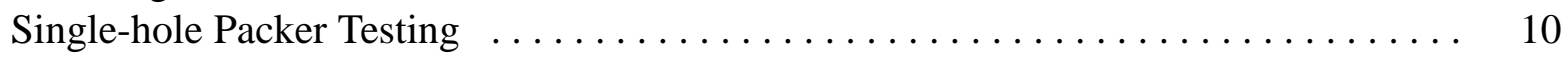

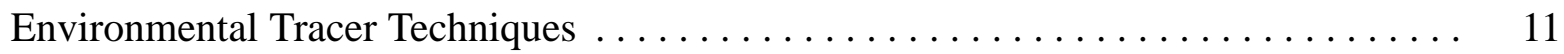

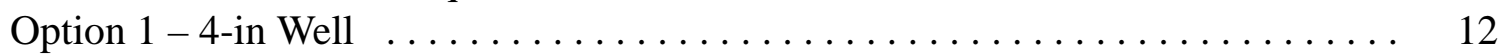

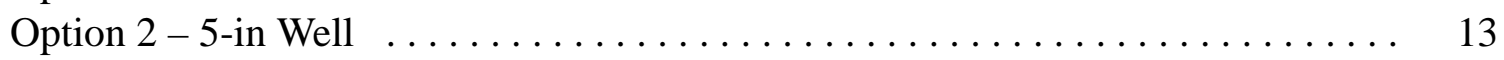

Single-well Tracer Test $\ldots \ldots \ldots \ldots \ldots \ldots \ldots \ldots \ldots \ldots \ldots \ldots \ldots \ldots \ldots \ldots$

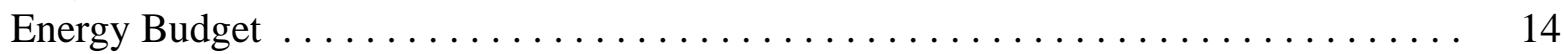

Vadose Zone Model $\ldots \ldots \ldots \ldots \ldots \ldots \ldots \ldots \ldots \ldots \ldots \ldots \ldots$

TECHNICAL APPROACH $\ldots \ldots \ldots \ldots \ldots \ldots \ldots \ldots \ldots \ldots \ldots \ldots \ldots \ldots \ldots \ldots$

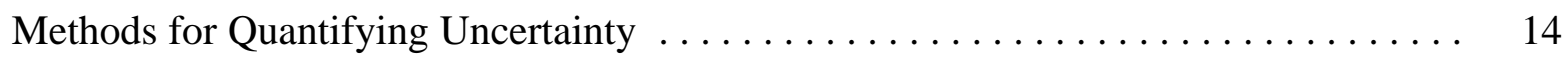

Derivation of Input Parameter Prior Distributions $\ldots \ldots \ldots \ldots \ldots \ldots \ldots \ldots \ldots \ldots \ldots$

Derivation of Posterior Distributions for Field Activities $\ldots \ldots \ldots \ldots \ldots \ldots$

Calculation of Uncertainty Reduction $\ldots \ldots \ldots \ldots \ldots \ldots \ldots \ldots \ldots \ldots \ldots$

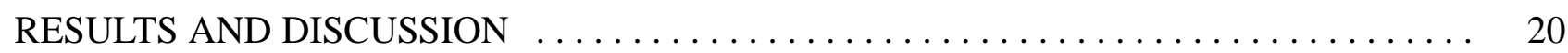

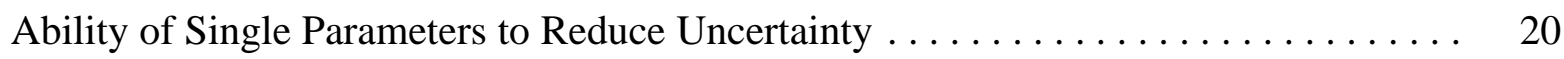

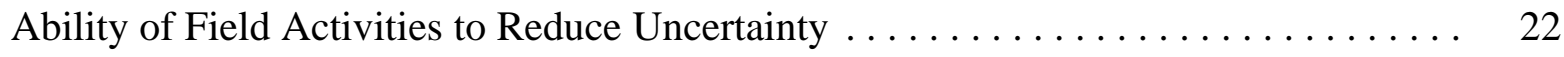

Cost-benefit Analysis . . . . . . . . . . . . . . . . . . . . 24

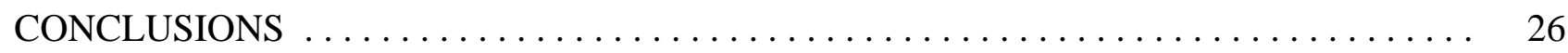

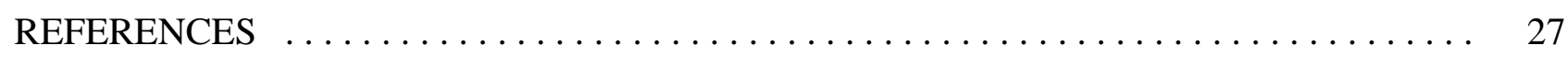

\section{APPENDICES}

A: EXPERT PANEL QUALIFICATIONS $\ldots \ldots \ldots \ldots \ldots \ldots \ldots \ldots \ldots \ldots \ldots \ldots$ A-1

B: DESCRIPTIONS OF FIELD ACTIVITIES $\ldots \ldots \ldots \ldots \ldots \ldots \ldots \ldots \ldots \ldots$ B-1

C: POSTERIOR DISTRIBUTIONS FOR THE FIELD ACTIVITIES $\ldots \ldots \ldots \ldots$. C-1

D: DEVELOPMENT OF THE SECOND ORDER - FIRST AND

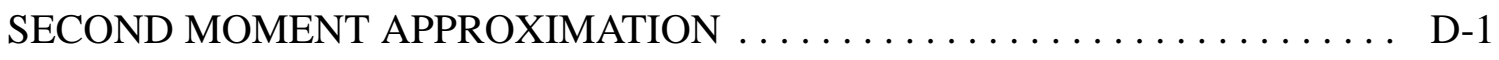

E: DETAILED COST ESTIMATES FOR FIELD ACTIVITIES $\ldots \ldots \ldots \ldots \ldots$ E-1 


\section{FIGURES}

1. Location of the Project Shoal Area with existing and historical wells. . . . . . . . 1

2. Summary of data decision analysis. $\ldots \ldots \ldots \ldots \ldots \ldots \ldots \ldots \ldots \ldots \ldots \ldots$

3. Standard deviation of the $\log 10$ transformed mean breakthrough time vs. the number of

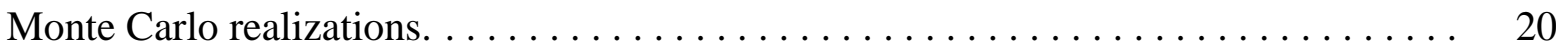

4. Expected model uncertainty reduction from the field activities vs. estimated costs for the

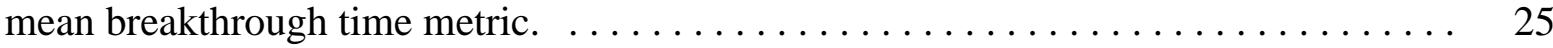

5. Expected model uncertainty reduction from the field activities vs. estimated costs for the peak concentration metric.

\section{TABLES}

1. Order-of-Magnitude Cost Estimates for the Top-ranked Field Activities. . . . . . . . 4

2. Prior Distributions for the Input Parameters. . . . . . . . . . . . . . . 18

3. Reduction in Model Uncertainty of Mean Breakthrough Time for the Nine Input Parameters Assuming Each Parameter is Known with Complete Certainty. . . . . .

4. Reduction in Model Uncertainty of Peak Concentration for the Nine Input Parameters Assuming Each Parameter is Known with Complete Certainty. . . . . . . . . .

5. The Ranked Uncertainty Reduction of Mean Breakthrough Time for the Field Activities.

6. The Ranked Uncertainty Reduction of Peak Concentration for the Field Activities. 


\section{INTRODUCTION}

The Project Shoal area (PSA) is located about $50 \mathrm{~km}$ southeast of Fallon, Nevada (Figure 1). The Shoal test consisted of a 12-kiloton-yield nuclear detonation (U.S. Department of Energy, 1994), which occurred on October 26, 1963. Project Shoal was part of studies to enhance seismic detection of underground nuclear tests, in particular, in active earthquake areas.

The Desert Research Institute (DRI) has been tasked by the U.S. Department of Energy (DOE) to characterize the subsurface hydrogeologic environment and to construct a groundwater flow and transport model. The purpose of the model is to formalize the conceptual model of the flow and transport system, predict future migration of test-related solutes, and to quantify the uncertainty in the model predictions.

A preliminary groundwater flow and transport model for the PSA has been created by Pohll et al. (1998). Although all available data were used to parameterize the model, a certain degree of uncertainty exists in its ability to predict solute migration (output uncertainty). This output uncertainty is due to uncertainty in the mean parameters and natural spatial heterogeneity. The purpose of this data decision analysis is to determine through a statistical analysis the model output

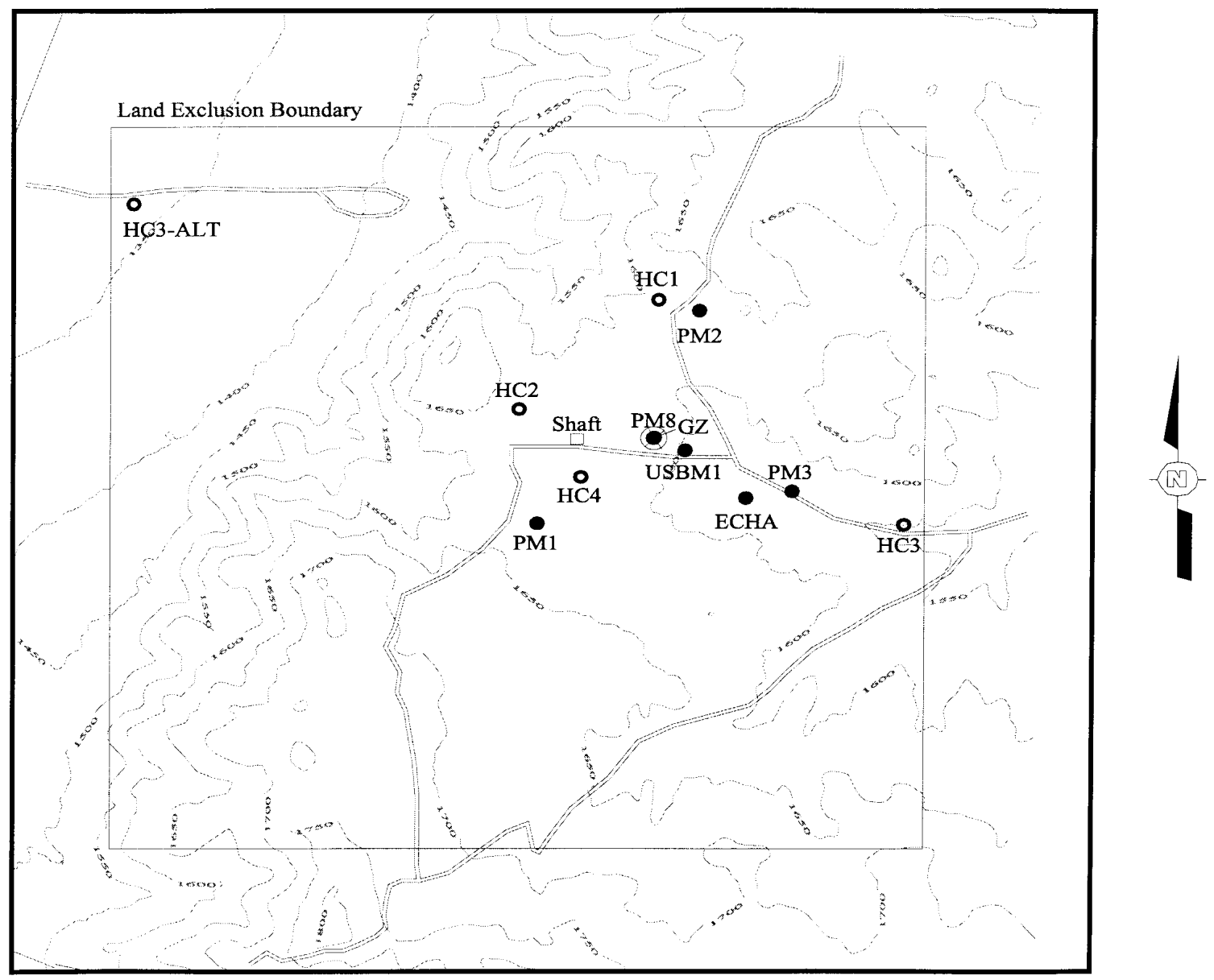

Figure 1. Location of the Project Shoal area with existing and historical wells. 
uncertainty due to the current uncertainty in the mean parameters, the reduction in uncertainty if the mean parameters were known with certainty, and which field activities are optimal in terms of reduction of the output uncertainty per unit cost due to the uncertainty in the mean parameters. Although spatial variability is included in this analysis, the reduction in uncertainty from additional characterization is not directly included in this analysis because the uncertainty in the mean parameters is currently more significant than the natural heterogeneity in terms of output uncertainty.

The groundwater flow and transport model created by Pohll et al. (1998) is used in conjunction with expert judgement on the reliability of various field activities to estimate the possible reduction in output uncertainty due to an associated reduction in input parameter uncertainty. Numerous input parameters were deemed uncertain by Pohll et al. (1998). A sensitivity analysis was performed by Pohll et al. (1998) to determine which uncertain parameters provide significant uncertainty in the model predictions. A set of nine parameters were deemed uncertain. A list of the possible field activities that were assessed is provided in Appendix B. An expert panel from DRI was asked to determine how the uncertainty in the mean of the nine uncertain parameters would be reduced by each of the field activities. This reduction in uncertainty of the mean parameters was then used within a Monte Carlo analysis to determine the reduction in output uncertainty for each field activity. An additional analysis was performed to rank the input parameters in terms of reduction in output uncertainty.

Two characterization studies were conducted in the early 1960s (University of Nevada, 1965) and in 1996 (U.S. Department of Energy, 1998) to quantify the subsurface hydrogeology. This information was used to construct a groundwater flow and transport model of the PSA. The details of the model construction, predictions and associated uncertainty are provided in Pohll et al. (1998). Of the many parameters required to construct the numerical model, nine were identified as uncertain in terms of the model's ability to predict solute migration:

1. Effective porosity - This parameter describes the pore space available for solute transport. The effective porosity is defined as the total porosity minus the porosity that is not connected to the groundwater flow system. At the PSA, the effective porosity is primarily controlled by the size of the fractures in the granitic aquifer. The model assumes that the porosity is homogeneous throughout the model domain, although in a fractured system the porosity could be highly variable.

2. Hydraulic head - In the context of the groundwater model, this parameter relates to the specified hydraulic head at the downgradient model boundary. The HC-3 well is the closest well to this model boundary, but problems with the well installation led to large uncertainties in the water levels. The water level measured in HC-3 is lower than water levels in Fairview Valley to the east, which indicates that this boundary condition is uncertain.

3. Recharge - This parameter describes the net amount of fluid (from precipitation) that reaches the groundwater system. It is assumed that the recharge is constant over the entire surface of the model domain. 
4. Hydraulic conductivity - The groundwater flow model assumes that there are three classes of fractures (\#1: small/no fractures, \#2: medium fractures, \#3: large fractures). Each model grid cell is assigned a fracture class and associated hydraulic conductivity $\left(\mathrm{K}_{1}, \mathrm{~K}_{2}, \mathrm{~K}_{3}\right)$ which represents the effective hydraulic conductivity due to the ensemble of fractures contained in a 40-cubic-meter zone. Field characterization of the hydraulic conductivity for each fracture class led to relatively certain estimates for the large and medium fracture classes, but limitations of the instruments introduced significant uncertainty in the estimated conductivity for the fracture class that contained little or no fractures (fracture class \#1). To ensure adequate agreement between the observed and simulated hydraulic head values, a linear relationship is derived between the recharge rate and the value of the hydraulic conductivity for fracture class \#1 $\left(\mathrm{K}_{1}\right)$. The linear relationship is derived by assuming a constant ratio between recharge and $\mathrm{K}_{1}$. For example, if the recharge rate increases, then an associated increase in $\mathrm{K}_{1}$ is required such that the simulated head values would not exceed the observed values. The groundwater model utilized in these numerical experiments also allowed for variable hydraulic conductivity values within each fracture class. The distribution within each class is described by a ln-normal distribution with the mean being equal to $\mathrm{K}_{1}, \mathrm{~K}_{2}, \mathrm{~K}_{3}$, as described above. Therefore, there are two uncertain parameters relating to hydraulic conductivity: 1) $\mathrm{K}_{1}$, which is determined by the linear relation with recharge (another uncertain variable), and 2) the ln-variance of hydraulic conductivity.

5. Fracture connectivities (i.e., correlation scales) - The spatial distribution of the fracture classes is simulated via a geostatistical algorithm. One of the critical parameters in this model is the correlation scale of the fractures, which describes how the fracture classes persist along the strike and dip directions.

6. Fracture orientations (strike angle) - The geostatistical model requires that the angle of the strike be specified. The analysis of Pohll et al. (1998) and University of Nevada (1965) are in agreement on the northeast trending fractures, but there is less agreement on the northwest trending fractures. Pohll et al. (1998) identified an orientation N8W, while the University of Nevada (1965) found the trend to be N50W. Therefore, the northeast strike angle is assumed to be a deterministic (i.e., known with certainty) parameter, while the northwest angle is treated as a random variable.

7. Fracture dip - Similar to the strike orientation, this parameter describes the dip angle of the fracture classes. Pohll et al. (1998) reported moderate dip angles between 31E 44SE, while University of Nevada (1965) reported a wider range of 40E - 90SE. The dip angle is treated as a random variable and the dip angles for each strike orientation are assumed to be independent.

8. Glass dissolution rates - The solute transport model includes an algorithm to calculate the rate of nuclear glass dissolution. The model uses a dissolution rate coefficient that is highly dependent on the specific surface area of the melt glass. 
9. Retardation - The dissolved radionuclides are subject to a variety of chemical reactions that can retard their movement relative to water. A linear isotherm is used to model the impact of sorption on solute migration. The retardation factor used by the transport model is parameterized by a distribution coefficient and the fracture aperture, each of which contain uncertainty.

The model sensitivity to each of these parameters was addressed by Pohll et al. (1998), but the analysis was focused on sensitivity, not on the quantification of uncertainty. This report addresses through quantitative statistical analysis, the uncertainty in the model predictions. Once the uncertainty is quantified, this information can be used to help decision makers evaluate cost-effective information-collection options to reduce these uncertainties.

\section{COST ANALYSIS FOR FIELD ACTIVITIES}

The cost estimates for the top-ranking field activities (as determined by this data decision analysis) were prepared by IT Corporation (IT) and DRI. It is important to note that these are scoping cost estimates prepared for comparative purposes alone and are likely to change with detailed budgeting. The scope of work, and a brief description of the task, is given below for the top 10 field activities. Supporting assumptions used to scope the budget for each of the activities are provided in Appendix E. Table 1 summarizes the costs for the individual activities.

Table 1. Cost Estimates for the Top-ranked Field Activities.

\begin{tabular}{|c|c|c|c|c|}
\hline \multirow[b]{2}{*}{ Activity Number } & \multirow[b]{2}{*}{ Field Activity } & \multicolumn{2}{|c|}{ 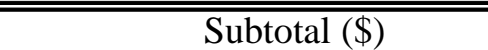 } & \multirow[b]{2}{*}{ Total $(\$)$} \\
\hline & & IT & DRI & \\
\hline 1 & Two-well Tracer Test & 284,708 & 302,631 & 587,339 \\
\hline 2 & Barometric/Vapor Ext. & 194,640 & 95,885 & 290,525 \\
\hline 3 & Cross-hole Packer & $1,773,310$ & 109,975 & $1,883,285$ \\
\hline 4 & Hydraulic Head & 262,058 & 40,354 & 302,412 \\
\hline 5 & Natural Gradient & 494,965 & 273,420 & 768,385 \\
\hline 6 & Single-well Packer & 501,870 & 55,270 & 557,140 \\
\hline 7 & Environmental Tracer & $1,082,948^{1}$ & 156,000 & $1,238,948$ \\
\hline 8 & Single-well Tracer & 0 & 243,895 & 243,895 \\
\hline 9 & Energy Budget & 0 & 112,428 & 112,428 \\
\hline 10 & Vadose Zone Modeling & 0 & 66,299 & 66,299 \\
\hline
\end{tabular}

${ }^{1}$ Assumes $13 \mathrm{~cm}$ (5 in) well will be drilled

\section{Two-well Tracer Test}

A tracer is introduced into the aquifer at one well while pumping and monitoring a second, downgradient well. The discharge water from the pumped well will be recirculated and injected in the upgradient well to increase the hydraulic gradient. 
This test requires the installation of a single $457 \mathrm{~m}(1,500 \mathrm{ft})$ deep, nominal $13 \mathrm{~cm}(5 \mathrm{in})$

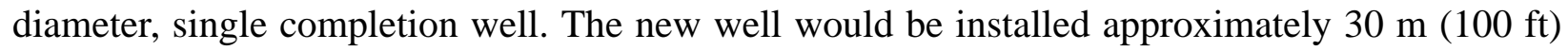
downgradient of existing well HC-1.

A nominal $56 \mathrm{~cm}$ (22 in) diameter borehole will be drilled to $30 \mathrm{~m}$ (100 ft) bgs and nominal $46 \mathrm{~cm}$ (18 in) conductor casing installed and grouted into place. A nominal $41 \mathrm{~cm}$ (16 in) hole will then be drilled to approximately $15 \mathrm{~m}(50 \mathrm{ft}$ ) below the static water level (approximately $305 \mathrm{~m}$ [1,000 ft] bgs), five geophysical logs (caliper, natural gamma ray, spectral gamma ray, directional survey, and epithermal neutron) will be collected from the unsaturated zone, and nominal $30 \mathrm{~cm}$ (12 in) intermediate casing installed and grouted into place. A nominal $30 \mathrm{~cm}$ (12 in) diameter borehole will then be advanced to total depth.

Upon completion of drilling to total depth, nine geophysical logs (caliper, natural gamma ray, spectral gamma ray, directional survey, formation density, borehole televiewer, micro-resistivity, temperature and delta temperature, and compensated neutron) will be collected from the saturated portion of the open borehole. Cross-hole tomography logs will also be collected. Drilling and geophysical logging are expected to require eight days to complete. DRI will video-log the well after the geophysical logs are completed.

Lithological data and geophysical data will be used to finalize the well design. Tentatively, the well completion will consist of slotted casing from total depth to approximately $15 \mathrm{~m}(50 \mathrm{ft})$ below the static water level. The well casing will be hung on the conductor casing. No filter pack or grout seals will be installed. The well will be developed by surging the saturated portion of the well. It is expected to require six days to build and develop the well.

The pump currently installed in HC-4, which is capable of lifting 19 liters per minute ( 5 gallons per minute) from a depth of $381 \mathrm{~m}(1250 \mathrm{ft}) \mathrm{bgs}$, will be removed from HC-4 and installed in the downgradient well. At this time, the wellhead will be plumbed to allow testing. The pump work and test setup will be supervised by IT and is expected to require three days to complete.

DRI will be onsite during the drilling and setup period to provide technical assistance. After the drilling and test setup is completed, DRI will supervise and operate the tracer test. This includes monitoring the tracer introduction and withdrawal and sampling. Following installation of the pump, a tracer will be introduced into the upgradient well (HC-1) as pumping and groundwater sampling of the downgradient well begin. Weekly groundwater sampling of the downgradient well will continue until a high enough concentration of tracer is found in the downgradient well to confirm breakthrough. Once the initial breakthrough is found, high-resolution groundwater sampling will be implemented. Groundwater sampling should be completed within two to three months.

Following the conclusion of the test program, the pump will be removed from the new well and reinstalled in HC-4 to allow long-term monitoring. The pump work will be supervised by IT and is expected to require two days to complete. DRI will temperature log the well after the well has reached equilibrium conditions.

The IT cost estimate prepared for this activity includes the installation of a new well, removal of the existing pump in HC-4, installation of the pump in the new well, and supervision of the field 
activities through test setup by IT personnel. DRI's cost estimate includes onsite technical assistance during drilling and setup, supervision of the test operations, partial laboratory analysis, video and temperature logging, and analysis of the test results. Neither estimate includes the cost of the tracers, consultation with Los Alamos National Laboratory and analysis of non-traditional tracers. It is assumed that these costs will be direct billed to DOE. Costs for removal of the pump from the new well, reinstallation of the pump in HC-4, and IT oversight of these post-testing activities have been included in this cost estimate.

\section{Barometric Tests (Including Vapor Extraction Tests)}

The temporal water level response in an aquifer due to the combined effects of surface barometric pressure fluctuations and aquifer properties is useful in the inverse sense to determine aquifer hydraulic properties. The testing program will first consist of vapor extraction (or injection) tests followed by barometric response tests.

These tests require the installation of 24 shallow (30 m [100 ft]), nominal $13 \mathrm{~cm}$ (5 in) boreholes in the vadose zone. The boreholes will be placed in a two-dimensional 4 x 6 matrix with 3 to $6 \mathrm{~m}$ $(10-20 \mathrm{ft})$ between boreholes.

For each well a nominal $25 \mathrm{~cm}$ (10 in) diameter borehole will be drilled to $15 \mathrm{~m}(50 \mathrm{ft}) \mathrm{bgs}$ and nominal $15 \mathrm{~cm}$ (6 in) conductor casing installed and grouted into place. A nominal $13 \mathrm{~cm}$ (5 in) borehole will then be drilled to total depth. It is important that the conductor casing have an air-tight grout seal. The surface completions will consist of a nominal $13 \mathrm{~cm}$ (5 in) diameter casing coupler welded to a steel plate, which in turn is welded to the upper portion of the conductor casing. A 1 x $1 \mathrm{~m}$ (4 x $4 \mathrm{ft})$ concrete pad will be installed at the wellhead. It is important that the surface completion also be air tight.

Upon completion of the 24 wells, high resolution pressure transducers will be installed in all the wells. The well bores will then be pressurized using a high-volume air compressor and sealed. The pressure response in each well will be monitored. The pressure in the wells will be allowed to equilibrate. The wells will remain sealed and the wellbore pressure response to variations in atmospheric barometric pressure variations monitored. Monitoring will continue for a period of several weeks.

IT's cost estimate for this activity includes the drilling and construction of 24 wells, compressor rental, and IT oversight of the drilling and startup of the test. DRI's cost estimate includes technical assistance during drilling, supervision of the test, and interference testing.

\section{Cross-hole Packer Test}

Cross-hole packer tests are conducted by injecting fluid into a packed-off interval in one borehole, and the resultant hydraulic head variations are measured in packed-off intervals in adjacent boreholes. The objective of the test is to measure, on a field scale, the hydraulic conductivity tensor and the specific storage of a fractured rock aquifer. The test can be performed in open boreholes or completed wells.

This test requires the installation of three $610 \mathrm{~m}(2,000 \mathrm{ft})$ deep, nominal $10 \mathrm{~cm}$ (4 in) diameter, multiple-completion wells. The three new wells will be located in a triangular pattern with legs approximately $30 \mathrm{~m}(100 \mathrm{ft})$ in length. 
A nominal $48 \mathrm{~cm}$ (19 in) diameter borehole will be drilled to $30 \mathrm{~m}$ (100 ft) bgs and nominal $10 \mathrm{~cm}$ (4 in) conductor casing installed and grouted into place. A nominal $30 \mathrm{~cm}$ (12 in) hole will be drilled approximately $15 \mathrm{~m}(50 \mathrm{ft})$ below the static water level, five geophysical logs (caliper, natural gamma ray, spectral gamma ray, directional survey, and epithermal neutron) will be collected from the unsaturated zone, and nominal $20 \mathrm{~cm}(8 \mathrm{in})$ intermediate casing installed and grouted into place. A nominal $20 \mathrm{~cm}$ ( 8 in) borehole will then be advanced to total depth.

Upon completion of drilling to total depth, nine geophysical logs (caliper natural gamma ray, spectral gamma ray, directional survey, formation density, borehole televiewer, micro-resistivity, temperature and delta temperature, and compensated neutron) will be collected from the saturated zone of the open borehole. Cross-hole tomography logs will also be collected. DRI will video-log the wells following geophysical logging. Following conclusion of the geophysical logging program, the drill rig will move to the next location and began drilling. Drilling and geophysical logging are expected to require 12 days to complete.

The proposed hydraulic testing program will be conducted in the open, $610 \mathrm{~m}(2,000 \mathrm{ft})$ deep boreholes once all three boreholes have been advanced to total depth, if hole stability allows. The three boreholes will be arranged in a triangular fashion. The proposed hydraulic testing program will consist of isolating the same 15 to $30 \mathrm{~m}(50$ to $100 \mathrm{ft})$ interval in each of the three boreholes with packers, injecting fluid into the packed-off interval of one borehole under constant flow conditions, and monitoring the pressure head response in the adjacent well. During fluid injection, the pressure head response will be monitored in the packed-off interval, and above and below the packed-off interval of the injection borehole. The pressure response will also be monitored in the packed-off interval of the two adjacent boreholes. Injection will continue for a period of one hour. Pressure response will be monitored and the borehole allowed to rest for a period of approximately six hours. The packers in the adjacent holes will then be moved to an interval below the injection interval and fluid injected and pressure response monitored, as above. The packers in the adjacent boreholes will be moved to the interval above the injection interval and fluid injected and pressure response monitored, as above. This will constitute the test of one interval in the test borehole. The packers in the test borehole will then be moved up and the testing process repeated in the next section of borehole. The testing program will begin at total depth and progress upward through the saturated zone. Ten intervals of the test borehole will be tested. Test results may lead to modification of the testing program.

If required by hole conditions, $10 \mathrm{~cm}$ (4 in), inside diameter wells will be constructed with $24 \mathrm{~m}(80 \mathrm{ft})$ slotted intervals alternating with $6 \mathrm{~m}(20 \mathrm{ft})$ blank intervals. The blank intervals will be sealed with grout and/or external packers. The testing program would then be conducted in the completed wells. Again, ten zones will be tested. Testing is expected to require approximately 30 days to complete.

Lithologic data, geophysical data, and hydraulic testing results will be used to complete the final well design for each of the three wells. Tentatively, the well completions will consist of alternating $24 \mathrm{~m}(80 \mathrm{ft})$ intervals of slotted casing and $6 \mathrm{~m}(20 \mathrm{ft})$ intervals of blank casing from total depth to approximately $15 \mathrm{~m}(50 \mathrm{ft})$ below the static water level. Filter pack, consisting of silica sand, will be installed behind the perforated intervals. The annular space behind the blank casing sections 
will be sealed with grout. The filter pack and grout seals will be placed via tremie. The well will be developed by surging the saturated interval. It is expected to require 12 days to build and develop the three wells.

IT's cost estimate for this activity includes the installation of three $610 \mathrm{~m}(2,000 \mathrm{ft})$ wells, hydraulic testing, and IT oversight of all field activities. DRI will be onsite during the drilling and testing phases to provide technical assistance. DRI's cost estimate includes drilling and testing oversight, video and temperature logging, and analysis of the results. For costing purposes, it is assumed that the drill rig will remain on standby during the geophysical logging programs and the hydraulic testing.

Two scenarios have been proposed for the completion of the well: 1) install filter pack and grout via tremie, and 2) install external casing packers to provide hydraulic isolation of the perforated intervals. Costs have been estimated with filter pack and grout installed via tremie. Costs for the use of external casing packers have also been provided as an alternative for the completion of the well. Additionally, cost estimates for the use of port collars, in place of perforated casing to provide access to the formation, have been prepared as an alternative well completion.

Two hydraulic-testing scenarios have also been proposed: 1) the use of modular hydraulic testing tools that incorporate inflatable packers (Schlumberger), and 2) the use of more traditional inflatable packers (TAM). The Schlumberger system can be conveyed either by wireline or tubing. This system has a maximum test interval of $15 \mathrm{~m}(50 \mathrm{ft})$. The TAM system is tubing conveyed. This system offers more flexibility in the length of the test interval. The cost estimate is based on the Schlumberger system, although costs for the TAM system have been provided as an alternative testing program.

\section{Hydraulic Head Measurements}

Measurements of hydraulic head within the flow system provide an indication of the groundwater flow directions. It is important to install piezometers throughout the flow system. Water levels in existing well HC-3 are inconsistent with the regional potentiometric surface. Therefore, a new well will be installed near HC-3 to confirm the depth to water in this area.

This activity requires the installation of one additional well. A $457 \mathrm{~m}$ (1,500 ft) deep, nominal $10 \mathrm{~cm}$ (4 in), single-completion well will be installed near existing well HC-3.

A nominal $48 \mathrm{~cm}$ (19 in) diameter borehole will be drilled to $30 \mathrm{~m}$ (100 ft) bgs and nominal $36 \mathrm{~cm}$ (14 in) conductor casing installed and grouted into place. A nominal $30 \mathrm{~cm}$ (12 in) hole will

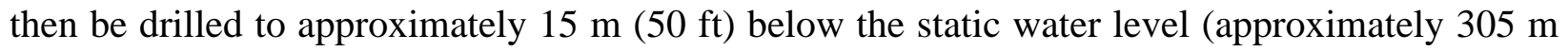
$[1,000 \mathrm{ft}] \mathrm{bgs}$ ), five geophysical logs (caliper, natural gamma ray, spectral gamma ray, directional survey, and epithermal neutron) will be collected from the unsaturated zone, and nominal $20 \mathrm{~cm}$ (8 in) intermediate casing installed and grouted into place. A nominal $20 \mathrm{~cm}$ (8 in) diameter borehole will then be advanced to total depth.

Upon completion of drilling to total depth, nine geophysical logs (caliper, natural gamma ray, spectral gamma ray, directional survey, formation density, borehole televiewer, micro-resistivity,

temperature and delta temperature, and compensated neutron) will be collected from the saturated 
portion of the open borehole. Drilling and geophysical logging are expected to require six days to complete. DRI will video-log the well after completion of the geophysical logging. DRI will temperature log the well after hydraulic conditions return to equilibrium.

Lithological data and geophysical data will be used to finalize the well design. Tentatively, the well completion will consist of slotted casing from total depth to approximately $15 \mathrm{~m}(50 \mathrm{ft})$ below the static water level. The well casing will be hung on the conductor casing. No filter pack or grout seals will be installed. The well will be developed by surging the saturated portion of the well. It is expected to require five days to build and develop the well.

The cost estimate for this activity includes the installation of a $457 \mathrm{~m}(1,500 \mathrm{ft})$ deep well and IT oversight of these field activities. For costing purposes, it is assumed that the drill rig will remain on standby during the geophysical logging program. DRI's cost estimate includes drilling and testing oversight, video and temperature logging, and analysis of the results.

\section{Natural-gradient Tracer Test}

During the natural-gradient test, a tracer is introduced with little disturbance to the aquifer. The tracer concentration is monitored over time at one or more points downgradient.

This test requires the installation of two $457 \mathrm{~m}(1,500 \mathrm{ft})$ deep, nominal $10 \mathrm{~cm}$ (4 in) diameter, single-completion wells. One of the two new wells will be located approximately $15 \mathrm{~m}(50 \mathrm{ft})$ downgradient and approximately $6 \mathrm{~m}(20 \mathrm{ft})$ across gradient from existing well HC-1. The second of the two new wells will be located approximately $30 \mathrm{~m}(100 \mathrm{ft})$ downgradient and approximately $6 \mathrm{~m}(20 \mathrm{ft}$ ) across gradient (on the opposite side from the first well) from existing well HC-1.

A nominal of $48 \mathrm{~cm}$ (19 in) diameter borehole will be drilled to $30 \mathrm{~m}$ (100 ft) bgs and nominal $36 \mathrm{~cm}$ (14 in) conductor casing installed and grouted into place. A nominal $30 \mathrm{~cm}$ (12 in) hole will then be drilled approximately $15 \mathrm{~m}$ (50 ft) below the static water level, five geophysical logs (caliper, natural gamma ray, spectral gamma ray, directional survey, and epithermal neutron) will be collected from the unsaturated zone, and nominal $20 \mathrm{~cm}$ (8 in) intermediate casing installed and grouted into place. A nominal $20 \mathrm{~cm}$ ( 8 in) diameter borehole will then be advanced to total depth.

Upon completion of drilling to total depth, nine geophysical logs (caliper, natural gamma ray, spectral gamma ray, directional survey, formation density, borehole televiewer, micro-resistivity, temperature and delta temperature, and compensated neutron) will be collected from the saturated portion of the open borehole. Cross-hole tomography logs will also be collected. DRI will video-log the wells following geophysical logging. Drilling and geophysical logging are expected to require six days to complete.

Lithological data and geophysical data will be used to finalize the well design. Tentatively, the

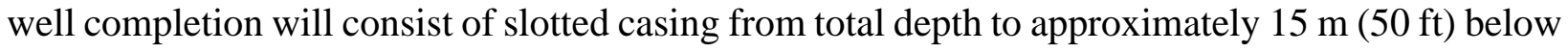
the static water level. The well casing will be hung on the conductor casing. No filter pack or grout seals will be installed. The well will be developed by surging the saturated section of the well. It is expected that the construction of the two wells will require 6 days to complete.

Following installation of the two downgradient wells, a tracer will be introduced into the

upgradient well (HC-1) and sampling of the downgradient wells will begin. Weekly groundwater 
sampling of the two downgradient wells will continue until tracer breakthrough has been captured sufficiently by the downgradient wells. Once the initial breakthrough is identified, high-resolution groundwater sampling will be implemented. For costing purposes, it was assumed that the monitoring would continue for a total of one year.

IT's cost estimate for this activity includes the installation of the two downgradient wells and IT supervision of the field activities through well development. DRI will be onsite during the drilling to provide technical assistance. DRI's cost estimate includes technical assistance during drilling, supervision of the test, laboratory analysis and analysis of the results.

\section{Single-hole Packer Testing}

Injection or slug tests provide information on well hydraulics. The tests can be performed in the packed-off intervals of a single open borehole or completed well.

This test requires the installation of a single $610 \mathrm{~m}(2,000 \mathrm{ft})$ deep, nominal $10 \mathrm{~cm}(4 \mathrm{in})$ diameter, multiple-completion well. A nominal $48 \mathrm{~cm}$ (19 in) diameter borehole will be drilled to $30 \mathrm{~m}$ (100 ft) bgs and nominal $36 \mathrm{~cm}$ (14 in) conductor casing installed and grouted into place. A

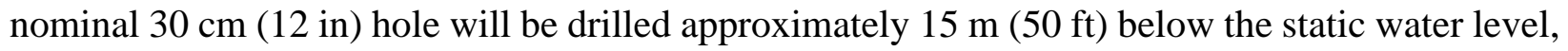
five geophysical logs (caliper, natural gamma ray, spectral gamma ray, directional survey, and epithermal neutron) will be collected from the unsaturated zone, and nominal $20 \mathrm{~cm}$ ( 8 in) intermediate casing installed and grouted into place. A nominal $20 \mathrm{~cm}(8 \mathrm{in})$ borehole will then be advanced to total depth.

Upon completion of drilling to total depth, nine geophysical logs (caliper, natural gamma ray, spectral gamma ray, directional survey, formation density, borehole televiewer, micro-resistivity, temperature and delta temperature, and compensated neutron) will be collected from the saturated zone of the open borehole. DRI will video-log the wells following geophysical logging. Drilling and geophysical logging are expected to require three days to complete.

The proposed hydraulic testing program will be conducted in the open, $610 \mathrm{~m}(2,000 \mathrm{ft})$ deep borehole, if hole stability allows. The proposed testing program will consist of isolating 15 to $30 \mathrm{~m}$ (50 to $100 \mathrm{ft}$ ) intervals of the borehole with packers, instantaneously changing the pressure head within the interval by the addition of fluid, and monitoring the pressure head response. The pressure head response will be monitored in the packed-off interval, and above and below the packed-off interval. The packers will be moved up and the next section of borehole tested. The testing program will begin at total depth and continue through the saturated zone. Ten zones will be tested. It is assumed that the pressure response will be monitored for a period of one hour. Test results may lead to modification of the testing program (e.g., changing the length of the packed-off interval, shorter or longer period of monitoring, etc.).

If required by hole conditions, a $10 \mathrm{~cm}$ (4 in) inside diameter well will be constructed as described below. The testing program would then be conducted in the completed well. Again, ten zones will be tested. Testing is expected to require six days to complete.

Lithologic data, geophysical data, and testing results will be used to complete the final well design. Tentatively, the well completion will consist of ten alternating $24 \mathrm{~m}(80 \mathrm{ft})$ intervals of slotted 
casing and $6 \mathrm{~m}(20 \mathrm{ft})$ intervals of blank casing from total depth to approximately $15 \mathrm{~m}(50 \mathrm{ft})$ below the static water level. Filter pack, consisting of silica sand will be installed behind the perforated intervals. The annular space behind the blank casing sections will be sealed with grout. The filter pack and grout seals will be placed via tremie.

The well will be developed by surging the saturated portion of the well. It is expected to require three days to build and develop a well. IT's cost estimate for this activity includes the installation of a $610 \mathrm{~m}(2,000 \mathrm{ft})$ deep well, the testing program, and IT oversight of all field activities. DRI's cost estimate includes drilling and testing oversight, video and temperature logging, and analysis of the results. For costing purposes, it is assumed that the drill rig will remain on standby during the geophysical logging program and the hydraulic testing program.

Two scenarios have been proposed for the completion of the well: 1) install filter pack and grout via tremie, and 2) install external casing packers to provide hydraulic isolation of the perforated intervals. Costs have been estimated with filter pack and grout installed via tremie. Costs for the use of external casing packers have also been provided as an alternative for the completion of the well. Additionally, costs estimates for the use of port collars, in place of perforated casing, to provide access to the formation, have been prepared as an alternative well completion.

Two hydraulic testing scenarios have also been proposed: 1) the use of modular hydraulic testing tools that incorporate inflatable packers (Schlumberger), and 2) the use of more TAM. The Schlumberger system can be conveyed either by wireline or tubing. This system has a maximum test interval of $15 \mathrm{~m}(50 \mathrm{ft})$. The TAM system is tubing conveyed. This system offers more flexibility in the length of the test interval. The cost estimate is based on the Schlumberger system, although costs for the TAM system have been provided as an alternative testing program.

\section{Environmental Tracer Techniques}

Stable and radiogenic tracers can be used to determine the recharge and flow characteristics or to directly calculate the age of recharging water. This method requires the collection of representative, depth-discreet samples from a relatively deep well.

This activity requires the installation of a 1,219 $\mathrm{m}$ (4,000 ft) deep, multiple-completion well that will allow the collection of representative, depth-discreet groundwater samples uninfluenced by atmospheric carbon. Two well-completion and sampling scenarios have been proposed. The first scenario involves completing the well with $10 \mathrm{~cm}$ (4 in) diameter casing, using a rented internal-inflation, straddle-packer assembly to isolate the interval, and purging the interval by swabbing with a drill rig. The second scenario involves completing the well with $13 \mathrm{~cm}(5 \mathrm{in})$ diameter casing, using a purchased external-inflation, straddle-packer assembly to isolate the interval, and purging the interval using a submersible pump installed as part of the straddle-packer assembly.

Costs have been estimated for the drilling, installation, and development of the 1,219 $\mathrm{m}$ (4,000 ft) deep well for each of the two scenarios discussed above. IT will provide oversight of the drilling, geophysical logging, well construction, well development, and placement of the packers during the sampling program. DRI's cost estimate includes technical assistance during drilling, 
video and temperature logging, supervision of the purging portion of the test, laboratory analysis and analysis of the results. The unique aspects of the two sampling scenarios are discussed below.

\section{Option 1: $10 \mathrm{~cm}(4 \mathrm{in})$ Well}

A nominal $48 \mathrm{~cm}$ (19 in) diameter borehole will be drilled to $30 \mathrm{~m} \mathrm{(100} \mathrm{ft)} \mathrm{bgs} \mathrm{and} \mathrm{nominal}$ $36 \mathrm{~cm}$ (14 in) conductor casing installed and grouted into place. A nominal $30 \mathrm{~cm}$ (12 in) hole will then be drilled to approximately $15 \mathrm{~m}(50 \mathrm{ft}$ ) below the static water level (approximately $305 \mathrm{~m}$ $[1,000 \mathrm{ft}] \mathrm{bgs}$ ), five geophysical logs (caliper, natural gamma ray, spectral gamma ray, directional survey, and epithermal neutron) will be collected from the unsaturated zone, and nominal $20 \mathrm{~cm}$ (8 in) intermediate casing installed and grouted into place. A nominal $20 \mathrm{~cm}$ (8 in) diameter borehole will then be advanced to total depth.

Upon completion of drilling to total depth, nine geophysical logs (caliper, natural gamma ray, spectral gamma ray, directional survey, formation density, borehole televiewer, micro-resistivity, temperature and delta temperature, and compensated neutron) will be collected from the saturated portion of the open borehole. Combinable Magnetic Resonance logs will also be collected from the saturated zone. Drilling and geophysical logging are expected to require 20 days to complete.

Lithological data and geophysical data will be used to finalize the well design. Tentatively, the well completion will consist of alternating $61 \mathrm{~m}(200 \mathrm{ft})$ lengths of slotted casing and $30 \mathrm{~m}(100 \mathrm{ft})$ intervals of blank casing from total depth to approximately $30 \mathrm{~m}(100 \mathrm{ft})$ below the static water level. Filter pack, consisting of silica sand, will be installed behind the slotted intervals. The annular space behind the blank intervals will be sealed with grout. The filter pack and grout seals will be placed via tremie. The well will be developed by surging and airlifting the saturated portion of the well. It is expected that well construction and development will require eight days.

The proposed sampling program will be conducted in the completed, 1,219 $\mathrm{m}(4,000 \mathrm{ft})$ deep well. The proposed sampling program for the $10 \mathrm{~cm}(4 \mathrm{in})$ well will consist of isolating $61 \mathrm{~m}$ $(200 \mathrm{ft})$ intervals of the borehole with an internally inflated, straddle-packer assembly, thoroughly purging the interval, possibly for a period of up to a week, and collecting a groundwater sample that has not been contaminated by atmospheric carbon. Pressures will be monitored above, below, and within the packed-off zone during purging. Fluids used for drilling will be tagged with a tracer. Purging will continue in the isolated zone until the tracer is not detected. Purging will be conducted initially by surging, airlifting, and swabbing. For sampling purposes, a positive-displacement, pneumatic piston pump (e.g., Bennett pump) will be installed between packers to allow collection of the sample directly from the pump discharge line to eliminate contamination by atmospheric carbon. The packers will then be moved up to the next $61 \mathrm{~m}(200 \mathrm{ft})$ zone to be sampled. Three intervals will be sampled: 335 to $396 \mathrm{~m}(1,100$ to 1,300 ft) below ground surface, $701 \mathrm{~m}$ to $762 \mathrm{~m}$ (2,300 to 2,500 ft) below ground surface, and 1,158 to $1,219 \mathrm{~m}(3,800$ to $4,000 \mathrm{ft})$ below ground surface. Test results may lead to modification of the testing program (e.g., modification of the isolated interval, etc.). It is expected the sampling program will require one month to complete.

Following development of the well, the large rig used to construct the well will be demobilized and a smaller rig mobilized to the site for setting the straddle-packer assembly and purging the isolated interval by swabbing. For costing purposes, it is assumed that the straddle-packer assembly, 
tubing to convey the packer assembly, support technician and truck, and downhole instrumentation will be rented for a period of one month. The packer assembly proposed for this scenario is inflated through the tubing from which the packer assembly is hung, and requires a rig to inflate and deflate the packers.

Purging prior to sampling will be conducted by swabbing using the rig. For costing purposes, it has been assumed that the rig will be mobilized three separate times, purging for each interval will require three 24-hour days, and IT will provide field oversight of the packer installation and purging. No costs have been estimated for installation of a positive-displacement, pneumatic- piston pump, if required for sampling. No costs have be estimated for laboratory analysis.

\section{Option 2: $13 \mathrm{~cm}(5 \mathrm{in})$ Well}

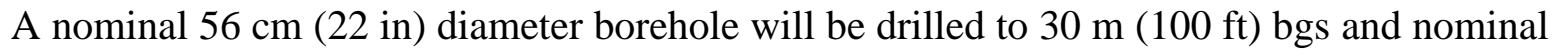
$46 \mathrm{~cm}$ (18 in) conductor casing installed and grouted into place. A nominal $41 \mathrm{~cm}$ (16 in) hole will then be drilled to approximately $15 \mathrm{~m}(50 \mathrm{ft})$ below the static water level (approximately $305 \mathrm{~m}$ $[1,000 \mathrm{ft}] \mathrm{bgs}$ ), five geophysical logs (caliper, natural gamma ray, spectral gamma ray, directional survey, and epithermal neutron) will be collected from the unsaturated zone, and nominal $30 \mathrm{~cm}$ (12 in) intermediate casing installed and grouted into place. A nominal $30 \mathrm{~cm}$ (12 in) diameter borehole will then be advanced to total depth.

Upon completion of drilling to total depth, nine geophysical logs (caliper, natural gamma ray, spectral gamma ray, directional survey, formation density, borehole televiewer, micro-resistivity, temperature and delta temperature, and compensated neutron) will be collected from the saturated portion of the open borehole. Combinable Magnetic Resonance logs will also be collected from the saturated zone. Drilling and geophysical logging are expected to require 28 days to complete.

Lithological data and geophysical data will be used to finalize the well design. Tentatively, the well completion will consist of alternating $61 \mathrm{~m}(200 \mathrm{ft})$ lengths of slotted casing and $30 \mathrm{~m} \mathrm{(100} \mathrm{ft)}$ intervals of blank casing from total depth to approximately $30 \mathrm{~m}(100 \mathrm{ft})$ below the static water level. Filter pack, consisting of silica sand, will be installed behind the slotted intervals. The annular space behind the blank intervals will be sealed with grout. The filter pack and grout seals will be placed via tremie. The well will be developed by surging and airlifting the saturated portion of the well. It is expected that well construction and development will require eight days.

The proposed sampling program will be conducted in the completed, 1,219 $\mathrm{m}(4,000 \mathrm{ft})$ deep well. The proposed sampling program for the $13 \mathrm{~cm}(5 \mathrm{in})$ well will consist of isolating $61 \mathrm{~m}$ $(200 \mathrm{ft}$ ) intervals of the borehole with an externally inflated, straddle-packer assembly, thoroughly purging the interval, possibly for a period of up to a week, and collecting a groundwater sample that has not been contaminated by atmospheric carbon. Pressures will be monitored above, below, and within the packed-off zone. Fluids used for drilling will be tagged with a tracer. Purging will continue in the isolated zone until the tracer is not detected. Purging will be conducted using a submersible pump installed within the straddle-packer assembly. The sample will be collected directly from the pump discharge line to eliminate contamination by atmospheric carbon. The packers will then be moved up to the next $61 \mathrm{~m}(200 \mathrm{ft})$ zone to be sampled. Three intervals will be sampled: $335 \mathrm{~m}$ to $396 \mathrm{~m}(1,100$ to $1,300 \mathrm{ft})$ below ground surface, 701 to $762 \mathrm{~m}$ (2,300 to 
2,500 ft) below ground surface, and 1,158 to 1,219 m (3,800 to 4,000 ft )below ground surface. Test results may lead to modification of the testing program (e.g., modification of the isolated interval, etc.). It is expected the sampling program will require one month to complete.

Following development of the well, the large rig used to construct the well will be demobilized and a smaller rig mobilized to the site for setting the straddle-packer/pump assembly. A submersible pump will be utilized to purge the isolated interval. For costing purposes, it is assumed that the submersible pump and associated hardware, pump column, inflatable packers, and inflation line will be purchased. The packer assembly proposed for this scenario is inflated through an external inflation line.

For costing purposes, it has been assumed that the rig will be mobilized three separate times, a packer technician will be mobilized three separate times, and IT will provide field oversight of the packer/pump installation. No costs have be estimated for laboratory analysis, downhole instrumentation during purging, or IT oversight during purging.

\section{Single-well Tracer Test}

This test would utilize an existing well to introduce a tracer by injecting fluid for a period of one week, then removing the tracer by pumping for a period of two months. Analytical solutions can be used to estimate the effective porosity near the borehole. Because drilling would not be required for this activity, IT did not prepare a cost estimate. DRI's cost estimate includes oversight of the test, laboratory analysis, and analysis of the results.

\section{Energy Budget}

This test would require the installation of an Eddy-correlation and meteorological station to measure the evapotranspiration (ET) and precipitation. The difference between the ET and precipitation is an estimate of the net infiltration or surface recharge. The test will be monitored for a period of one year. Drilling would not be required for this activity, therefore, IT did not prepare a cost estimate. DRI's cost estimate includes oversight of the test and analysis of the results.

\section{Vadose Zone Model}

Vadose zone modeling can be used for hypothesis testing of various recharge and hydraulic conductivity relationships. Specifically, it would identify ranges of possible recharge rates and subsurface hydraulic conductivity values and test the flow system response under different combinations of each parameter (Jury et al., 1991). Since drilling would not be required for this activity, IT did not prepare a cost estimate. DRI's cost estimate includes review of available data, development of a conceptual model, construction of the base model, simulation of various conceptual models, writing the final report and report review.

\section{TECHNICAL APPROACH}

\section{Methods for Quantifying Uncertainty}

There are a variety of statistical techniques that can be used to quantify the uncertainty of model

predictions. The most common method to describe a distribution of probable outcomes is a 
probability distribution (PDF). The height of the PDF at any point is proportional to the probability that a certain value will be chosen from a given distribution. To describe the central tendency or mean for a continuous distribution we use:

$$
\mu=\int_{-\infty}^{\infty} x f(x) d x
$$

where $f(x)$ is the density function, $\mu$ is the mean, $x$ is the random variable. Likewise, the tendency of the variable to deviate is described by the variance:

$$
\sigma^{2}=\int_{-\infty}^{\infty}(x-\mu)^{2} f(x) d x
$$

The standard deviation $(\sigma)$ is simply the square root of the variance $\left(\sigma^{2}\right)$. For a symmetric PDF $(e . g$., normal distribution), it is known that 95 percent of the values of the random variable range between $\mu \pm 1.96 \sigma$.

The numerical flow and transport model constructed for the PSA contains numerous input parameters. As noted above, there are nine uncertainty parameters. Therefore, there are nine random variables that describe the migration of solutes. Likewise there are many other parameters that are required to simulate migration, but these are considered deterministic variables (i.e., not random).

To characterize the uncertainty in the model predictions, one needs to characterize the PDFs of each input random variable and then construct a relationship to determine how these uncertainties propagate through the model itself. The description of the input parameter PDFs is sometimes termed a prior probability. The prior probability describes the likelihood of obtaining the true estimate of a parameter given the current state of knowledge.

The changes in uncertainty resulting from collection of additional data are determined by first characterizing the posterior distribution of the input parameters. The posterior distribution is a description of the likelihood of obtaining the true parameter estimate using a particular data collection activity. There are many methods to estimate the posterior distribution. One method utilizes Bayes theorem to calculate the posterior distribution based on the likelihood of various test outcomes (IT Corporation, 1998). This method assumes that additional characterization may produce outcomes that are similar or completely different than the prior distributions. For example, additional testing of effective porosity may indicate that the mean value is less than, greater than or equal to the original estimate. Another approach is to assume that the mean of the estimated parameter will not change significantly. In this case, the estimation of the posterior distribution is simplified, because one needs to estimate only the certainty of the testing procedure about the mean. The latter method requires less subjective judgement about the uncertainty of each test activity, but it does not allow for dramatic changes in the input parameters following testing. The posterior distributions calculated for this analysis utilized the latter method.

There are two methods available to estimate the output uncertainty. The method of Monte Carlo simulation samples from the input distributions, then a model simulation is performed. This process 
is repeated hundreds of times such that the output distribution can be characterized. The second-order second-moment method uses a Taylor series approximation to estimate the output variance. This method utilizes the first and second derivatives of an output metric with respect to the input variables, which can be calculated numerically. The output variance is a function of the input variances and the first and second derivatives. A combination of both approaches is used in this uncertainty analysis. The Monte Carlo method is used to calculate the output variances based on the prior and posterior distributions. Next, the second order-second moment method is compared to the Monte Carlo method for verification purposes. The second-order second-moment analysis can be used to quickly reevaluate the uncertainty analysis given another set of posterior distributions as the computational requirements are minimal.

The last step is to review the activities in terms of a cost-benefit analysis. The estimated costs of the top ranking activities were prepared by IT Corporation and DRI. Figure 2 summarizes the entire uncertainty analysis approach.

\section{Derivation of Input Parameter Prior Distributions}

The prior distributions for nine parameters are determined from a combination of currently available data, literature assessment, and subjective analysis of possible ranges of values for a particular variable. The prior distributions represent the range of possible values that might be expected given the currently available information and not the PDF of the population distribution. Uniform distributions were chosen to represent the prior probabilities for all input variables (although some were uniform in $\log _{10}$-space) implying that there is an equally likely probability of obtaining the "true" value of an input parameter within the specified range. If the true distributions are known with more certainty, then it might be more appropriate to chose normal or ln-normal prior distributions.

The mean and variance for a uniform distribution can be calculated using the following expressions:

$$
\begin{gathered}
\mu=\frac{b-a}{2} \\
\sigma^{2}=\frac{(b-a)^{2}}{12} \\
\sigma=\sqrt{\sigma^{2}}
\end{gathered}
$$

where $\mathrm{a}$ and $\mathrm{b}$ are the lower and upper bounds, respectively, of the uniform distribution, $\mu$ is the mean, $\sigma^{2}$ is the variance, and $\sigma$ is the standard deviation.

Table 2 shows the prior distributions for each of the nine input parameters. Since uniform distributions were chosen for each parameter, the minimum and maximum values describe the entire PDF. Two of the parameters (effective porosity and glass dissolution rate) varied over many orders of magnitude, so a uniform distribution of the $\log _{10}$ transformed values is used. This method preserves uniformity over the many orders of magnitude. 


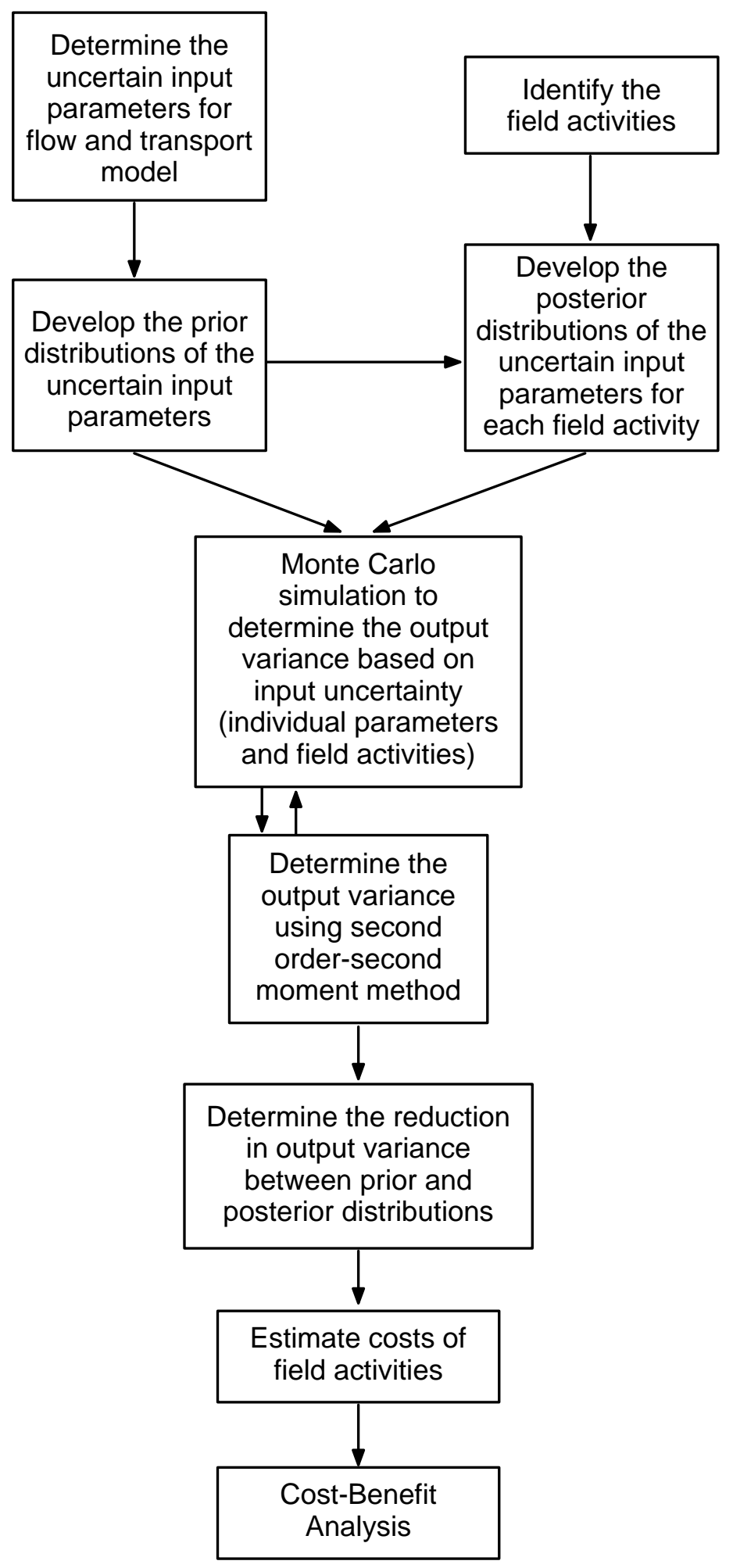

Figure 2. Summary of data decision analysis. 
Table 2. Prior Distributions for the Input Parameters.

\begin{tabular}{lrrrrll}
\hline \hline \multicolumn{1}{c}{ Parameter } & Minimum & Mean & Maximum & Variance & Distribution & Source \\
\hline Porosity & -3.3 & -2.65 & -2 & 0.14 & Uniform of $\log _{10}$ & Literature \\
Hydraulic Head & 1,150 & 1,185 & 1,220 & 408 & Uniform & PSA Data \\
Recharge & 0.2 & 1.1 & 2 & 0.27 & Uniform & PSA Data \\
Variance K & 0 & 1 & 2 & 0.33 & Uniform & Literature \\
Fracture & 50 & 375 & 700 & 35,000 & Uniform & PSA Data \\
Correlation Scale & & & & & & \\
Fracture Orientation & 8 & 29 & 50 & 147 & Uniform & PSA Data \\
Dip Angle & 30 & 60 & 90 & 300 & Uniform & PSA Data \\
Glass Dissolution & -8.39 & -6.69 & -4.69 & 1.33 & Uniform of Log 10 & Literature \\
Retardation & 1.57 & 1.73 & 1.88 & 0.01 & Uniform & PSA Data \\
\hline \hline
\end{tabular}

\section{Derivation of Posterior Distributions for Field Activities}

The posterior probabilities of the input parameters were obtained from a group of experts at DRI. The prior probabilities were presented to the group of experts (see Appendix A for a description of the expert panel) and the individuals were asked to first review the proposed field activities. After a review of the field activities (see Appendix B for a description of the field activities), the experts were asked to provide a reliability factor for each parameter based on the individual field activity. The reliability factor is defined as a number between 0 and 1 such that a value of one would indicate the field activity provides the true value of the parameter, while a value of zero would represent no information gain. The reliability factor is then used to calculate the posterior distribution as:

$$
\begin{aligned}
& a_{\text {post }}=m-(1-R) \frac{\left(b_{\text {prior }}-a_{\text {prior }}\right)}{2} \\
& b_{\text {post }}=m+(1-R) \frac{\left(b_{\text {prior }}-a_{\text {prior }}\right)}{2}
\end{aligned}
$$

where $a_{\text {post }}$ and $b_{\text {post }}$ are the lower and upper bounds, respectively, of the posterior uniform distribution, $a_{\text {prior }}$ and $b_{\text {prior }}$ are the lower and upper bounds, respectively, of the prior uniform distribution, $\mathrm{R}$ is the reliability factor ranging between 0 and 1 , and $\mathrm{m}$ is the mean of the prior distribution. The mean of the posterior distribution is assumed to be identical to the prior distribution (i.e., the field activities will not produce significantly different mean values of the input parameters).

To reduce the individual biasing of the reliability assignment, the group of experts met to discuss the points of agreement and disagreement. After a thorough discussion on each of the field activities the group came to a consensus on the most appropriate reliability factors. Appendix $\mathrm{C}$ summarizes the final consensus of the posterior distributions.

Many of the field activities required the drilling of new wells. Therefore, it was decided that the reliability factors would incorporate secondary field activities that most likely would be performed after drilling a new well. For example, following the installation of a new well, standard geophysical techniques such as acoustic televiewer logs would be performed. This would provide 
information on strike and dip angles. Likewise, temperature logs would be taken in new wells, which would provide additional information on surface recharge.

\section{Calculation of Uncertainty Reduction}

The analysis of model uncertainty is performed within a Monte Carlo framework. The model uncertainty is calculated by sampling from the distribution (either prior or posterior) of the nine input parameters and then running a simulation of the groundwater flow and transport model. A variety of output metrics can be calculated from the numerical model. The mean breakthrough time to the downgradient control plane and the peak concentration (any time during the simulation) at the control plane are used as the output metrics, while the peak concentration is an extreme measure. The solute ${ }^{137} \mathrm{Cs}$ is used for all simulations because it is dependent on all of the input parameters. Other solutes (e.g., ${ }^{3} \mathrm{H}$ and ${ }^{90} \mathrm{Sr}$ ) could have been used, but many are not dependent on the full suite of transport processes. For example, retardation was not included in the ${ }^{3} \mathrm{H}$ simulations because it does not react with the solid phase.

The Monte Carlo analysis is first used to calculate the model uncertainty based on the prior distribution of the input parameters. This analysis represents the current uncertainty of the model, which is also the maximum uncertainty of all numerical experiments. Next, the uncertainty reduction of each individual parameter is tested by reducing the variance of that input parameter to zero. This analysis represents the uncertainty of the model if a single parameter is known completely, and the remaining eight are not. Therefore, this allows the parameter's sensitivity to be ranked in terms of model prediction accuracy. The posterior distributions are then used in a Monte Carlo analysis to calculate the uncertainty reduction for each field activity. This analysis provides information on the relative merit of each activity's ability to reduce model uncertainty. The Monte Carlo analysis is then compared to the second-order second-moment analysis to test its validity. The second-order second-moment method can also be used to quickly reevaluate the uncertainty analysis given another set of posterior distributions as the computational burden is minimal (i.e., it can be performed in a spreadsheet program).

It is important to distinguish between the uncertainty due to subsurface variability and uncertainty in the mean value of each parameter. To address this issue, a single random seed is used for all of the fracture class geostatistical simulations such that subsurface variability is the same for all realizations.

All of the analysis presented in this report utilized the same groundwater flow and transport model as described in Pohll et al. (1998). It is important to note that the mean of the output distributions presented in this report should not be compared to the output from Pohll et al. (1998). The mean values used in this analysis do not represent the deterministic constants used in the previous modeling study. The mean values of the input distributions are calculated after the ranges of the uniform distributions are determined, so in some cases the mean values deviate from the constant values utilized previously.

A numerical experiment is performed to determine the appropriate number of Monte Carlo realizations such that the estimated mean and variance statistics are reliable and stable. The experiment evaluates the standard deviation and its confidence interval as a function of the number 
of realizations (between 2 and 1,000). The prior distribution of input parameters is used for this experiment. The stability and confidence intervals would be more stable and contain less error for the posterior distribution simulations as there is less variability. The results are as shown in Figure 3. The figure shows the progression of the sample variance and its confidence intervals (based on $\chi^{2}$ statistic) as a function of the number of realizations. For all simulations, 200 realizations were used, which translates to an accuracy of approximately \pm 8 percent in the estimate output variance. This is important in terms of deciding on the optimal field activity as this analysis will provide a ranked list of field activities based on its ability to reduce model uncertainty, but field activities that are ranked relatively close to one another may not be significantly different from one another.

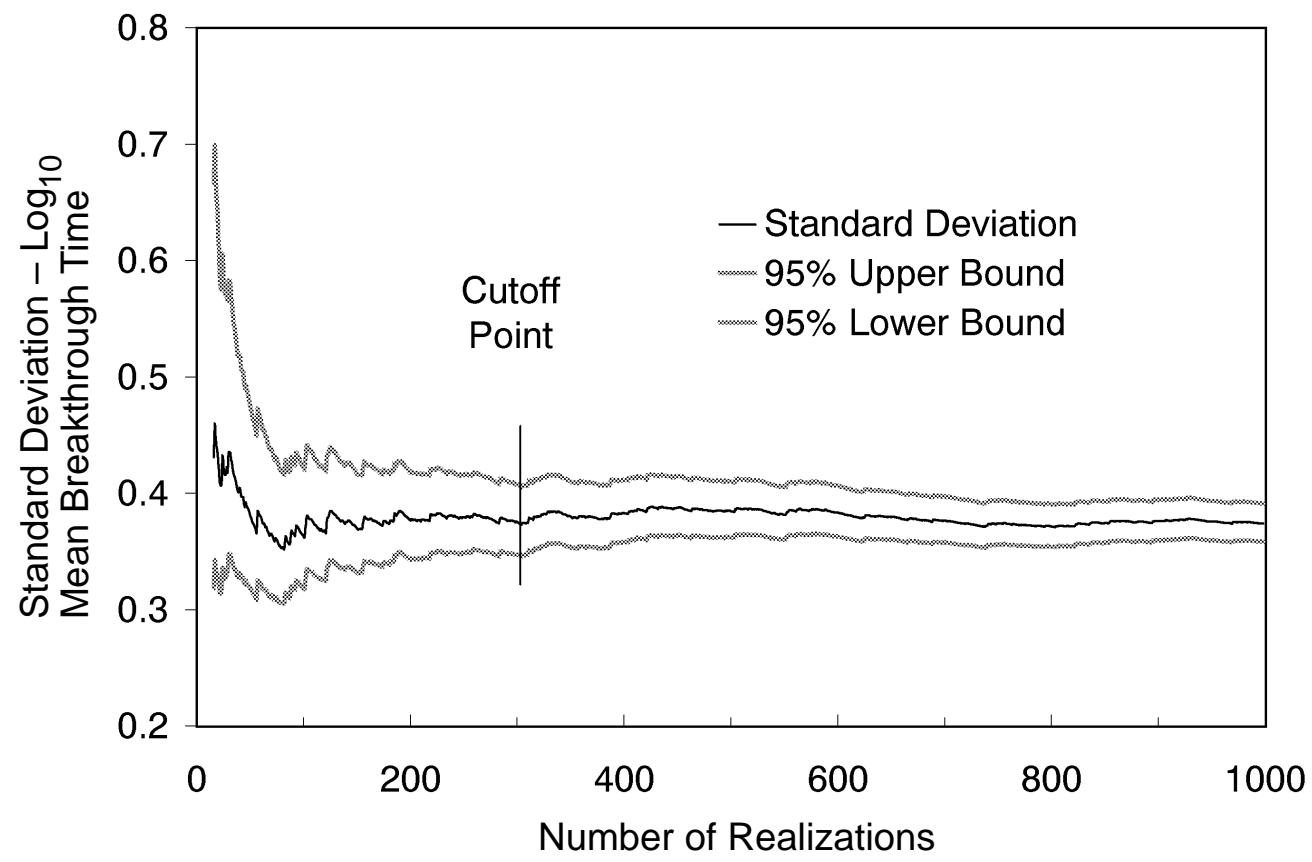

Figure 3. Standard deviation of the $\log _{10}$ transformed mean breakthrough time vs. the number of Monte Carlo realizations. The cutoff point of 300 realizations, which was used for all simulations, is also shown.

\section{RESULTS AND DISCUSSION}

\section{Ability of Single Parameters to Reduce Uncertainty}

The reduction in uncertainty of each individual parameter is tested by reducing the variance of the input parameter to zero. This process is repeated for the nine uncertain parameters to represent the uncertainty of the model if a single parameter is known completely, and the remaining eight are not. This allows the parameter's sensitivity to be ranked in terms of model prediction accuracy. The reduction in parameter uncertainty is calculated as:

$$
\phi_{\mathrm{i}}=1-\frac{\sigma_{\mathrm{i}}^{2}}{\sigma_{\mathrm{t}}^{2}}
$$


where $\phi_{\mathrm{i}}$ is the reduction in relative model uncertainty between the full input parameter uncertainty $\left(\sigma_{\mathrm{i}}^{2}\right)$ and that obtained with full knowledge of parameter $i\left(\sigma_{\mathrm{t}}^{2}\right)$. The results are presented in Tables 3 and 4 for the mean breakthrough time and peak concentration metrics, respectively. The tables also show the 95 percent confidence intervals, assuming that the output distributions are log-normal.

Table 3. Reduction in Model Uncertainty of Mean Breakthrough Time for the Nine Input Parameters Assuming Each Parameter is Known with Complete Certainty.

\begin{tabular}{lcccc}
\hline \hline \multicolumn{1}{c}{$\begin{array}{c}\text { Ranked Parameters by Variance Reduction } \\
\text { Metric: Mean Breakthrough Time }\end{array}$} & $\begin{array}{c}\log _{10} \\
\text { Std. Deviation }\end{array}$ & \% Reduction & \multicolumn{2}{c}{$\begin{array}{c}\text { L5\% Confidence Interval } \\
\text { Lowigh (years) }\end{array}$} \\
\hline Porosity & 0.241 & 38.0 & 82 & 726 \\
Recharge & 0.294 & 24.6 & 65 & 918 \\
Correlation Scale & 0.373 & 4.1 & 45 & 1,315 \\
Dip & 0.380 & 2.3 & 44 & 1,358 \\
Head & 0.381 & 2.0 & 44 & 1,364 \\
Dissolution Rate & 0.385 & 1.1 & 43 & 1,387 \\
Variance Conductivity & 0.386 & 0.9 & 43 & 1,392 \\
Retardation & 0.387 & 0.7 & 43 & 1,397 \\
Strike & 0.399 & 0.7 & 42 & 1,412 \\
\hline \hline
\end{tabular}

Table 4. Reduction in Model Uncertainty of Peak Concentration for the Nine Input Parameters Assuming Each Parameter is Known with Complete Certainty.

\begin{tabular}{|c|c|c|c|c|c|}
\hline $\begin{array}{c}\text { Ranked Parameters by Variance Reduction } \\
\text { Metric: Peak Concentration }\end{array}$ & $\begin{array}{l}\quad \log _{10} \\
\text { Std. Deviation }\end{array}$ & $\%$ Reduction & $\begin{array}{l}95 \% \text { Confid } \\
\text { Low (years) }\end{array}$ & $\begin{array}{l}\text { ence Interval } \\
\text { High (years) }\end{array}$ & $\begin{array}{c}\text { Range } \\
\text { Order-of-mag. }\end{array}$ \\
\hline Porosity & 0.850 & 60.5 & 1.E-15 & 2.E-08 & 7 \\
\hline Recharge & 2.350 & 49.8 & 1.E-16 & 2.E-07 & 9 \\
\hline Strike & 4.420 & 5.7 & 1.E-29 & 2.E-03 & 17 \\
\hline Correlation Scale & 4.510 & 3.7 & 7.E-21 & 4.E-03 & 18 \\
\hline Variance Conductivity & 4.635 & 1.1 & 4.E-21 & 6.E-03 & 18 \\
\hline Head & 4.715 & -0.6 & 3.E-21 & 9.E-03 & 18 \\
\hline Dip & 4.718 & -0.7 & 3.E-21 & 9.E-03 & 18 \\
\hline Dissolution Rate & 4.765 & -1.7 & 2.E-21 & 1.E-02 & 19 \\
\hline Retardation & 4.791 & -2.2 & 2.E-21 & 1.E-02 & 19 \\
\hline
\end{tabular}

The current uncertainty in the output metrics is not shown, but it was calculated during the analysis. The $\log _{10}$ standard deviation of the mean breakthrough time is 0.389 . Therefore, if one assumes that the distribution is log-normal, then the 95 percent confidence intervals for the mean breakthrough time range between 42 and 1,412 years. It is important to note that this differs dramatically from the analysis of Pohll et al. (1998) because their analysis of uncertainty focused only 
on the spatial variability, but not on the uncertainty of the mean values of the input parameters. The analysis presented in this report is focused solely on the uncertainty of the mean parameter estimates. As noted earlier, the random seed was kept constant for all simulations such that the spatial variability uncertainty would not be incorporated. Since the uncertainty in the parameter estimates dominates the uncertainty, this analysis is in effect representing the majority of the model uncertainty. Although additional characterization will reduce the majority of the model uncertainty, it cannot be reduced to zero because of the natural heterogeneity within the system.

Table 3 indicates that most of the uncertainty in predicting mean breakthrough time is derived by uncertainty in porosity, surface recharge and the correlation scale of the fracture classes. A complete knowledge of porosity would reduce the uncertainty by 38 percent, with 95 percent of the mean travel times ranging between 82 and 726 years. Complete knowledge of surface recharge would reduce the uncertainty by 25 percent which would represent 95 percent confidence intervals ranging between 65 and 918 years. Correlation scale has only a minor effect of uncertainty reduction (4 percent), while the remaining parameters have essentially no effect.

Table 4 shows similar behavior in each parameter's ability to reduce model uncertainty of peak concentration. Porosity and recharge were most important as was found with the mean breakthrough time metric, but the strike angle was slightly more important than correlation scale. A complete knowledge of porosity would reduce the uncertainty by 61 percent, with 95 percent of the peak concentrations ranging between $10^{-15}$ and $10^{-8} \mathrm{moles} / \mathrm{m}^{3}$, or a seven order-of-magnitude range (the model assumed a unit mole initial mass). Complete knowledge of surface recharge would reduce the uncertainty by 50 percent, which would represent 95 percent confidence intervals ranging between $10^{-16}$ to $10^{-7}$ moles $/ \mathrm{m}^{3}$, or a nine order-of-magnitude range. The strike angle and correlation scale have only a minor effect of uncertainty reduction, 6 and 4 percent, respectively. The remaining parameters have essentially no effect on model uncertainty.

\section{Ability of Field Activities to Reduce Uncertainty}

The posterior probabilities were used to calculate the uncertainty reduction obtained by each field activity. The results are presented in Tables 5 and 6 for the mean breakthrough time and peak concentration metrics, respectively.

In terms of reducing the uncertainty of the mean breakthrough time, the activities that provide information on effective porosity provide the best uncertainty reduction. For example, the top five activities (natural-gradient test, two-well recirculation test, tracer techniques, single-well tracer test, and the barometric test) all provide significant information on the effective porosity, as well as other parameters. Therefore, the first two activities reduce the uncertainty greater (44.8 and 39.2 percent) than if porosity was known completely (38 percent). The natural-gradient test would reduce the uncertainty by 45 percent, with 95 percent of the mean travel times ranging between 93 and 643 years. The two-well recirculating test would reduce the uncertainty by 40 percent, which would represent 95 percent confidence intervals ranging between 84 and 710 years.

The results for the uncertainty reduction of the peak concentration (Table 6) are relatively similar to the mean breakthrough time metric. The natural-gradient test, two-well recirculation test, tracer techniques, and single-well tracer tests were ranked identical to the rankings of the mean 
breakthrough time metric. The primary difference between the rankings of the two metrics is the ranking of the barometric test. The barometric test ranked number 5 for the mean breakthrough time metric and number 7 for the peak concentration metric. The natural-gradient test would reduce the uncertainty by 70 percent, with 95 percent of the peak concentration ranging between $10^{-15}$ and $10^{-9}$ moles $/ \mathrm{m}^{3}$, or six orders of magnitude range. The two-well recirculating test would reduce the uncertainty by 63 percent, which would represent 95 percent confidence intervals ranging between $10^{-15}$ and $10^{-8}$ moles $/ \mathrm{m}^{3}$, or seven orders of magnitude range.

Table 5. The Ranked Uncertainty Reduction of Mean Breakthrough Time for the Field Activities.

\begin{tabular}{lcccc}
\hline \hline Ranked Parameters by Variance Reduction & Log 10 & \multicolumn{3}{c}{$95 \%$ Confidence Interval } \\
\multicolumn{1}{c}{ Metric: Mean Breakthrough Time } & Std. Deviation & \% Reduction & Low (years) & High (years) \\
\hline Natural-gradient Test & 0.215 & 44.8 & 93 & 643 \\
Two-well TracerTest & 0.237 & 39.2 & 84 & 710 \\
Tracer Techniques & 0.250 & 35.7 & 79 & 755 \\
Single-well Tracer Test & 0.274 & 29.5 & 71 & 842 \\
Barometric Test & 0.305 & 21.6 & 62 & 966 \\
Cross-hole Packer Test & 0.323 & 17.1 & 57 & 1,048 \\
Single-hole Packer Test & 0.327 & 15.9 & 56 & 1,069 \\
Hydraulic Head Measurement & 0.331 & 15.0 & 55 & 1,087 \\
Energy Budget & 0.333 & 14.6 & 54 & 1,094 \\
Vadose Zone Model & 0.333 & 14.6 & 54 & 1,094 \\
Borehole Scanner & 0.344 & 11.7 & 52 & 1,152 \\
Cavity Drillback & 0.351 & 9.8 & 50 & 1,189 \\
Acoustic Televiewer & 0.357 & 8.3 & 59 & 1,221 \\
Oriented Video & 0.357 & 8.3 & 59 & 1,221 \\
Temperature Profiles & 0.358 & 8.0 & 49 & 1,227 \\
Neutron Logs & 0.364 & 6.4 & 47 & 1,263 \\
Gamma-gamma Log & 0.364 & 6.4 & 47 & 1,263 \\
Flowmeter Testing & 0.366 & 5.9 & 47 & 1,275 \\
Mining Drift Data & 0.380 & 2.4 & 44 & 1,356 \\
Analogues & 0.380 & 2.3 & 44 & 1,359 \\
Retardation Experiment & 0.389 & 0.0 & 42 & 1,415 \\
\hline \hline
\end{tabular}


Table 6. The Ranked Uncertainty Reduction of Peak Concentration for the Field Activities.

\begin{tabular}{|c|c|c|c|c|c|}
\hline $\begin{array}{c}\text { Ranked Parameters by Variance Reduction } \\
\text { Metric: Peak Concentration }\end{array}$ & $\begin{array}{l}\log _{10} \\
\text { Std. Deviation }\end{array}$ & $\%$ Reduction & $\begin{array}{l}95 \% \text { Confid } \\
\text { Low (years) }\end{array}$ & $\begin{array}{l}\text { ence Interval } \\
\text { High (years) }\end{array}$ & $\begin{array}{c}\text { Range } \\
\text { Order-of-mag. }\end{array}$ \\
\hline Natural-gradient Test & 1.414 & 69.8 & 9.E-15 & 3.E-09 & 6 \\
\hline Two-well Tracer Test & 1.739 & 62.9 & 2.E-15 & 1.E-08 & 7 \\
\hline Tracer Techniques & 1.840 & 60.7 & 1.E-15 & 2.E-08 & 7 \\
\hline Single-well Tracer Test & 2.428 & 48.2 & 9.E-17 & 3.E-07 & 10 \\
\hline Single-hole Packer Test & 2.855 & 39.1 & 1.E-17 & 2.E-06 & 11 \\
\hline Cross-hole Packer Test & 2.865 & 38.8 & 1.E-17 & 2.E-06 & 11 \\
\hline Barometric Test & 2.984 & 36.3 & 7.E-18 & 4.E-06 & 12 \\
\hline Hydraulic Head Measurements & 3.006 & 35.8 & 7.E-18 & 4.E-06 & 12 \\
\hline Energy Budget & 3.060 & 34.7 & 5.E-18 & 5.E-06 & 12 \\
\hline Vadose Zone Model & 3.060 & 34.7 & 5.E-18 & 5.E-06 & 12 \\
\hline Cavity Drillback & 3.443 & 26.5 & 9.E-19 & 3.E-05 & 13 \\
\hline Borehole Scanner & 3.490 & 25.5 & 7.E-19 & 4.E-05 & 14 \\
\hline Acoustic Televiewer & 3.576 & 23.7 & 5.E-19 & 5.E-05 & 14 \\
\hline Oriented Video & 3.576 & 23.7 & 5.E-19 & 5.E-05 & 14 \\
\hline Temperature Profiles & 3.611 & 22.9 & 4.E-19 & 6.E-05 & 14 \\
\hline Flowmeter Testing & 3.857 & 17.7 & 1.E-19 & 2.E-04 & 15 \\
\hline Neutron Logs & 4.222 & 9.9 & 3.E-20 & 1.E-03 & 17 \\
\hline Gamma-gamma Log & 4.222 & 9.9 & 3.E-20 & 1.E-03 & 17 \\
\hline Analogues & 4.412 & 5.8 & 1.E-20 & 2.E-03 & 17 \\
\hline Mining Drift Data & 4.630 & 1.2 & 4.E-21 & 6.E-03 & 18 \\
\hline Retardation Experiment & 4.666 & 0.4 & 4.E-21 & 7.E-03 & 18 \\
\hline
\end{tabular}

\section{Cost-benefit Analysis}

Figures 4 and 5 show the expected uncertainty reduction of the field activities versus estimated costs for the mean breakthrough time and peak concentration metrics, respectively. The activities that have the largest expected uncertainty reduction for a given cost are considered favorable. The set of activities that plot in the upper left-hand corner can be considered the optimal activities in terms of cost versus benefit. Figures 4 and 5 identify the same five field activities as "optimal" in terms of parameter uncertainty reduction per unit of cost. These include vadose zone modeling, energy budget, single-well, two-well and the natural-gradient tracer tests.

Many of the activities shown in Figures 4 and 5 provide duplicate information in terms of characterizing a single parameter. For example, the three tracer test activities primarily characterize effective porosity. If the single-well and natural-gradient tests are removed from the list of possible field activities (to reduce duplicate tests), then the set of optimal field activities would include the vadose zone model, barometric test, energy budget, and the two-well tracer test for the peak breakthrough time metric. The optimal activities for the peak concentration metric would include the vadose zone model, barometric test, energy budget, two-well tracer test, single-well packer test and the hydraulic head measurements. 
Field Activity Numbers

\begin{tabular}{|c|c|c|c|}
\hline \multicolumn{4}{|c|}{ Field Activity Numbers } \\
\hline 1 & Two-well Tracer & 6 & Single-well Packer \\
\hline 2 & Barometric/Vapor Ext. & 7 & Environmental Tracer \\
\hline 3 & Cross-hole Packer & 8 & Single-well Tracer \\
\hline 4 & Hydraulic Head & 9 & Energy Budget \\
\hline 5 & Natural Gradient & 10 & Vadose Zone Modeling \\
\hline
\end{tabular}

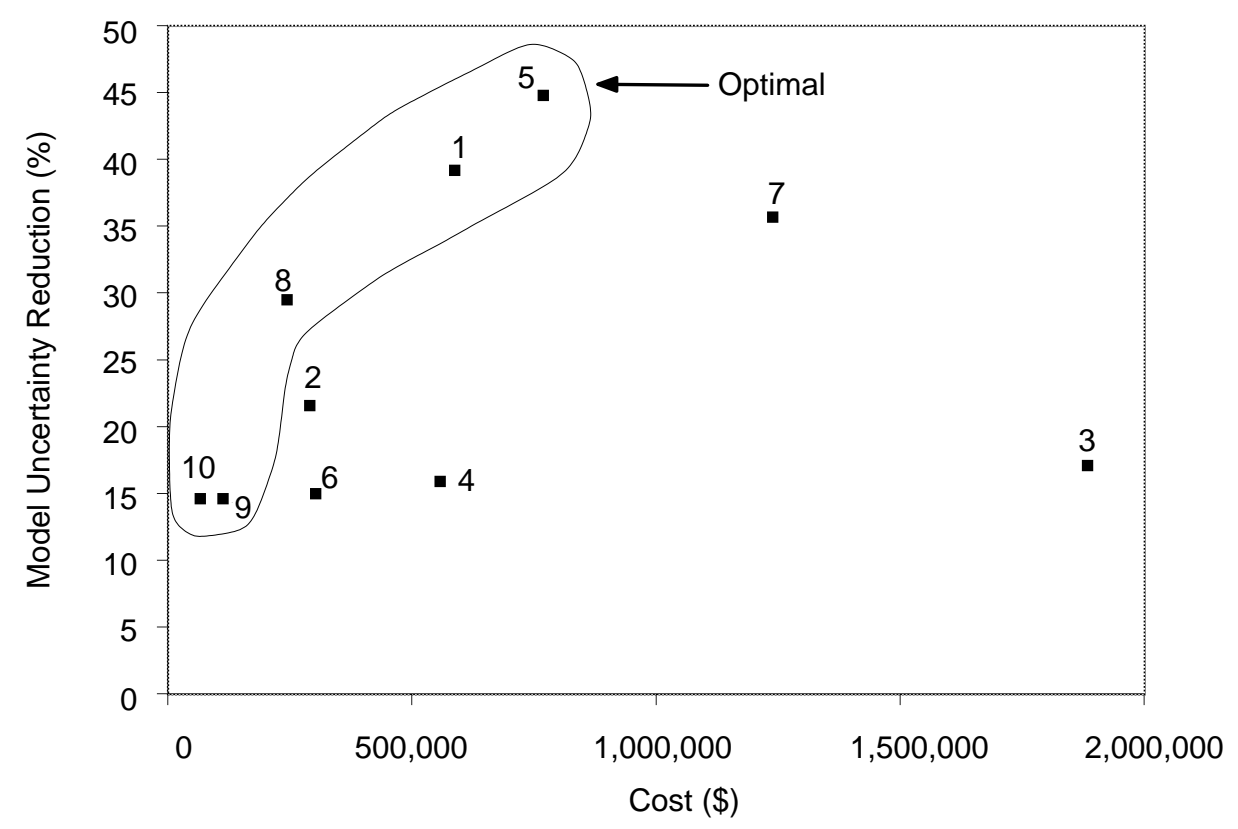

Figure 4. Expected model uncertainty reduction from the field activities vs. estimated costs for the mean breakthrough time metric.

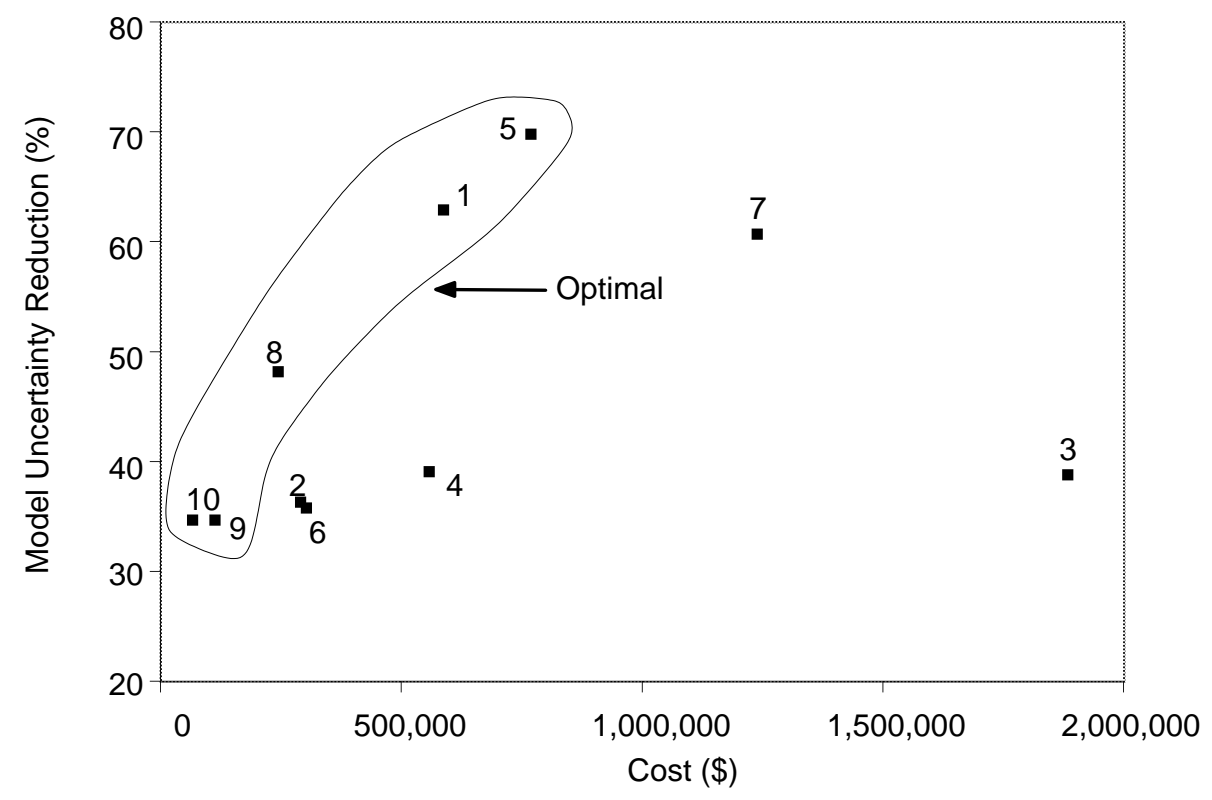

Figure 5. Expected model uncertainty reduction from the field activities vs. estimated costs for the peak concentration metric. 
Although the environmental tracer activity was not found to be optimal in terms of this uncertainty analysis, it could provide useful information to further characterize the groundwater flow and transport system. The environmental tracer activity can be used to characterize the surface recharge, effective porosity, and the hydraulic conductivity and depending on the location of this new well, it can also be used to determine the migration of the test-related solutes. Therefore, this activity should not be discounted simply because it was not found to be optimal in terms of its effectiveness to parameterize the model, as it could provide useful information about the groundwater system.

\section{CONCLUSIONS}

The following conclusions can be drawn from this data decision analysis and previous modeling efforts (Pohll et al., 1998) for the PSA:

1. Nine uncertain parameters were identified from the previous groundwater and flow modeling.

2. The uncertainty in the means of these nine parameters propagates to a $\log _{10}$ standard deviation of 0.389 for the mean breakthrough time metric. Therefore, the 95 percent confidence intervals in mean breakthrough time range between 42 and 1,412 years.

3. The uncertainty in the means of these nine parameters propagates to a $\log _{10}$ standard deviation of 4.685 for the peak concentration metric. Therefore, the 95 percent confidence intervals in mean breakthrough time range over 18 orders of magnitude in concentration.

4. The uncertainty in the means of effective porosity and recharge dominate the uncertainty in the model predictions. The other parameters play a less significant role on model uncertainty.

5. The natural-gradient tracer test, two-well recirculating test, environmental tracer techniques, and the single well tracer techniques were found to reduce the model uncertainty the most. Uncertainty reductions for these four tests range between 30 and 45 percent and 49 and 70 percent for the mean breakthrough time and peak concentration metrics, respectively.

6. Although additional characterization will reduce the dominating uncertainties in the input parameters, a certain amount of uncertainty will always exist due to the natural heterogeneity of the system.

7. The top four ranking field activities were ranked in exactly the same order for both output metrics.

8. There were five activities that were found to be optimal in terms of uncertainty reduction per unit cost: vadose zone modeling, energy budget, single-well, two-well, and the natural-gradient test for both the peak concentration and peak breakthrough time metrics. 
9. If duplicate activities are removed from the analysis (i.e., single-well tracer test and natural-gradient test), then the vadose zone model, barometric test, energy budget, and the two-well tracer test are optimal in terms of reducing the uncertainty in the peak breakthrough time metric. The vadose zone model, barometric test, energy budget, two-well tracer test, single-well packer test, and the hydraulic head measurements were found to be optimal for the peak concentration metric.

10. Although this analysis used rigorous statistical procedures to develop the "optimal" field activities in terms of cost benefit, many assumptions were required. Therefore, the decisions made to determine the final field characterization plan should use this analysis in combination with expert judgement.

11. The calculated uncertainty reductions are estimates based on the subjective analysis of the reliability of each field activity. Therefore, it should not be assumed that actual field activities will reduce model uncertainty at the same magnitude as the estimates provided. Secondly, the uncertainty in the natural heterogeneity, that was not included in this analysis, will always exist.

\section{REFERENCES}

IT Corporation, 1998. Value of Information Analysis for Corrective Action Unit Nos. 101 and 102: Central and Western Pahute Mesa, Nevada Test Site, Nevada, ITLV/13052, Las Vegas, NV.

Jury, W.A., W.R. Gardner and W.H. Gardner, 1991. Soil Physics, John Wiley and Sons, Inc., New York, $328 \mathrm{p}$.

Pohll, G., J. Chapman, A. Hassan, C. Papelis, R. Andricevic and C. Shirley, 1998. Evaluation of Groundwater Flow and Transport at the Shoal Underground Nuclear Test: An Interim Report, Desert Research Institute, Water Resources Center Publication No. 45162.

University of Nevada, 1965. Geological, Geophysical, Chemical and Hydrological Investigations of the Sand Springs Range, Fairview Valley and Fourmile Flat, Churchill County, Nevada. U.S. Atomic Energy Commission, Vela Uniform Report, vol. 1001. P. 369.

U.S. Department of Energy, 1998. Data Report, Project Shoal Area, Churchill County, Nevada, Environmental Restoration Division, Nevada Operations Office. DOE/NV-505.

U.S. Department of Energy, 1994. Announced United States Nuclear Tests July 1945 through December 1992. DOE/NV-209 (Rev. 14), 104 p. 


\section{CONTENTS}

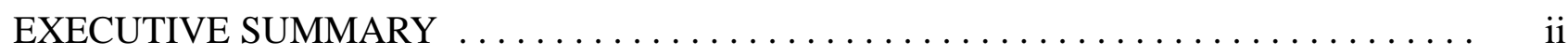

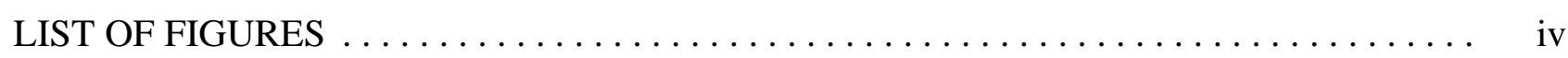

LIST OF TABLES $\ldots \ldots \ldots \ldots \ldots \ldots \ldots \ldots \ldots \ldots \ldots \ldots \ldots \ldots \ldots \ldots \ldots \ldots \ldots \ldots$

INTRODUCTION $\ldots \ldots \ldots \ldots \ldots \ldots \ldots \ldots \ldots \ldots \ldots \ldots \ldots \ldots \ldots \ldots \ldots \ldots$

COST ANALYSIS FOR FIELD ACTIVITIES $\ldots \ldots \ldots \ldots \ldots \ldots \ldots \ldots \ldots \ldots \ldots \ldots$

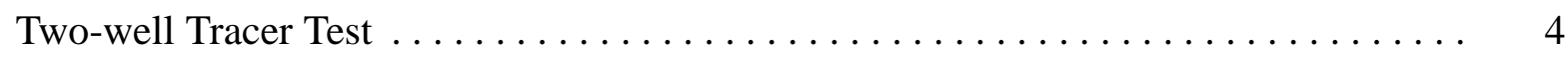

Barometric Tests (Including Vapor Extraction Tests) $\ldots \ldots \ldots \ldots \ldots \ldots \ldots$

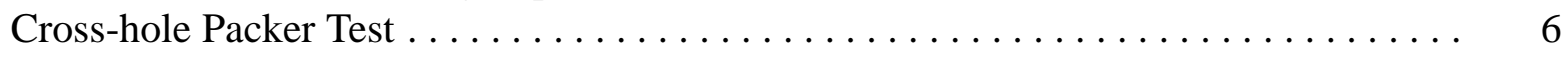

Hydraulic Head Measurements $\ldots \ldots \ldots \ldots \ldots \ldots \ldots \ldots \ldots \ldots \ldots \ldots \ldots$

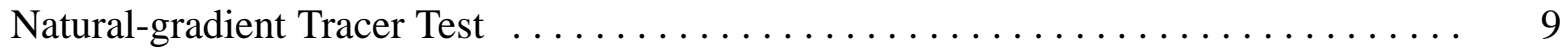

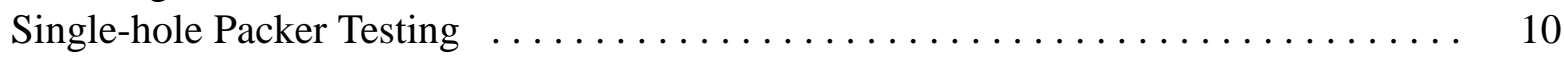

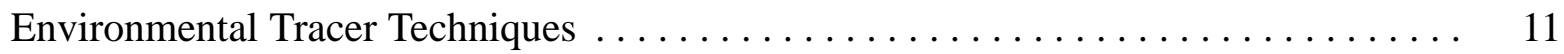

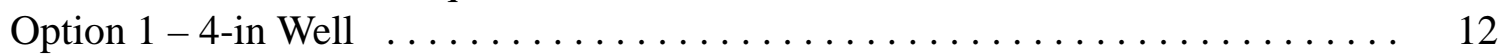

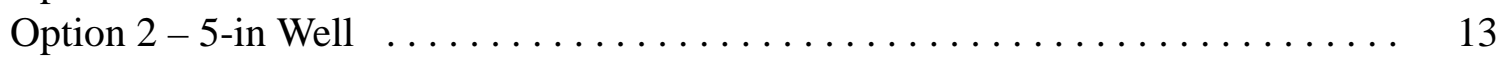

Single-well Tracer Test $\ldots \ldots \ldots \ldots \ldots \ldots \ldots \ldots \ldots \ldots \ldots \ldots \ldots \ldots \ldots \ldots$

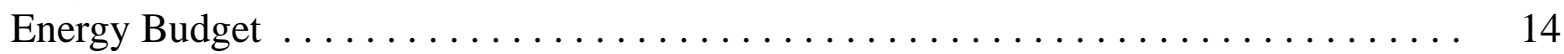

Vadose Zone Model $\ldots \ldots \ldots \ldots \ldots \ldots \ldots \ldots \ldots \ldots \ldots \ldots \ldots$

TECHNICAL APPROACH $\ldots \ldots \ldots \ldots \ldots \ldots \ldots \ldots \ldots \ldots \ldots \ldots \ldots \ldots \ldots \ldots$

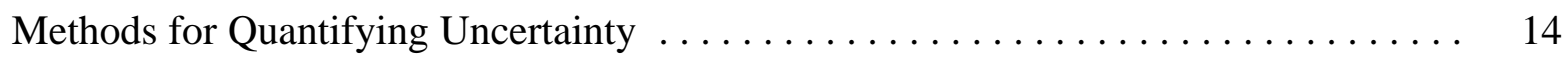

Derivation of Input Parameter Prior Distributions $\ldots \ldots \ldots \ldots \ldots \ldots \ldots \ldots \ldots \ldots \ldots$

Derivation of Posterior Distributions for Field Activities $\ldots \ldots \ldots \ldots \ldots \ldots$

Calculation of Uncertainty Reduction $\ldots \ldots \ldots \ldots \ldots \ldots \ldots \ldots \ldots \ldots \ldots$

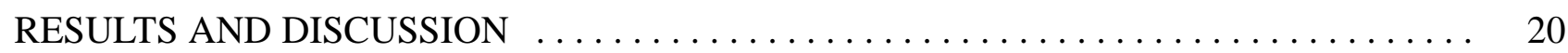

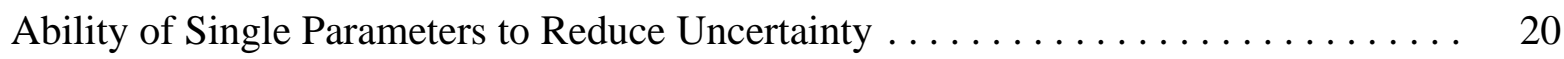

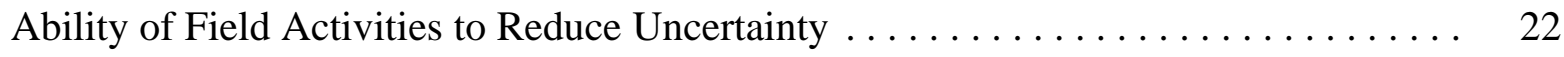

Cost-benefit Analysis . . . . . . . . . . . . . . . . . . . . 24

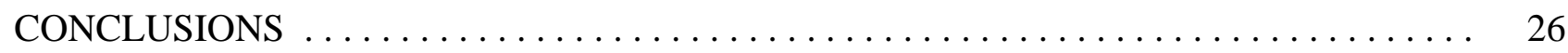

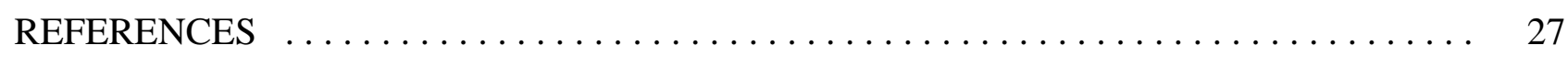

\section{APPENDICES}

A: EXPERT PANEL QUALIFICATIONS $\ldots \ldots \ldots \ldots \ldots \ldots \ldots \ldots \ldots \ldots \ldots \ldots$ A-1

B: DESCRIPTIONS OF FIELD ACTIVITIES $\ldots \ldots \ldots \ldots \ldots \ldots \ldots \ldots \ldots \ldots$ B-1

C: POSTERIOR DISTRIBUTIONS FOR THE FIELD ACTIVITIES $\ldots \ldots \ldots \ldots$. C-1

D: DEVELOPMENT OF THE SECOND ORDER - FIRST AND

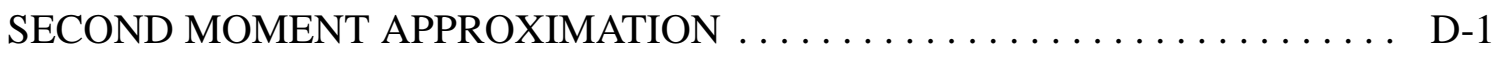

E: DETAILED COST ESTIMATES FOR FIELD ACTIVITIES $\ldots \ldots \ldots \ldots \ldots$ E-1 


\section{FIGURES}

1. Location of the Project Shoal Area with existing and historical wells. . . . . . . . 1

2. Summary of data decision analysis. $\ldots \ldots \ldots \ldots \ldots \ldots \ldots \ldots \ldots \ldots \ldots \ldots$

3. Standard deviation of the $\log 10$ transformed mean breakthrough time vs. the number of

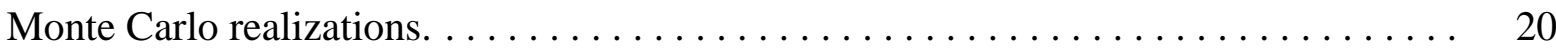

4. Expected model uncertainty reduction from the field activities vs. estimated costs for the

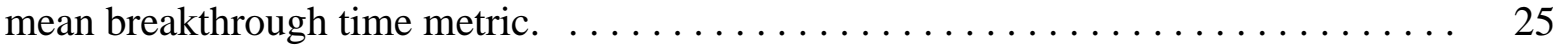

5. Expected model uncertainty reduction from the field activities vs. estimated costs for the peak concentration metric.

\section{TABLES}

1. Order-of-Magnitude Cost Estimates for the Top-ranked Field Activities. . . . . . . . 4

2. Prior Distributions for the Input Parameters. . . . . . . . . . . . . . . 18

3. Reduction in Model Uncertainty of Mean Breakthrough Time for the Nine Input Parameters Assuming Each Parameter is Known with Complete Certainty. . . . . .

4. Reduction in Model Uncertainty of Peak Concentration for the Nine Input Parameters Assuming Each Parameter is Known with Complete Certainty. . . . . . . . . .

5. The Ranked Uncertainty Reduction of Mean Breakthrough Time for the Field Activities.

6. The Ranked Uncertainty Reduction of Peak Concentration for the Field Activities. 


\section{APPENDIX A}

\section{EXPERT PANEL QUALIFICATIONS}

\section{GREG POHLL}

Position: $\quad$ Assistant Research Professor

Education: $\quad$ Ph.D., Hydrology and Hydrogeology, University of Nevada, Reno

M.S., Hydrology, University of Nevada, Reno

B.S., Mathematics, University of Nevada, Reno

Professional Interests: Dr. Pohll's major research interests are in numerical simulation of coupled hydrologic systems. Evaluation of complex hydrologic systems requires tools from the traditionally fragmented fields of surface water hydrology and groundwater hydrogeology. He is specifically interested in the development and application of numerical models that integrate surface and subsurface processes to describe the physics of subsurface moisture and contaminant migration. He also has extensive experience in analysis and simulation stochastic groundwater flow and transport processes.

\section{BRAD LYLES}

Position: Assistant Research Hydrogeologist

Education: M.S., Hydrogeology, University of Nevada, Reno

B.A., Geology, California State University, Fresno

Professional Interests: Mr. Lyles' research and experience are focused on the study of ion and isotope geochemistry. Current research has included the use of geostatistics to refine groundwater gradients to further understand geochemical mixing in carbonate and alluvial aquifers of southern Nevada. Hydraulic parameters and geochemical variability have been used successfully to delineate buried geologic structures of Las Vegas Valley. Time-series spring data have been used to identify groundwater recharge characteristics. Other research interests include the development of data acquisition systems for hydrologic studies, such as: the development of a water stage and chemistry data logging system in a limestone cave in Kings Canyon Sequoia National Park; the design and development of a hydrochemical logging tool capable of measuring temperature, electrical conductance, $\mathrm{pH}$, dissolved oxygen, and bromide, consecutively; and the development of a thermal-pulse flowmeter logging tool for measuring vertical groundwater flow in boreholes. 


\section{JENNY CHAPMAN}

Position: Associate Research Hydrogeologist

Education: $\quad$ M.S., Geology, University of Texas at Austin

B.S. Geology, Sul Ross State University, Alpine, Texas

Professional Interests: Ms. Chapman is interested in helping solve problems related to waste disposal, contaminant transport, and water supply in arid regions where paleoclimates may continue to influence flow systems or pose uncertainties for the future. Previous and current work rely heavily on isotopic (stable and radiogenic) and geochemical tracers for evaluating recharge and paleohydrologic systems. Borehole logging, time-domain reflectometry, and analytic solute-flux modeling are other techniques that have been useful in her work.

\section{TODD MIHEVC}

\section{Position: Assistant Research Hydrogeologist \\ Education: $\quad$ M.S., Hydrogeology, University of Nevada, Reno B.S., Geology, University of Nevada, Reno}

Professional Interests: Mr. Mihevc has a broad range of hydrologic interests. Current research is directed toward the understanding of groundwater flow systems in the desert environment. As an element of the broader topic, an intensive investigation was conducted to estimate groundwater recharge from perennial stream channels. Other research is focused on the evaluation of monitoring wells through the use of hydrophysical logging equipment. A chemical logging tool was developed to determine chemical and physical parameters in deep wells. These data are combined with other physical measurements and chemical analysis to determine the effectiveness of monitoring wells. 


\section{APPENDIX B}

\section{DESCRIPTIONS OF FIELD ACTIVITIES}

Several measurement techniques exist for the eight parameters listed above. Each technique will be evaluated for data worth (via the data decision analysis), accuracy, feasibility, and cost. The possible techniques include:

Single-well withdrawal-injection test. The tracer is introduced into the groundwater system for a set time period followed by pumping from the same well and monitoring the tracer concentration versus time (Percious, 1969, Fried et al., 1974). Single-well tests provide only limited information near the borehole.

Natural-gradient tracer test. A tracer is introduced with little disturbance to the aquifer. The tracer is monitored at one or more points downgradient (Fried, 1976). Natural-gradient tests are costly and may require long periods of time before the tracer moves a significant distance from the injection point.

Two-well tracer test. The tracer is injected into the aquifer at one well, then it is pumped out of a second while recirculating through the withdrawal-injection system (Grove and Beetem, 1971; Pohll and Pohlmann, 1996; Claassen and Cordes, 1975). Recirculating tests distort the natural flow field and do not provide much information about in situ groundwater velocities.

Barometric tests. The combined effects of barometric fluctuations and aquifer properties on the hydraulic head have been shown to be useful in the inverse sense to determine aquifer hydraulic properties (Furbish, 1991; Landmeyer, 1996). The method utilizes the temporal response in the surface barometric pressure changes within the aquifer.

Neutron $\log$. Neutron logs can be used to determine the total porosity in the saturated zone or moisture content in the unsaturated zone. Neutrons are emitted from a source and then a detector senses the number of neutrons returning. The porosity (or moisture content) is inversely proportional to the number of detected neutrons. It is very important to calibrate the neutron log for each site (Driscoll, 1986).

Gamma-gamma log. An active source of gamma radiation is lowered into the borehole along with a detector that is shielded so it counts only the back-scattered gamma rays. This tool is primarily used to infer formation density, but if the grain density is known, then total porosity can be determined (Driscoll, 1986).

Analogues. Published values of effective porosity, obtained using various testing methods, can be researched for similar hydrogeologic environments. A relatively large number of published values are available from fractured granitic rock as a result of nuclear waste disposal programs in European countries (Werner, 1996).

Measurements in wells, including vertical gradients. Measurements of hydraulic head within the flow system provide an indication of the groundwater flow directions. It is important to install 
piezometers throughout the flow system such that vertical and horizontal head gradients can be calculated.

Single-hole packer testing. Single-hole packer tests can be divided into two categories: 1) injection tests and 2) slug tests. In an injection test, water (or air in the unsaturated zone) is injected under constant hydraulic head into a packed-off interval of the borehole and head and flow rate are monitored. In a slug test, the hydraulic head in the packed-off interval is instantaneously increased or decreased, and the subsequent head recovery is monitored (Hsieh et al., 1983; Spane and Wurstner, 1993; Spane, 1996).

Cross-hole packer testing (interference testing). Fluid is injected into a packed-off interval in one borehole, and the resultant hydraulic head variations are measured in packed-off intervals in adjacent boreholes. The objective of the test is to measure, on a field scale, the hydraulic conductivity tensor and the specific storage of a fractured rock aquifer (Hsieh et al., 1983; Spane and Wurstner, 1993; Spane, 1996).

Flowmeter testing. The thermal flowmeter is used to measure vertical flow at specified intervals in wells. In situ (non-stressed) flow measurements are made to quantify the flow rate between aquifers of differing hydrostatic heads. Measurements made while the well is being pumped or slugged are referred to as stress-flow measurements and are use to proportion the amount of water that flows out of or into the specific zone being tested (Paillet and Olson, 1994). The relative flow rates can be correlated to the relative conductivity of each discrete zone. The flowmeter has a finite detection limit, which limits its ability to estimate hydraulic conductivity in low permeability zones.

Temperature profiles. Measurements of the thermal profile from ground surface to the water table can yield information on the vertical fluid velocity due to surface recharge. The in situ temperature is measured at discrete intervals in the unsaturated zone. Analytical methods are used to determine the magnitude of the fluid velocity (Bredehoeft and Papadopulos, 1965).

Tracer techniques. Use of environmental tracers in groundwater recharge investigations began in the 1960s with the tracking of tritium movement in soil water (Zimmerman et al., 1967). Use of radiotracers has since expanded to include carbon-14 (though there are complications due to geochemical reactions and diffusion of carbon dioxide gas; Thorstenson et al., 1983), and chlorine-36 (Phillips et al., 1988). The nonradiogenic isotopes of deuterium and oxygen-18 have also been used extensively in unsaturated zone studies (Barnes and Allison, 1983), as has the chloride mass-balance method (Allison and Hughes, 1978). All of these techniques basically track the movement of a known substance, either a dissolved solute or a part of the water molecule itself, through the unsaturated zone. Knowing the input function, the age of recharging water can be calculated directly with the radiogenic tracers, whereas the stable tracers can be used to determine flow characteristics that can be used to calculate recharge.

Vertical hydraulic head measurements. Piezometer nests or multiple completion boreholes are used to measure the vertical hydraulic head gradient. If the vertical hydraulic conductivity is known, one can estimate the surface recahrge using Darcy's Law and the measured vertical head gradients (Toth, 1963). 
Vadose zone modeling. Vadose zone modeling can be used for hypothesis testing of various recharge and hydraulic conductivity relationships. Specifically, one would identify ranges of possible recharge rates and subsurface hydraulic conductivity values and test the flow system response under different combinations of each parameter (Jury et al., 1991).

Energy budget/turbulence methods. One can use either energy budget (Bowen ratio or Penman) or turbulence (Eddy-correlation) methods to calculate the near-surface water budget. Either method will yield an estimate of the bare soil evaporation and evapotranspiration which can be used to estimate the net surface recharge. Energy methods utilize direct or indirect measurements of the components of the heat balance, while the turbulence methods determine the turbulent fluxes of water vapor, momentum, and sensible heat from covariances (Brutsaert, 1982).

Horizontal borehole with borehole scanner. Radio waves emitted from a borehole radar tool may be used to detect fractures. The logging tool is lowered into the well on $1 \mathrm{~m}$ increments. Fracture zones with minimum widths of $10 \mathrm{~cm}$ can be mapped up to a $150 \mathrm{~m}$ radial distance from the well (SwedPower/SKB, 1991).

Mining drift data. The Shoal test involved mining a $320 \mathrm{~m}$ long drift through the Sand Springs granite. Detailed photography of the underground workings, designed to provide data on the geologic characteristics of the granite, was conducted after washing down the walls of the drift. Mapping also accompanied the photography. Though a description of the photography and mapping has been found (Jerome, 1965), the results are more elusive and were apparently never published. It is likely that the records exist in an archive.

Acoustic televiewer logs. The acoustic televiewer uses a transmitter to paint the surrounding borehole walls with an acoustic signal and a receiver to record the travel time and characteristics of the returning signal. The travel time, amplitude and phase coherence are affected by the character of the surrounding rock. For fracture analysis, marked attenuation is interpreted as a fracture. When a planar feature, such as a fracture, intersects a cylindrical borehole, a sinusoidal trace results (Driscoll, 1986).

Oriented video. Video logs can be oriented in non-cased wells by placing a magnetic diver's compass to the back of the video camera light-head. However, in wells with excessive deviation, the compass needle may not spin freely.

Cavity drillback. A post-test hole could be drilled into the Shoal cavity to obtain samples of the melt glass and samples of the associated groundwater. There are very few studies available that measure the presence of radionuclides in cavity fluids (Kersting, 1996), adding great uncertainty as to the availability of radionuclides to migrate in groundwater. The core samples could be used to evaluate glass composition and dissolution, and search for reaction products that may mantle surfaces. The groundwater would reveal the dissolved component coexisting with the solid phase, and would represent what portion of the radiologic source term is available for transport.

Retardation laboratory experiments. Equilibrium sorption experiments (either batch and/or column) can be performed to estimate the partitioning of an ion between the solution and the solid under 
equilibrium conditions. Many sorption experiments have been performed on granite materials, but the results are specific to the site mineralogy and hydrochemistry (Stenhouse and Pottinger, 1994; Frick et al., 1991; Werner, 1996; Failor et al., 1982; Beall et al., 1980). It is important to design the laboratory sorption experiments using local granite and fluid with hydrochemical characteristics similar to the Shoal site.

\section{REFERENCES}

Allison, G.B. and M.W. Hughes, 1978. The use of environmental tritium and chloride to estimate total recharge to an unconfined aquifer. Aust. J. Soil Res., 16, 181-195.

Barnes, C.J. and G.B. Allison, 1983. The distribution of deuterium and ${ }^{18} \mathrm{O}$ in dry soils, 1 . Theory. J. Hydrol., 60:141-156.

Beall, G.W., G.D. O' Kelley and B. Allard, 1980. An autoradiographic study of actinide sorption on climax stock granite. Oak Ridge National Laboratory, ORNL-5617, 27 p.

Bredehoeft, J.D. and I.S. Papadopulos, 1965. Rates of vertical groundwater movement estimated from the earth's thermal profile. Water Resources Research, 1(2):325-328.

Brutsaert, W., 1982. Evaporation into the Atmosphere. Kluwer Academic Publishers, London, 299 p.

Claassen, H.C. and E.H. Cordes, 1975. Two-well recirculating tracer test in fractured carbonate rock, Nevada. Hydrological Sciences Bulletin, 20(3).

Driscoll, F.G, 1986, Groundwater and Wells, Johnson Screens. St. Paul, Minnesota, 1089 pp.

Failor, R., D. Isherwood, E. Raber and T. Vandergraaf, 1982. Laboratory studies of radionuclide transport in fractured climax granite. Lawrence Livermore National Laboratory, UCRL-53308, $73 \mathrm{p}$.

Frick, U., W. Alexander, B. Baeyens, P. Bossart, M.H. Bradbury, Ch. Buhler, J. Eikenberg, Th. Fierz, W. Heer, E. Hoehn, I.G. McKinley, P.A. Smith, 1991. Grimsel Test Site - The Radionuclide Migration Experiment - Overview of Investigations 1985 - 1990. National Cooperative for Disposal of Radioactive Waste Technical Report 91-94.

Fried, J.J. 1976. Groundwater Pollution, Elsevier, Amsterdam, 330 p.

Fried, J.J., P.C. Leveque, D. Poitrinal and J. Severac, 1974. Local studies of miscible pollution of groundwater: the single-well pulse technique. Groundwater Pollution in Europe, J.A. Cole (ed.). Water Information Center, Port Washington, NY, pp.388-406.

Furbish, D.J., 1991. The response of water level in a well to a time series of atmospheric loading under confined conditions. Water Resources Research, 27(4): 557-568.

Grove, D.B. and W.A. Beetem, 1971. Porosity and dispersion constant calculations for a fracture carbonate aquifer using the two well tracer method. Water Resources Research, 7(1):128-134. 
Hsieh, P.A., S.P. Neuman and E.S. Simpson, 1983. Pressure testing of fractured rocks - A methodology employing three-dimensional cross-hole tests. NUREG/CR-3213.

Jerome, S.E., 1965. Geologic Mapping and Guidance, In: University of Nevada, Geological, Geophysical, Chemical and Hydrological Investigations of the Sand Springs Range, Fairview Valley and Fourmile Flat, Churchill County, Nevada. VUF-1001, pp155-159.

Jury, W.A., W.R. Gardner and W.H. Gardner, 1991. Soil Physics. John Wiley and Sons, Inc., New York, $328 \mathrm{p}$.

Kersting, A.B., 1996. The state of the hydrologic source term. Lawrence Livermore National Laboratory, UCRL-ID-126557, 30 p.

Landmeyer, J.E., 1996. Aquifer response to record low barometric pressures in the southeastern United States. Groundwater, 34(5):917.

Paillet, F.L. and J.D. Olson, 1994. Analysis of the results of hydraulic-fracture stimulation of two crystalline bedrock boreholes, Grand Portage, Minnesota. U.S. Geological Survey, Water Resources Investigation Report 94-4044.

Percious, D. J., 1969. Aquifer dispersivity by recharge-discharge of a fluorescent dye tracer through a single well. Unpublished M.S. Thesis, University of Arizona.

Phillips, F.M., J.L. Mattick, T.A. Duval, D. Elmore and P.W. Kubick, 1988. Chlorine-36 and tritium from nuclear-weapons fallout as tracer for long-term liquid and vapor movement in desert soils. Water Resources Research, 24:1877-1891.

Pohll, G. and K. Pohlmann, 1996. Evaluation of the radionuclide tracer test conducted at the project Gnome underground nuclear test site, New Mexico. Desert Research Institute, Water Resources Center Publication \#45141.

Spane, F.A. and S.K. Wurstner, 1993. DERIV: A computer program for calculating pressure derivatives for use in hydraulic test analysis. Ground Water, Vol. 31(5):814-822.

Spane, F.A, 1996. Applicability of slug interference tests for hydraulic characterization of unconfined aquifers: (1) analytical assessment. Ground Water, Vol.34(1):66-74.

Stenhouse, M.J. and J. Pottinger, 1994. Comparison of sorption databases used in recent performance assessments involving crystalline host rock. Radiochimica Acta, 66/67:267-275.

SwedPower/SKB, 1991. Instrumentation for site characterization brochure.

Thorstenson, D.C., E.P. Weeks, H. Haas and D.W. Fisher, 1983. Distribution of gaseous 12CO2, $13 \mathrm{CO} 2,14 \mathrm{CO} 2$ in the subsoil unsaturated zone of the western United States. Radiocarbon 25(2):315-346.

Toth, J., 1963. A theoretical analysis of groundwater flow in small drainage basins. Journal of Geophysical Research, 68:4795-4812. 
Werner, K., 1996. Literature review and scoping calculations for the tracer retention understanding experiments at Aspo Hard Rock Laboratory, diss. Stockholm, Sweden: Royal Institute of Technology, $81 \mathrm{p}$.

Zimmerman, U., D. Ehhalt and K.O. Munnich, 1967. Soil water movement and evapotranspiration: changes in the isotopic composition of the water. In: Proceedings of the IAEA Symposium on Isotope Hydrology, Int. Atomic Energy Agency, Vienna. 


\section{APPENDIX C}

POSTERIOR DISTRIBUTIONS FOR THE FIELD ACTIVITIES

$$
\mathrm{C}-1
$$




\begin{tabular}{|lrrrrrr|}
\hline Single-well Tracer Test & \multicolumn{3}{c|}{ Prior } & \multicolumn{5}{c|}{ Posterior } \\
& \multicolumn{1}{c}{ Low } & \multicolumn{1}{c|}{ Mean } & \multicolumn{1}{c|}{ High } & \multicolumn{1}{c|}{ Low } & High & Reliability \\
\cline { 2 - 7 } Porosity & -3.30 & -2.65 & -2.00 & -2.91 & -2.39 & 0.6 \\
Hydraulic Head & 1160.00 & 1190.00 & 1220.00 & 1160.00 & 1220.00 & 0.0 \\
Recharge & $5.48 \mathrm{E}-06$ & $3.01 \mathrm{E}-05$ & $5.48 \mathrm{E}-05$ & $5.48 \mathrm{E}-06$ & $5.48 \mathrm{E}-05$ & 0.0 \\
Variance K & 0.00 & 1.00 & 2.00 & 0.00 & 2.00 & 0.0 \\
Correlation Scale & 50.00 & 375.00 & 700.00 & 50.00 & 700.00 & 0.0 \\
Strike & -95.00 & -74.00 & -53.00 & -95.00 & -53.00 & 0.0 \\
Dip & 30.00 & 60.00 & 90.00 & 30.00 & 90.00 & 0.0 \\
Glass Dissolution Rate & -8.69 & -6.69 & -4.69 & -8.69 & -4.69 & 0.0 \\
Retardation & 1.57 & 1.73 & 1.88 & 1.57 & 1.88 & 0.0 \\
\hline
\end{tabular}

\begin{tabular}{|lrrrrrr|}
\hline Natural-gradient Test & \multicolumn{5}{c|}{ Prior } & \multicolumn{5}{c|}{ Posterior } \\
& \multicolumn{1}{c}{ Low } & \multicolumn{1}{c|}{ Mean } & \multicolumn{1}{c|}{ High } & \multicolumn{1}{c|}{ Low } & High & Reliability \\
\cline { 2 - 7 } & -3.30 & -2.65 & -2.00 & -2.85 & -2.46 & 0.7 \\
Porosity & 1160.00 & 1190.00 & 1220.00 & 1160.00 & 1220.00 & 0.0 \\
Hydraulic Head & $5.48 \mathrm{E}-06$ & $3.01 \mathrm{E}-05$ & $5.48 \mathrm{E}-05$ & $1.04 \mathrm{E}-05$ & $4.99 \mathrm{E}-05$ & 0.2 \\
Recharge & 0.00 & 1.00 & 2.00 & 0.10 & 1.90 & 0.1 \\
Variance K & 50.00 & 375.00 & 700.00 & 50.00 & 700.00 & 0.0 \\
Correlation Scale & -95.00 & -74.00 & -53.00 & -90.80 & -57.20 & 0.2 \\
Strike & 30.00 & 60.00 & 90.00 & 36.00 & 84.00 & 0.2 \\
Dip & -8.69 & -6.69 & -4.69 & -8.69 & -4.69 & 0.0 \\
Glass Dissolution Rate & 1.57 & 1.73 & 1.88 & 1.57 & 1.88 & 0.0 \\
Retardation & & & & & & \\
\hline
\end{tabular}

\begin{tabular}{|lrrrrrr|}
\hline Two-well Tracer Test & \multicolumn{3}{c|}{ Prior } & \multicolumn{5}{c|}{ Posterior } \\
& \multicolumn{1}{c}{ Low } & \multicolumn{1}{c|}{ Mean } & \multicolumn{1}{c|}{ High } & \multicolumn{1}{c|}{ Low } & High & Reliability \\
\cline { 2 - 7 } & -3.30 & -2.65 & -2.00 & -2.91 & -2.39 & 0.6 \\
Porosity & 1160.00 & 1190.00 & 1220.00 & 1160.00 & 1220.00 & 0.0 \\
Hydraulic Head & $5.48 \mathrm{E}-06$ & $3.01 \mathrm{E}-05$ & $5.48 \mathrm{E}-05$ & $1.04 \mathrm{E}-05$ & $4.99 \mathrm{E}-05$ & 0.2 \\
Recharge & 0.00 & 1.00 & 2.00 & 0.00 & 2.00 & 0.0 \\
Variance K & 50.00 & 375.00 & 700.00 & 50.00 & 700.00 & 0.0 \\
Correlation Scale & -95.00 & -74.00 & -53.00 & -90.80 & -57.20 & 0.2 \\
Strike & 30.00 & 60.00 & 90.00 & 36.00 & 84.00 & 0.2 \\
Dip & -8.69 & -6.69 & -4.69 & -8.69 & -4.69 & 0.0 \\
Glass Dissolution Rate & 1.57 & 1.73 & 1.88 & 1.57 & 1.88 & 0.0 \\
Retardation & & & & & & \\
\hline
\end{tabular}




\begin{tabular}{|lrrrrrr|}
\hline Barometric Test & \multicolumn{3}{c|}{ Prior } & \multicolumn{5}{c|}{ Posterior } \\
& \multicolumn{1}{c}{ Low } & \multicolumn{1}{c|}{ Mean } & \multicolumn{1}{c|}{ High } & \multicolumn{1}{c|}{ Low } & High & Reliability \\
\cline { 2 - 8 } Porosity & -3.30 & -2.65 & -2.00 & -3.04 & -2.26 & 0.4 \\
Hydraulic Head & 1160.00 & 1190.00 & 1220.00 & 1160.00 & 1220.00 & 0.0 \\
Recharge & $5.48 \mathrm{E}-06$ & $3.01 \mathrm{E}-05$ & $5.48 \mathrm{E}-05$ & $5.48 \mathrm{E}-06$ & $5.48 \mathrm{E}-05$ & 0.0 \\
Variance K & 0.00 & 1.00 & 2.00 & 0.30 & 1.70 & 0.3 \\
Correlation Scale & 50.00 & 375.00 & 700.00 & 115.00 & 635.00 & 0.2 \\
Strike & -95.00 & -74.00 & -53.00 & -90.80 & -57.20 & 0.2 \\
Dip & 30.00 & 60.00 & 90.00 & 36.00 & 84.00 & 0.2 \\
Glass Dissolution Rate & -8.69 & -6.69 & -4.69 & -8.69 & -4.69 & 0.0 \\
Retardation & 1.57 & 1.73 & 1.88 & 1.57 & 1.88 & 0.0 \\
\hline
\end{tabular}

\begin{tabular}{|lrrrrrrr|}
\hline Neutron Logs & \multicolumn{5}{c|}{ Prior } & \multicolumn{5}{c|}{ Posterior } \\
& \multicolumn{1}{c}{ Low } & Mean & \multicolumn{1}{c|}{ High } & \multicolumn{1}{c|}{ Low } & High & Reliability \\
\cline { 2 - 8 } & -3.30 & -2.65 & -2.00 & -3.24 & -2.07 & 0.1 \\
Porosity & 1160.00 & 1190.00 & 1220.00 & 1160.00 & 1220.00 & 0.0 \\
Hydraulic Head & $5.48 \mathrm{E}-06$ & $3.01 \mathrm{E}-05$ & $5.48 \mathrm{E}-05$ & $5.48 \mathrm{E}-06$ & $5.48 \mathrm{E}-05$ & 0.0 \\
Recharge & 0.00 & 1.00 & 2.00 & 0.00 & 2.00 & 0.0 \\
Variance K & 50.00 & 375.00 & 700.00 & 50.00 & 700.00 & 0.0 \\
Correlation Scale & -95.00 & -74.00 & -53.00 & -95.00 & -53.00 & 0.0 \\
Strike & 30.00 & 60.00 & 90.00 & 30.00 & 90.00 & 0.0 \\
Dip & -8.69 & -6.69 & -4.69 & -8.69 & -4.69 & 0.0 \\
Glass Dissolution Rate & 1.57 & 1.73 & 1.88 & 1.57 & 1.88 & 0.0 \\
Retardation & & & & & & \\
\hline
\end{tabular}

\begin{tabular}{|lrrrrrr|}
\hline Gamma-Gamma Log & \multicolumn{5}{c|}{ Prior } & \multicolumn{5}{c|}{ Posterior } \\
& \multicolumn{1}{c}{ Low } & Mean & \multicolumn{1}{c|}{ High } & \multicolumn{1}{c|}{ Low } & High & Reliability \\
\cline { 2 - 7 } & -3.30 & -2.65 & -2.00 & -3.24 & -2.07 & 0.1 \\
Porosity & 1160.00 & 1190.00 & 1220.00 & 1160.00 & 1220.00 & 0.0 \\
Hydraulic Head & $5.48 \mathrm{E}-06$ & $3.01 \mathrm{E}-05$ & $5.48 \mathrm{E}-05$ & $5.48 \mathrm{E}-06$ & $5.48 \mathrm{E}-05$ & 0.0 \\
Recharge & 0.00 & 1.00 & 2.00 & 0.00 & 2.00 & 0.0 \\
Variance K & 50.00 & 375.00 & 700.00 & 50.00 & 700.00 & 0.0 \\
Correlation Scale & -95.00 & -74.00 & -53.00 & -95.00 & -53.00 & 0.0 \\
Strike & 30.00 & 60.00 & 90.00 & 30.00 & 90.00 & 0.0 \\
Dip & -8.69 & -6.69 & -4.69 & -8.69 & -4.69 & 0.0 \\
Glass Dissolution Rate & 1.57 & 1.73 & 1.88 & 1.57 & 1.88 & 0.0 \\
Retardation & & & & & & \\
\hline
\end{tabular}




\begin{tabular}{|lrrrrrr|}
\hline Analogues & \multicolumn{5}{c|}{ Prior } \\
& \multicolumn{1}{c|}{ Low } & \multicolumn{1}{c|}{ Mean } & \multicolumn{1}{c|}{ High } & \multicolumn{1}{c|}{ Low } & High & Reliability \\
\cline { 2 - 7 } & -3.30 & -2.65 & -2.00 & -3.27 & -2.03 & 0.05 \\
Porosity & 1160.00 & 1190.00 & 1220.00 & 1160.00 & 1220.00 & 0.0 \\
Hydraulic Head & $5.48 \mathrm{E}-06$ & $3.01 \mathrm{E}-05$ & $5.48 \mathrm{E}-05$ & $5.48 \mathrm{E}-06$ & $5.48 \mathrm{E}-05$ & 0.0 \\
Recharge & 0.00 & 1.00 & 2.00 & 0.00 & 2.00 & 0.0 \\
Variance K & 50.00 & 375.00 & 700.00 & 50.00 & 700.00 & 0.0 \\
Correlation Scale & -95.00 & -74.00 & -53.00 & -95.00 & -53.00 & 0.0 \\
Strike & 30.00 & 60.00 & 90.00 & 30.00 & 90.00 & 0.0 \\
Dip & -8.69 & -6.69 & -4.69 & -8.69 & -4.69 & 0.0 \\
Glass Dissolution Rate & 1.57 & 1.73 & 1.88 & 1.57 & 1.88 & 0.0 \\
Retardation & & & & & & \\
\hline
\end{tabular}

\begin{tabular}{|c|c|c|c|c|c|c|}
\hline \multicolumn{7}{|l|}{ Hydraulic Head Meas. } \\
\hline & \multirow[b]{2}{*}{ Low } & \multicolumn{2}{|l|}{ Prior } & \multicolumn{2}{|c|}{ Posterior } & \multirow[b]{2}{*}{ Reliability } \\
\hline & & Mean & High & Low & High & \\
\hline Porosity & -3.30 & -2.65 & -2.00 & -3.30 & -2.00 & 0.0 \\
\hline Hydraulic Head & 1160.00 & 1190.00 & 1220.00 & 1178.00 & 1202.00 & 0.6 \\
\hline Recharge & 5.48E-06 & 3.01E-05 & 5.48E-05 & $1.78 \mathrm{E}-05$ & $4.25 E-05$ & 0.5 \\
\hline Variance $\mathrm{K}$ & 0.00 & 1.00 & 2.00 & 0.00 & 2.00 & 0.0 \\
\hline Correlation Scale & 50.00 & 375.00 & 700.00 & 50.00 & 700.00 & 0.0 \\
\hline Strike & -95.00 & -74.00 & -53.00 & -90.80 & -57.20 & 0.2 \\
\hline Dip & 30.00 & 60.00 & 90.00 & 36.00 & 84.00 & 0.2 \\
\hline Glass Dissolution Rate & -8.69 & -6.69 & -4.69 & -8.69 & -4.69 & 0.0 \\
\hline Retardation & 1.57 & 1.73 & 1.88 & 1.57 & 1.88 & 0.0 \\
\hline
\end{tabular}

\begin{tabular}{|lrrrrrr|}
\hline Single Hole Packer & \multicolumn{3}{c|}{ Prior } & \multicolumn{5}{c|}{ Posterior } \\
& \multicolumn{1}{c}{ Low } & \multicolumn{1}{c|}{ Mean } & \multicolumn{1}{c|}{ High } & \multicolumn{1}{c|}{ Low } & High & Reliability \\
\cline { 2 - 7 } & -3.30 & -2.65 & -2.00 & -3.30 & -2.00 & 0.0 \\
Porosity & 1160.00 & 1190.00 & 1220.00 & 1160.00 & 1220.00 & 0.0 \\
Hydraulic Head & $5.48 \mathrm{E}-06$ & $3.01 \mathrm{E}-05$ & $5.48 \mathrm{E}-05$ & $1.78 \mathrm{E}-05$ & $4.25 \mathrm{E}-05$ & 0.5 \\
Recharge & 0.00 & 1.00 & 2.00 & 0.30 & 1.70 & 0.3 \\
Variance K & 50.00 & 375.00 & 700.00 & 50.00 & 700.00 & 0.0 \\
Correlation Scale & -95.00 & -74.00 & -53.00 & -90.80 & -57.20 & 0.2 \\
Strike & 30.00 & 60.00 & 90.00 & 36.00 & 84.00 & 0.2 \\
Dip & -8.69 & -6.69 & -4.69 & -8.69 & -4.69 & 0.0 \\
Glass Dissolution & 1.57 & 1.73 & 1.88 & 1.57 & 1.88 & 0.0 \\
Retardation & & & & & & \\
\hline
\end{tabular}




\begin{tabular}{|lrrrrrr|}
\hline Cross-Hole Packer & \multicolumn{3}{c|}{ Prior } & \multicolumn{4}{c|}{ Posterior } \\
& \multicolumn{1}{c}{ Low } & \multicolumn{1}{c|}{ Mean } & \multicolumn{1}{c|}{ High } & \multicolumn{1}{c|}{ Low } & High & Reliability \\
\cline { 2 - 7 } & -3.30 & -2.65 & -2.00 & -3.30 & -2.00 & 0.0 \\
Porosity & 1160.00 & 1190.00 & 1220.00 & 1160.00 & 1220.00 & 0.0 \\
Hydraulic Head & $5.48 \mathrm{E}-06$ & $3.01 \mathrm{E}-05$ & $5.48 \mathrm{E}-05$ & $1.78 \mathrm{E}-05$ & $4.25 \mathrm{E}-05$ & 0.5 \\
Recharge & 0.00 & 1.00 & 2.00 & 0.50 & 1.50 & 0.5 \\
Variance K & 50.00 & 375.00 & 700.00 & 115.00 & 635.00 & 0.2 \\
Correlation Scale & -95.00 & -74.00 & -53.00 & -86.60 & -61.40 & 0.4 \\
Strike & 30.00 & 60.00 & 90.00 & 42.00 & 78.00 & 0.4 \\
Dip & -8.69 & -6.69 & -4.69 & -8.69 & -4.69 & 0.0 \\
Glass Dissolution Rate & 1.57 & 1.73 & 1.88 & 1.57 & 1.88 & 0.0 \\
Retardation & & & & & & \\
\hline
\end{tabular}

\begin{tabular}{|lrrrrrr|}
\hline Flowmeter Testing & \multicolumn{3}{c|}{ Prior } & \multicolumn{5}{c|}{ Posterior } \\
& \multicolumn{1}{c}{ Low } & Mean & \multicolumn{1}{c|}{ High } & \multicolumn{1}{c|}{ Low } & High & Reliability \\
\cline { 2 - 7 } & -3.30 & -2.65 & -2.00 & -3.30 & -2.00 & 0.0 \\
Porosity & 1160.00 & 1190.00 & 1220.00 & 1160.00 & 1220.00 & 0.0 \\
Hydraulic Head & $5.48 \mathrm{E}-06$ & $3.01 \mathrm{E}-05$ & $5.48 \mathrm{E}-05$ & $1.04 \mathrm{E}-05$ & $4.99 \mathrm{E}-05$ & 0.2 \\
Recharge & 0.00 & 1.00 & 2.00 & 0.40 & 1.60 & 0.4 \\
Variance K & 50.00 & 375.00 & 700.00 & 50.00 & 700.00 & 0.0 \\
Correlation Scale & -95.00 & -74.00 & -53.00 & -90.80 & -57.20 & 0.2 \\
Strike & 30.00 & 60.00 & 90.00 & 36.00 & 84.00 & 0.2 \\
Dip & -8.69 & -6.69 & -4.69 & -8.69 & -4.69 & 0.0 \\
Glass Dissolution Rate & 1.57 & 1.73 & 1.88 & 1.57 & 1.88 & 0.0 \\
Retardation & & & & & & \\
\hline
\end{tabular}

\begin{tabular}{|lrrrrrr|}
\hline Temperature Profiles & \multicolumn{3}{c|}{ Prior } & \multicolumn{5}{c|}{ Posterior } \\
& \multicolumn{1}{c}{ Low } & \multicolumn{1}{c|}{ Mean } & \multicolumn{1}{c|}{ High } & \multicolumn{1}{c|}{ Low } & High & Reliability \\
\cline { 2 - 7 } Porosity & -3.30 & -2.65 & -2.00 & -3.30 & -2.00 & 0.0 \\
Hydraulic Head & 1160.00 & 1190.00 & 1220.00 & 1160.00 & 1220.00 & 0.0 \\
Recharge & $5.48 \mathrm{E}-06$ & $3.01 \mathrm{E}-05$ & $5.48 \mathrm{E}-05$ & $1.04 \mathrm{E}-05$ & $4.99 \mathrm{E}-05$ & 0.2 \\
Variance K & 0.00 & 1.00 & 2.00 & 0.00 & 2.00 & 0.0 \\
Correlation Scale & 50.00 & 375.00 & 700.00 & 50.00 & 700.00 & 0.0 \\
Strike & -95.00 & -74.00 & -53.00 & -90.80 & -57.20 & 0.2 \\
Dip & 30.00 & 60.00 & 90.00 & 36.00 & 84.00 & 0.2 \\
Glass Dissolution Rate & -8.69 & -6.69 & -4.69 & -8.69 & -4.69 & 0.0 \\
Retardation & 1.57 & 1.73 & 1.88 & 1.57 & 1.88 & 0.0 \\
\hline
\end{tabular}




\begin{tabular}{|lrrrrrr|}
\hline Tracer Techniques & \multicolumn{5}{c|}{ Prior } & \multicolumn{5}{c|}{ Posterior } \\
& \multicolumn{1}{c}{ Low } & \multicolumn{1}{c|}{ Mean } & \multicolumn{1}{c|}{ High } & \multicolumn{1}{c|}{ Low } & High & Reliability \\
\cline { 2 - 7 } & -3.30 & -2.65 & -2.00 & -3.11 & -2.20 & 0.3 \\
Porosity & 1160.00 & 1190.00 & 1220.00 & 1160.00 & 1220.00 & 0.0 \\
Hydraulic Head & $5.48 \mathrm{E}-06$ & $3.01 \mathrm{E}-05$ & $5.48 \mathrm{E}-05$ & $1.78 \mathrm{E}-05$ & $4.25 \mathrm{E}-05$ & 0.5 \\
Recharge & 0.00 & 1.00 & 2.00 & 0.50 & 1.50 & 0.5 \\
Variance K & 50.00 & 375.00 & 700.00 & 82.50 & 667.50 & 0.1 \\
Correlation Scale & -95.00 & -74.00 & -53.00 & -90.80 & -57.20 & 0.2 \\
Strike & 30.00 & 60.00 & 90.00 & 36.00 & 84.00 & 0.2 \\
Dip & -8.69 & -6.69 & -4.69 & -8.69 & -4.69 & 0.0 \\
Glass Dissolution Rate & 1.57 & 1.73 & 1.88 & 1.57 & 1.88 & 0.0 \\
Retardation & & & & & & \\
\hline
\end{tabular}

\begin{tabular}{|lrrrrrrr|}
\hline Vadose Zone Model & \multicolumn{5}{c|}{ Prior } & \multicolumn{5}{c|}{ Posterior } \\
& \multicolumn{1}{c}{ Low } & \multicolumn{1}{c|}{ Mean } & \multicolumn{1}{c|}{ High } & \multicolumn{1}{c|}{ Low } & \multicolumn{1}{c|}{ High } & Reliability \\
\cline { 2 - 7 } & -3.30 & -2.65 & -2.00 & -3.30 & -2.00 & 0.0 \\
Porosity & 1160.00 & 1190.00 & 1220.00 & 1160.00 & 1220.00 & 0.0 \\
Hydraulic Head & $5.48 \mathrm{E}-06$ & $3.01 \mathrm{E}-05$ & $5.48 \mathrm{E}-05$ & $1.29 \mathrm{E}-05$ & $4.74 \mathrm{E}-05$ & 0.3 \\
Recharge & 0.00 & 1.00 & 2.00 & 0.00 & 2.00 & 0.0 \\
Variance K & 50.00 & 375.00 & 700.00 & 50.00 & 700.00 & 0.0 \\
Correlation Scale & -95.00 & -74.00 & -53.00 & -95.00 & -53.00 & 0.0 \\
Strike & 30.00 & 60.00 & 90.00 & 30.00 & 90.00 & 0.0 \\
Dip & -8.69 & -6.69 & -4.69 & -8.69 & -4.69 & 0.0 \\
Glass Dissolution Rate & 1.57 & 1.73 & 1.88 & 1.57 & 1.88 & 0.0 \\
Retardation & & & & & & \\
\hline
\end{tabular}

\begin{tabular}{|lrrrrrr|}
\hline Energy Budget & \multicolumn{3}{c|}{ Prior } & \multicolumn{4}{c|}{ Posterior } \\
& \multicolumn{1}{c}{ Low } & \multicolumn{1}{c|}{ Mean } & \multicolumn{1}{c|}{ High } & \multicolumn{1}{c|}{ Low } & High & Reliability \\
\cline { 2 - 7 } & -3.30 & -2.65 & -2.00 & -3.30 & -2.00 & 0.0 \\
Porosity & 1160.00 & 1190.00 & 1220.00 & 1160.00 & 1220.00 & 0.0 \\
Hydraulic Head & $5.48 \mathrm{E}-06$ & $3.01 \mathrm{E}-05$ & $5.48 \mathrm{E}-05$ & $1.29 \mathrm{E}-05$ & $4.74 \mathrm{E}-05$ & 0.3 \\
Recharge & 0.00 & 1.00 & 2.00 & 0.00 & 2.00 & 0.0 \\
Variance K & 50.00 & 375.00 & 700.00 & 50.00 & 700.00 & 0.0 \\
Correlation Scale & -95.00 & -74.00 & -53.00 & -95.00 & -53.00 & 0.0 \\
Strike & 30.00 & 60.00 & 90.00 & 30.00 & 90.00 & 0.0 \\
Dip & -8.69 & -6.69 & -4.69 & -8.69 & -4.69 & 0.0 \\
Glass Dissolution Rate & 1.57 & 1.73 & 1.88 & 1.57 & 1.88 & 0.0 \\
Retardation & & & & & & \\
\hline
\end{tabular}




\begin{tabular}{|lrrrrrr|}
\hline Borehole Scanner & \multicolumn{3}{c|}{ Prior } & \multicolumn{4}{c|}{ Posterior } \\
& \multicolumn{1}{c}{ Low } & \multicolumn{1}{c|}{ Mean } & \multicolumn{1}{c|}{ High } & \multicolumn{1}{c|}{ Low } & High & Reliability \\
\cline { 2 - 7 } & -3.30 & -2.65 & -2.00 & -3.30 & -2.00 & 0.0 \\
Porosity & 1160.00 & 1190.00 & 1220.00 & 1160.00 & 1220.00 & 0.0 \\
Hydraulic Head & $5.48 \mathrm{E}-06$ & $3.01 \mathrm{E}-05$ & $5.48 \mathrm{E}-05$ & $1.04 \mathrm{E}-05$ & $4.99 \mathrm{E}-05$ & 0.2 \\
Recharge & 0.00 & 1.00 & 2.00 & 0.00 & 2.00 & 0.0 \\
Variance K & 50.00 & 375.00 & 700.00 & 147.50 & 602.50 & 0.3 \\
Correlation Scale & -95.00 & -74.00 & -53.00 & -84.50 & -63.50 & 0.5 \\
Strike & 30.00 & 60.00 & 90.00 & 45.00 & 75.00 & 0.5 \\
Dip & -8.69 & -6.69 & -4.69 & -8.69 & -4.69 & 0.0 \\
Glass Dissolution Rate & 1.57 & 1.73 & 1.88 & 1.57 & 1.88 & 0.0 \\
Retardation & & & & & & \\
\hline
\end{tabular}

\begin{tabular}{|lrrrrrr|}
\hline Mining Drift Data & \multicolumn{5}{c|}{ Prior } & \multicolumn{5}{c|}{ Posterior } \\
& \multicolumn{1}{c}{ Low } & \multicolumn{1}{c|}{ Mean } & \multicolumn{1}{c|}{ High } & \multicolumn{1}{c|}{ Low } & High & Reliability \\
\cline { 2 - 7 } & -3.30 & -2.65 & -2.00 & -3.30 & -2.00 & 0.0 \\
Porosity & 1160.00 & 1190.00 & 1220.00 & 1160.00 & 1220.00 & 0.0 \\
Hydraulic Head & $5.48 \mathrm{E}-06$ & $3.01 \mathrm{E}-05$ & $5.48 \mathrm{E}-05$ & $5.48 \mathrm{E}-06$ & $5.48 \mathrm{E}-05$ & 0.0 \\
Recharge & 0.00 & 1.00 & 2.00 & 0.00 & 2.00 & 0.0 \\
Variance K & 50.00 & 375.00 & 700.00 & 82.50 & 667.50 & 0.1 \\
Correlation Scale & -95.00 & -74.00 & -53.00 & -92.90 & -55.10 & 0.1 \\
Strike & 30.00 & 60.00 & 90.00 & 33.00 & 87.00 & 0.1 \\
Dip & -8.69 & -6.69 & -4.69 & -8.69 & -4.69 & 0.0 \\
Glass Dissolution Rate & 1.57 & 1.73 & 1.88 & 1.57 & 1.88 & 0.0 \\
Retardation & & & & & & \\
\hline
\end{tabular}

\begin{tabular}{|lrrrrrr|}
\hline Acoustic Televiewer & \multicolumn{3}{c|}{ Prior } & \multicolumn{5}{c|}{ Posterior } \\
& \multicolumn{1}{c}{ Low } & \multicolumn{1}{c|}{ Mean } & \multicolumn{1}{c|}{ High } & \multicolumn{1}{c|}{ Low } & High & Reliability \\
\cline { 2 - 7 } & -3.30 & -2.65 & -2.00 & -3.30 & -2.00 & 0.0 \\
Porosity & 1160.00 & 1190.00 & 1220.00 & 1160.00 & 1220.00 & 0.0 \\
Hydraulic Head & $5.48 \mathrm{E}-06$ & $3.01 \mathrm{E}-05$ & $5.48 \mathrm{E}-05$ & $1.04 \mathrm{E}-05$ & $4.99 \mathrm{E}-05$ & 0.2 \\
Recharge & 0.00 & 1.00 & 2.00 & 0.00 & 2.00 & 0.0 \\
Variance K & 50.00 & 375.00 & 700.00 & 50.00 & 700.00 & 0.0 \\
Correlation Scale & -95.00 & -74.00 & -53.00 & -90.80 & -57.20 & 0.2 \\
Strike & 30.00 & 60.00 & 90.00 & 36.00 & 84.00 & 0.2 \\
Dip & -8.69 & -6.69 & -4.69 & -8.69 & -4.69 & 0.0 \\
Glass Dissolution Rate & 1.57 & 1.73 & 1.88 & 1.57 & 1.88 & 0.0 \\
Retardation & & & & & & \\
\hline
\end{tabular}




\begin{tabular}{|lrrrrrr|}
\hline Oriented Video & \multicolumn{3}{c|}{ Prior } & \multicolumn{5}{c|}{ Posterior } \\
& \multicolumn{1}{c}{ Low } & \multicolumn{1}{c|}{ Mean } & \multicolumn{1}{c|}{ High } & \multicolumn{1}{c|}{ Low } & High & Reliability \\
\cline { 2 - 8 } & -3.30 & -2.65 & -2.00 & -3.30 & -2.00 & 0.0 \\
Porosity & 1160.00 & 1190.00 & 1220.00 & 1160.00 & 1220.00 & 0.0 \\
Hydraulic Head & $5.48 \mathrm{E}-06$ & $3.01 \mathrm{E}-05$ & $5.48 \mathrm{E}-05$ & $1.04 \mathrm{E}-05$ & $4.99 \mathrm{E}-05$ & 0.2 \\
Recharge & 0.00 & 1.00 & 2.00 & 0.00 & 2.00 & 0.0 \\
Variance K & 50.00 & 375.00 & 700.00 & 50.00 & 700.00 & 0.0 \\
Correlation Scale & -95.00 & -74.00 & -53.00 & -90.80 & -57.20 & 0.2 \\
Strike & 30.00 & 60.00 & 90.00 & 36.00 & 84.00 & 0.2 \\
Dip & -8.69 & -6.69 & -4.69 & -8.69 & -4.69 & 0.0 \\
Glass Dissolution & 1.57 & 1.73 & 1.88 & 1.57 & 1.88 & 0.0 \\
Retardation & & & & & & \\
\hline
\end{tabular}

\begin{tabular}{|lrrrrrr|}
\hline Cavity Drillback & \multicolumn{5}{c|}{ Prior } & \multicolumn{5}{c|}{ Posterior } \\
& \multicolumn{1}{c}{ Low } & \multicolumn{1}{c|}{ Mean } & \multicolumn{1}{c|}{ High } & \multicolumn{1}{c|}{ Low } & High & Reliability \\
\cline { 2 - 8 } & -3.30 & -2.65 & -2.00 & -3.30 & -2.00 & 0.0 \\
Porosity & 1160.00 & 1190.00 & 1220.00 & 1160.00 & 1220.00 & 0.0 \\
Hydraulic Head & $5.48 \mathrm{E}-06$ & $3.01 \mathrm{E}-05$ & $5.48 \mathrm{E}-05$ & $1.04 \mathrm{E}-05$ & $4.99 \mathrm{E}-05$ & 0.2 \\
Recharge & 0.00 & 1.00 & 2.00 & 0.00 & 2.00 & 0.0 \\
Variance K & 50.00 & 375.00 & 700.00 & 50.00 & 700.00 & 0.0 \\
Correlation Scale & -95.00 & -74.00 & -53.00 & -90.80 & -57.20 & 0.2 \\
Strike & 30.00 & 60.00 & 90.00 & 36.00 & 84.00 & 0.2 \\
Dip & -8.69 & -6.69 & -4.69 & -8.09 & -5.29 & 0.3 \\
Glass Dissolution Rate & 1.57 & 1.73 & 1.88 & 1.57 & 1.88 & 0.0 \\
Retardation & & & & & & \\
\hline
\end{tabular}

\begin{tabular}{|c|c|c|c|c|c|c|}
\hline \multicolumn{7}{|l|}{ Retardation Exp. } \\
\hline & Low & Mean & High & Low & High & Reliability \\
\hline Porosity & -3.30 & -2.65 & -2.00 & -3.30 & -2.00 & 0.0 \\
\hline Hydraulic Head & 1160.00 & 1190.00 & 1220.00 & 1160.00 & 1220.00 & 0.0 \\
\hline Recharge & 5.48E-06 & 3.01E-05 & 5.48E-05 & 5.48E-06 & 5.48E-05 & 0.0 \\
\hline Variance $\mathrm{K}$ & 0.00 & 1.00 & 2.00 & 0.00 & 2.00 & 0.0 \\
\hline Correlation Scale & 50.00 & 375.00 & 700.00 & 50.00 & 700.00 & 0.0 \\
\hline Strike & -95.00 & -74.00 & -53.00 & -95.00 & -53.00 & 0.0 \\
\hline Dip & 30.00 & 60.00 & 90.00 & 30.00 & 90.00 & 0.0 \\
\hline Glass Dissolution Rate & -8.69 & -6.69 & -4.69 & -8.69 & -4.69 & 0.0 \\
\hline Retardation & 1.57 & 1.73 & 1.88 & 1.65 & 1.80 & 0.5 \\
\hline
\end{tabular}




\section{APPENDIX D \\ DEVELOPMENT OF THE SECOND ORDER - FIRST AND SECOND MOMENT APPROXIMATION}

\section{First Moment Approximation}

If we define a multivariate function as $\mathrm{f}(\mathbf{x})$, where $\mathbf{x}$ is a vector of parameters with $\mathbf{x} \sim(\mu, \Sigma)$, where

$\mu$ is the mean and $\Sigma$ is the covariance matrix, then we can define a Taylor series expansion of $\mathrm{f}$ about $\left[\mathbf{x}_{0}\right]$ as:

$$
\mathrm{f}(\mathrm{x})=\mathrm{f}\left(\mathrm{x}_{0}\right)+\left\langle\left.\frac{\partial \mathrm{f}}{\partial \mathrm{x}}\right|_{\mathrm{x}_{0}}\right\rangle\left(\mathrm{x}-\mathrm{x}_{\mathrm{o}}\right)+\frac{1}{2}\left\langle\mathrm{x}-\mathrm{x}_{0}\right\rangle\left[\left.\frac{\partial^{2} \mathrm{t}}{\partial \mathrm{x}^{\mathrm{T}} \partial \mathrm{x}}\right|_{\mathrm{x}_{0}}\right]\left[\mathrm{x}-\mathrm{x}_{0}\right]+\cdots
$$

Truncating the series at the second derivative (third term) and letting $\mathbf{x}_{\mathrm{O}}=\mu$ yields:

$$
\mathrm{f}(\mathrm{x}) \approx \mathrm{f}(\mu)+\left\langle\left.\frac{\partial \mathrm{f}}{\partial \mathrm{x}}\right|_{\mu}\right\rangle(\mathrm{x}-\mu)+\frac{1}{2}<\mathrm{x}-\mu>\left[\left.\frac{\partial^{2} \mathrm{t}}{\partial \mathrm{x}^{\mathrm{T}} \partial \mathrm{x}}\right|_{\mu}\right][\mathrm{x}-\mu]
$$

Then taking the expected value of the expression results in

$$
\mathrm{E}[\mathrm{f}(\mathrm{x})] \approx \mathrm{E}\left[\mathrm{f}(\mu)+\left\langle\left.\frac{\partial \mathrm{f}}{\partial \mathrm{x}}\right|_{\mu}\right\rangle(\mathrm{x}-\mu)+\frac{1}{2}<\mathrm{x}-\mu>\left[\left.\frac{\partial^{2} \mathrm{f}}{\partial \mathrm{x}^{\mathrm{T}} \partial \mathrm{x}}\right|_{\mu}\right][\mathrm{x}-\mu]\right]
$$

Because $\mathrm{E}(\mathrm{a}+\mathrm{b})=\mathrm{E}(\mathrm{a})+\mathrm{E}(\mathrm{b})$, and $\mathrm{M}_{\mathrm{F}}$ can be assumed equal to $\mathrm{E}[\mathrm{F}(\mathrm{x})]$, we compute Eq. 11 as:

$$
\mu_{\mathrm{f}} \approx \mathrm{E}[\mathrm{f}(\mu)]+\mathrm{E}\left[\left\langle\left.\frac{\partial \mathrm{f}}{\partial \mathrm{x}}\right|_{\mu}\right\rangle(\mathrm{x}-\mu)\right]+\mathrm{E}\left[\frac{1}{2}<\mathrm{x}-\mu>\left[\left.\frac{\partial^{2} \mathrm{f}}{\partial \mathrm{x}^{\mathrm{T}} \partial \mathrm{x}}\right|_{\mu}\right][\mathrm{x}-\mu]\right]
$$

Note that:

$$
\mathrm{E}[\mathrm{f}(\mu)]=\mathrm{f}(\mu)
$$

and

$$
\mathrm{E}\left[\left\langle\left.\frac{\partial \mathrm{f}}{\partial \mathrm{x}}\right|_{\mu}\right\rangle(\mathrm{x}-\mu)\right]=0
$$

Knowing that $\Sigma=\mathrm{E}[\langle\mathrm{x}-\mu\rangle[\mathrm{x}-\mu]]$, we can rewrite Eq. 4 as:

$$
\mu_{\mathrm{f}}=\mathrm{f}(\mu)+\frac{1}{2} \operatorname{Tr}\left(\left[\left.\frac{\partial^{2} \mathrm{f}}{\partial \mathrm{x}^{\mathrm{T}} \partial \mathrm{x}}\right|_{\mu}\right]\left[\sum\right]\right)
$$

\section{Second Moment Approximation:}

The variance of $f(x)$ can be expressed as: 


$$
\sigma_{\mathrm{f}}^{2}=\mathbf{E}\left[\left(\mathrm{f}(\mathrm{x})-\mu_{\mathrm{f}}\right)^{2}\right]=\mathbf{E}\left[(\mathrm{f}(\mathrm{x}))^{2}\right]-\mu_{\mathrm{f}}^{2}
$$

Note that:

$$
\mathrm{E}\left[\mathrm{f}(\mathrm{x})^{2}\right] \approx \mathrm{E}\left[\left(\mathrm{f}(\mu)+\left\langle\left.\frac{\partial \mathrm{f}}{\partial \mathrm{x}}\right|_{\mu}\right\rangle(\mathrm{x}-\mu)+\frac{1}{2}<\mathrm{x}-\mu>\left[\left.\frac{\partial^{2} \mathrm{f}}{\partial \mathrm{x}^{\mathrm{T}} \partial \mathrm{x}}\right|_{\mu}\right][\mathrm{x}-\mu]\right)^{2}\right]
$$

Expanding we have:

$$
\mathrm{E}\left[\mathrm{f}(\mathrm{x})^{2}\right]=\left[\begin{array}{l}
\mathrm{f}(\mu)^{2}+\left\langle\left.\frac{\partial \mathrm{f}}{\partial \mathrm{x}}\right|_{\mu}\right\rangle(\mathrm{x}-\mu)\left\langle\left.\frac{\partial \mathrm{f}}{\partial \mathrm{x}}\right|_{\mu}\right\rangle(\mathrm{x}-\mu)+ \\
\frac{1}{4}<\mathrm{x}-\mu>\left[\left.\frac{\partial^{2} \mathrm{f}}{\partial \mathrm{x}^{\mathrm{T}} \partial \mathrm{x}}\right|_{\mu}\right][\mathrm{x}-\mu]<\mathrm{x}-\mu>\left[\left.\frac{\partial^{2} \mathrm{f}}{\partial \mathrm{x}^{\mathrm{T}} \partial \mathrm{x}}\right|_{\mu}\right][\mathrm{x}-\mu]+ \\
2 \mathrm{f}(\mu)\left\langle\left.\frac{\partial \mathrm{f}}{\partial \mathrm{x}}\right|_{\mu}\right\rangle(\mathrm{x}-\mu)+ \\
\mathrm{f}(\mu)<\mathrm{x}-\mu>\left[\left.\frac{\partial^{2} \mathrm{f}}{\partial \mathrm{x}^{\mathrm{T}} \partial \mathrm{x}}\right|_{\mu}\right][\mathrm{x}-\mathrm{u}]+ \\
\left\langle\left.\frac{\partial \mathrm{f}}{\partial \mathrm{x}}\right|_{\mu}\right\rangle(\mathrm{x}-\mu)<\mathrm{x}-\mu>\left[\left.\frac{\partial^{2} \mathrm{f}}{\partial \mathrm{x}^{\mathrm{T}} \partial \mathrm{x}}\right|_{\mu}\right]_{[\mathrm{x}-\mu]}
\end{array}\right]
$$

Also:

$$
E\left[f(\mu)^{2}\right]=f(\mu)^{2}
$$

If the skew and cross-skew are considered zero, then the remaining terms in Eq. 10 are:

$$
\begin{gathered}
E\left[\left\langle\left.\frac{\partial f}{\partial x}\right|_{\mu}\right\rangle(\mathrm{x}-\mu)\left\langle\left.\frac{\partial \mathrm{f}}{\partial \mathrm{x}}\right|_{\mu}\right\rangle(\mathrm{x}-\mu)\right]=\left\langle\left.\frac{\partial \mathrm{f}}{\partial \mathrm{x}}\right|_{\mu}\right\rangle\left(\sum\right)\left(\left.\frac{\partial \mathrm{f}}{\partial \mathrm{x}}\right|_{\mu}\right) \\
\mathrm{E}\left[\frac{1}{4}<\mathrm{x}-\mu>\left[\left.\frac{\partial^{2} \mathrm{f}}{\partial \mathrm{x}^{\mathrm{T}} \partial \mathrm{x}}\right|_{\mu}\right][\mathrm{x}-\mu]<\mathrm{x}-\mu>\left[\left.\frac{\partial^{2} \mathrm{f}}{\partial \mathrm{x}^{\mathrm{T}} \partial \mathrm{x}}\right|_{\mu}\right][\mathrm{x}-\mu]\right]= \\
\frac{1}{4}\left[2 \operatorname{Tr}\left\{\left[\left.\frac{\partial^{2} \mathrm{f}}{\partial \mathrm{x}^{\mathrm{T}} \partial \mathrm{x}}\right|_{\mu}\right]\left(\sum\right)\left[\left.\frac{\partial^{2} \mathrm{f}}{\partial \mathrm{x}^{\mathrm{T}} \partial \mathrm{x}}\right|_{\mu}\right]\left(\sum\right)\right\}+\operatorname{TR}\left\{\left[\left.\frac{\partial^{2} \mathrm{~F}}{\partial \mathrm{x}^{\mathrm{T}} \partial \mathrm{x}}\right|_{\mu}\right]\left(\sum\right)\right] \cdot \operatorname{TR}\left(\left[\left.\frac{\partial^{2} \mathrm{~F}}{\partial \mathrm{x}^{\mathrm{T}} \partial \mathrm{x}}\right|_{\mu}\right]\left(\sum\right)\right)\right\} \\
\mathrm{E}\left[2 \mathrm{f}(\mu)\left\langle\left.\frac{\partial \mathrm{f}}{\partial \mathrm{x}}\right|_{\mu}\right\rangle(\mathrm{x}-\mu)\right]=0 \\
{\left[\mathrm{f}(\mu)<\mathrm{x}-\mu>\left[\left.\frac{\partial^{2} \mathrm{f}}{\partial \mathrm{x}^{\mathrm{T}} \partial \mathrm{x}}\right|_{\mu}\right]_{[\mathrm{x}-\mu]}-\mathrm{f}(\mu) \operatorname{Tr}\left[\left(\left.\frac{\partial^{2} \mathrm{f}}{\partial \mathrm{x}^{\mathrm{T}} \partial \mathrm{x}}\right|_{\mu}\right)\left(\sum\right)\right]\right.}
\end{gathered}
$$




$$
\mathrm{E}\left[\left\langle\left.\frac{\partial \mathrm{f}}{\partial \mathrm{x}}\right|_{\mu}\right\rangle(\mathrm{x}-\mu)<\mathrm{x}-\mu>\left[\left.\frac{\partial^{2} \mathrm{f}}{\partial \mathrm{x}^{\mathrm{T}} \partial \mathrm{x}}\right|_{\mu}\right][\mathrm{x}-\mu]\right]=0
$$

The practical implications of these assumptions are that the $\mathbf{x}$ distributions are symmetric about the mean, and the variance of each variable is not dependent on the mean of the other variables.

From the first moment approximation we know that:

$$
\mu_{\mathrm{f}}^{2}=\left[\mathrm{f}(\mu)+\frac{1}{2} \operatorname{Tr}\left(\left[\left.\frac{\partial^{2} \mathrm{f}}{\partial \mathrm{x}^{\mathrm{T}} \partial \mathrm{x}}\right|_{\mu}\right][\Sigma]\right)\right]^{2}
$$

Expanding Eq. 25 we obtain:

$$
\mu_{\mathrm{f}}^{2}=\mathrm{f}(\mu)^{2}+\mathrm{f}(\mu) \operatorname{Tr}\left(\left[\left.\frac{\partial^{2} \mathrm{f}}{\partial \mathrm{x}^{\mathrm{T}} \partial \mathrm{x}}\right|_{\mu}\right]\left[\sum\right]\right)+\frac{1}{4}\left(\operatorname{Tr}\left(\left[\left.\frac{\partial^{2} \mathrm{f}}{\partial \mathrm{x}^{\mathrm{T}} \partial \mathrm{x}}\right|_{\mu}\right]\left[\sum\right]\right)\right)
$$

Combining Eq. 16 with Eq. 18 and Eq. 26 using the simplifications introduced in Equations 11-16, we obtain:

$$
\begin{aligned}
\sigma_{\mathrm{f}}^{2} & =\mathbf{E}\left[\mathrm{f}(\mathrm{x})^{2}\right]-\mu_{\mathrm{f}}^{2}=\mathrm{f}(\mu)^{2}-\mathrm{f}(\mu)^{2}+\left\langle\left.\frac{\partial \mathrm{f}}{\partial \mathrm{x}}\right|_{\mu}\right\rangle\left(\sum\right)\left(\left.\frac{\partial \mathrm{f}}{\partial \mathrm{x}}\right|_{\mu}\right) \\
& +\frac{1}{2} \operatorname{Tr}\left\{\left[\left.\frac{\partial^{2} \mathrm{f}}{\partial \mathrm{x}^{\mathrm{T}} \partial \mathrm{x}}\right|_{\mu}\right]\left(\sum\right)\left[\left.\frac{\partial^{2} \mathrm{f}}{\partial \mathrm{x}^{\mathrm{T}} \partial \mathrm{x}}\right|_{\mu}\right]\left(\sum\right)\right\}+\frac{1}{4} \operatorname{Tr}\left\{\left[\left.\frac{\partial^{2} \mathrm{~F}}{\partial \mathrm{x}^{\mathrm{T}} \partial \mathrm{x}}\right|_{\mu}\right]\left(\sum\right) \cdot \operatorname{Tr}\left(\left[\left.\frac{\partial^{2} \mathrm{~F}}{\partial \mathrm{x}^{\mathrm{T}} \partial \mathrm{x}}\right|_{\mu}\right]\left(\sum\right)\right)\right\} \\
& -\frac{1}{4}\left(\operatorname{Tr}\left\{\left[\left.\frac{\partial^{2} \mathrm{f}}{\partial \mathrm{x}^{\mathrm{T}} \partial \mathrm{x}}\right|_{\mu}\right]\left(\sum\right)\right\}\right)^{2} \\
& +0+\mathrm{f}(\mu) \operatorname{Tr}\left\{\left[\left.\frac{\partial^{2} \mathrm{f}}{\partial \mathrm{x}^{\mathrm{T}} \partial \mathrm{x}}\right|_{\mu}\right]\left(\sum\right)\right\}-\mathrm{f}(\mu) \operatorname{Tr}\left\{\left[\left.\frac{\partial^{2} \mathrm{f}}{\partial \mathrm{x}^{\mathrm{T}} \partial \mathrm{x}}\right|_{\mu}\right]\left(\sum\right)\right\}+0
\end{aligned}
$$

Simplifying the terms in Eq. 15 we have:

$$
\begin{aligned}
\sigma_{\mathrm{f}}^{2} & =+\left\langle\left.\frac{\partial \mathrm{f}}{\partial \mathrm{x}}\right|_{\mu}\right\rangle\left(\sum\right)\left(\left.\frac{\partial \mathrm{f}}{\partial \mathrm{x}}\right|_{\mu}\right)+\frac{1}{2} \operatorname{Tr}\left\{\left[\left.\frac{\partial^{2} \mathrm{f}}{\partial \mathrm{x}^{\mathrm{T}} \partial \mathrm{x}}\right|_{\mu}\right]\left(\sum\right)\left[\left.\frac{\partial^{2} \mathrm{f}}{\partial \mathrm{x}^{\mathrm{T}} \partial \mathrm{x}}\right|_{\mu}\right]\left(\sum\right)\right\} \\
& +\frac{1}{4} \operatorname{Tr}\left\{\left[\left.\frac{\partial^{2} \mathrm{~F}}{\partial \mathrm{x}^{\mathrm{T}} \partial \mathrm{x}}\right|_{\mu}\right]\left(\sum\right) \cdot \operatorname{Tr}\left(\left[\left.\frac{\partial^{2} \mathrm{~F}}{\partial \mathrm{x}^{\mathrm{T}} \partial \mathrm{x}}\right|_{\mu}\right]\left(\sum\right)\right)\right\} \\
& -\frac{1}{4}\left(\operatorname{Tr}\left[\frac{\partial^{2} \mathrm{f}}{\partial \mathrm{x}^{\mathrm{T}} \partial \mathrm{x}}\right]\left(\sum\right)\right)^{2}
\end{aligned}
$$




\section{APPENDIX E}

\section{DETAILED COST ESTIMATES FOR FIELD ACTIVITIES}

E-1 


\section{IT COST ESTIMATE}

\section{Estimated Costs for Barometric Testing Program}

Preparation of Road and Pads

$\$ 2,000$

Drill Twenty-four 100-foot Boreholes

$\$ 157,840$

IT Oversight of Drilling (Assume 10 Days)

$\$ 26,500$

Drilling Subtotal

$\$ 186,340$

Compressor Rental (Assume 2 Days)

$\$ 3,000$

IT Oversight of Testing (Assume 2 Days)

Test Startup Subtotal

Grand Total for Drilling and Test Startup
$\$ 8,300$

$\$ 194,640$ 


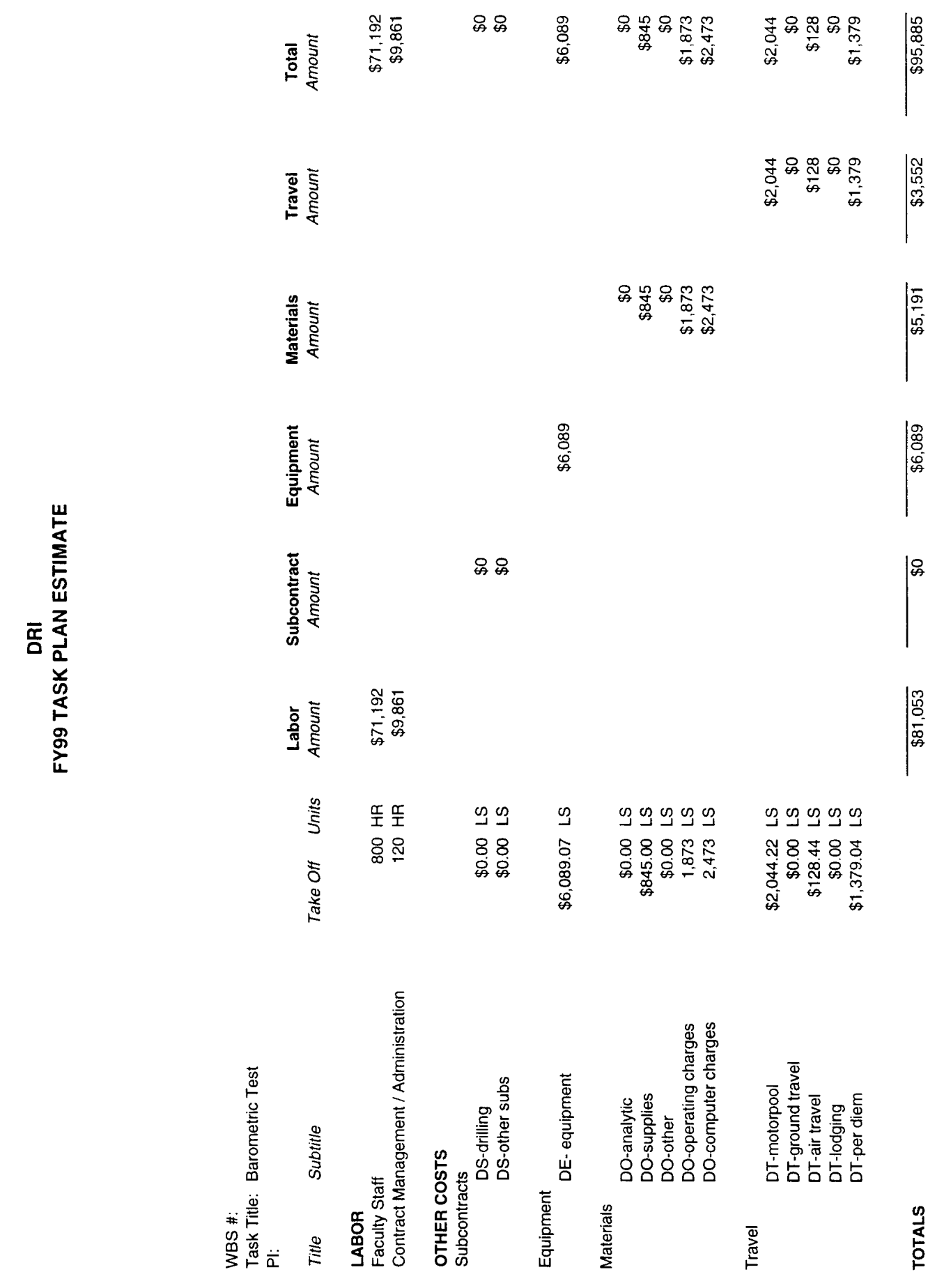

E-3 


\section{IT COST ESTIMATE}

Estimated Costs for Hydraulic Head Measurement Program

Preparation of EA for Well on BLM Land $\quad \$ 10,000$

Preparation of Road and One Pad $\quad \$ 3,000$

Drill One 1,500-foot Well $\quad \$ 178,730$

Standard Suite Borehole Geophysics - 1,500-foot Well $\quad \$ 18,590$

IT Oversight of Drilling and Geophysical Logging (Assume 3 Days) $\quad \$ 7,950$

Subtotal $\$ 218,270$

1,500-foot Well Construction (No Filter Pack or Seals) $\quad \$ 25,088$

Development of Two Wells $\quad \$ 13,500$

IT Oversight of Well Construction and Development (Assume 3 Days) $\quad \$ 7,950$

$\begin{array}{ll}\text { Well Construction and Development Subtotal } & \$ 46,538\end{array}$

Grand Total for Drilling, Testing, Well Construction and Development $\quad \$ 264,808$ 


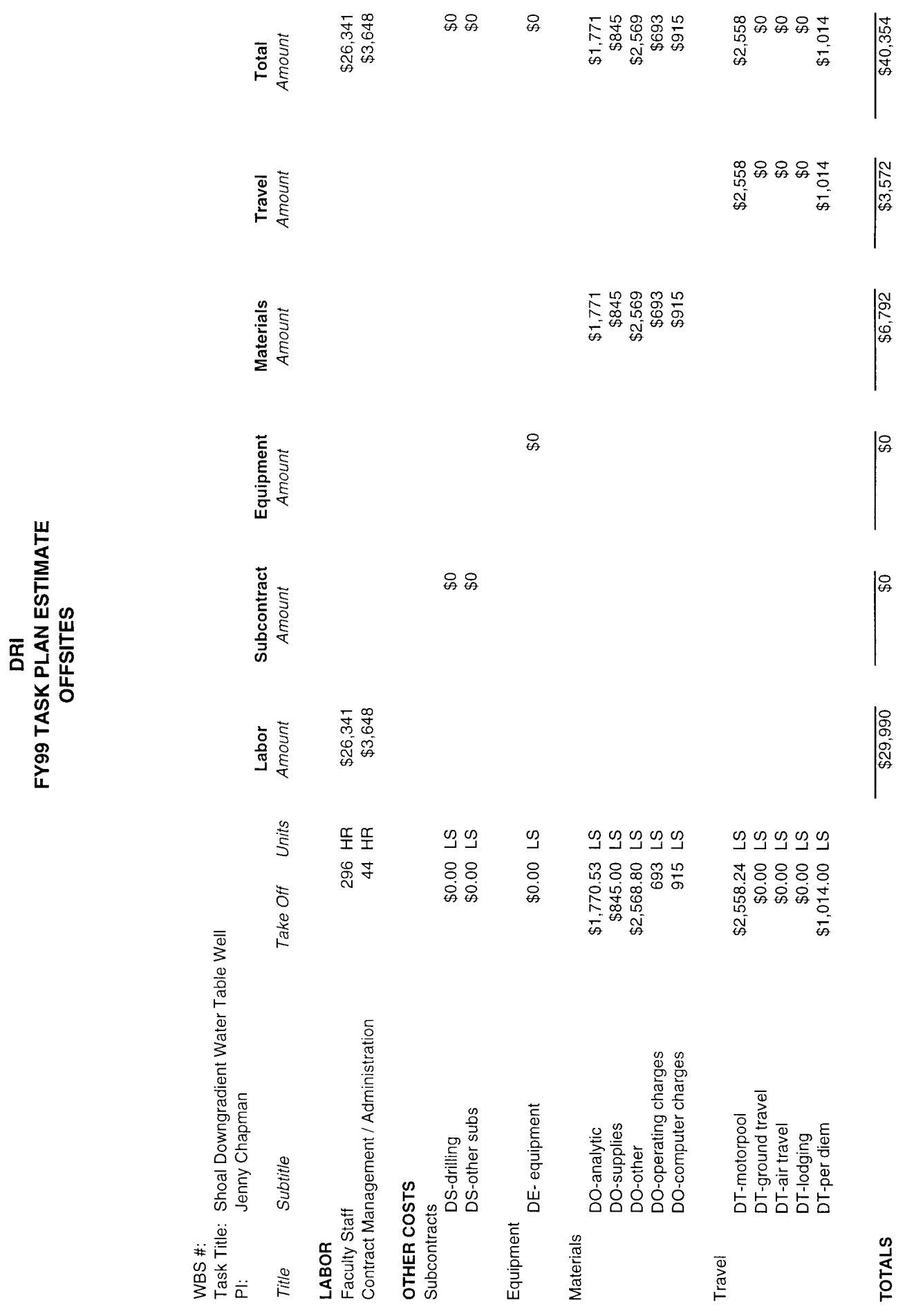

E-5 


\section{IT COST ESTIMATE}

\section{Estimated Costs for Cross-Hole Packer Testing Program}

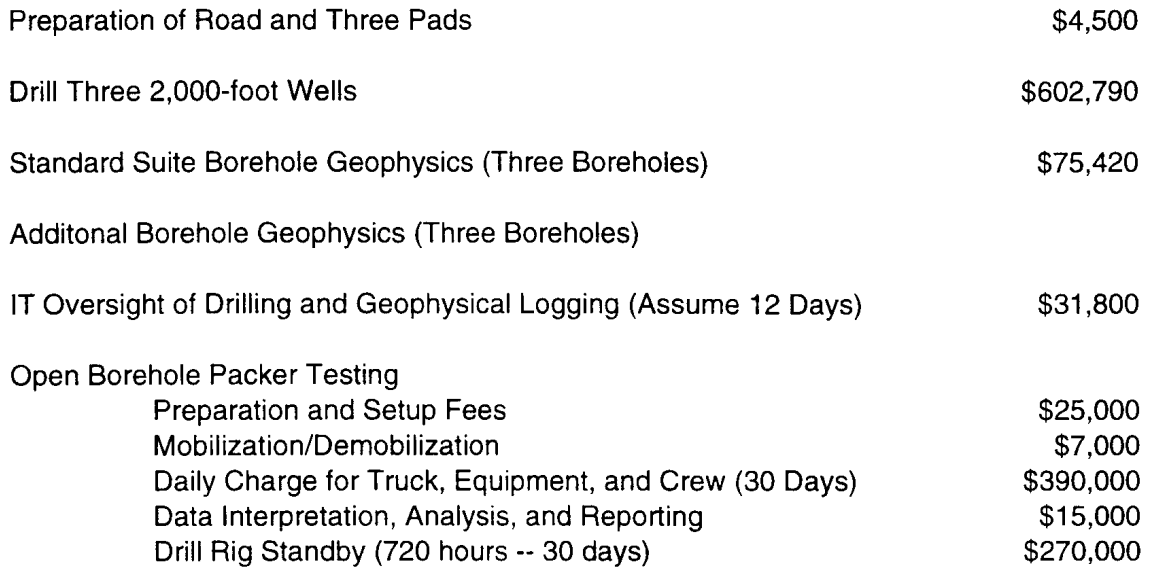

Grand Total for Drilling, Testing, Well Construction, and Development $\$ 1,773,310$

Alternate Open Borehole Packer Testing

Subtotal

Alternate Well Construction (Three Wells)

External Casing Packers $\quad \$ 705,000$

Minus Cost of Filter Pack and Grout Seals $\$ 14,100$

Subtotal $\$ 690,900$

Port Collars

$\$ 195,000$

Minus Cost of Perforated vs. Blank Casing

$\$ 14,400$

Subtotal $\$ 180,600$ 


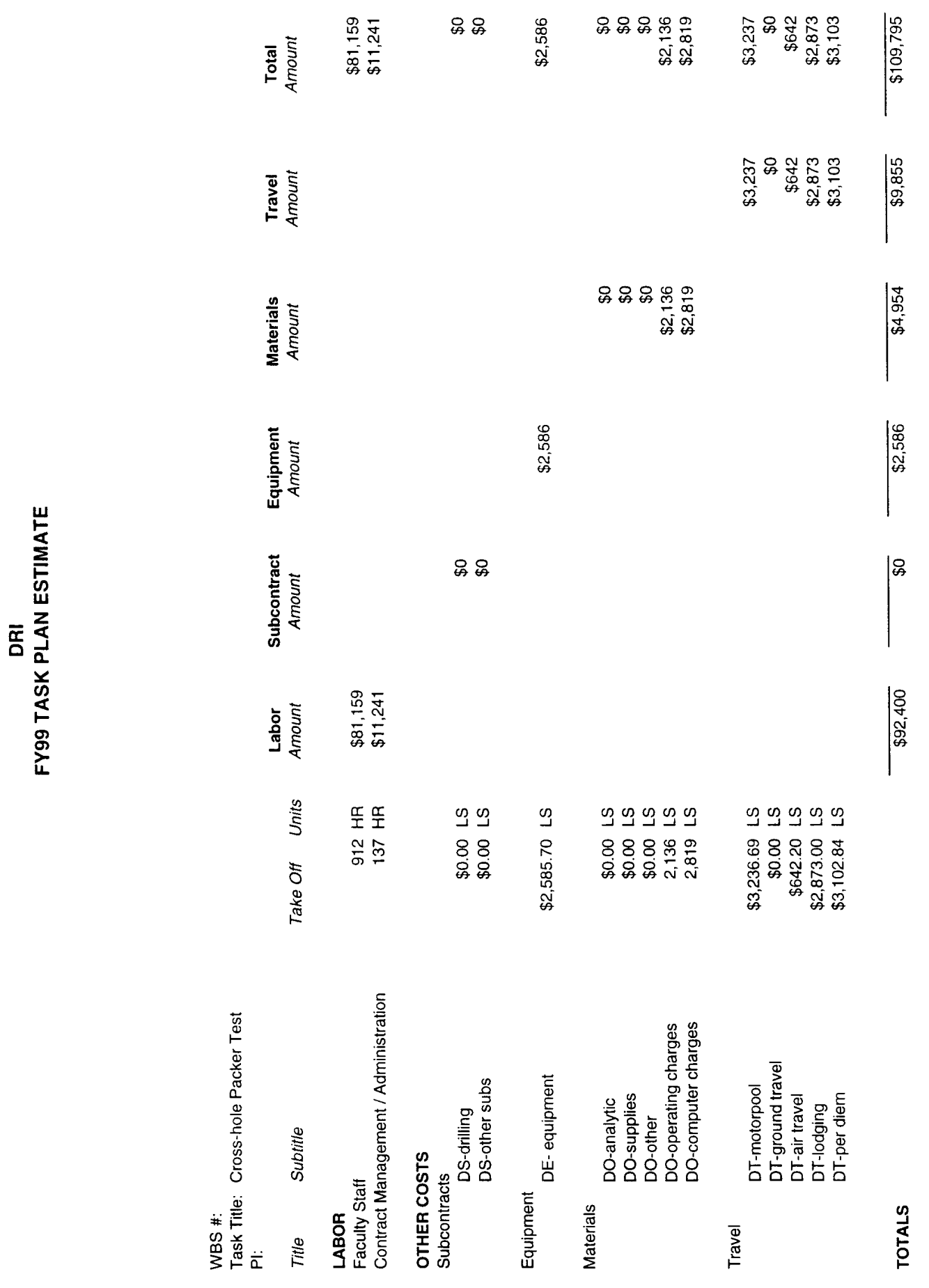




\section{IT COST ESTIMATE}

\section{Estimated Costs for Environmental Tracer Techniques Program (5-Inch Well)}

Estimated Costs for Environmental Tracer Techniques Program

$\begin{array}{lr}\text { Road and Pad Preparation } & \$ 1,500\end{array}$

$\begin{array}{ll}\text { Mob/Demob Drill Rig and Support Equipment } & \$ 50,000\end{array}$

$\begin{array}{ll}\text { Drill 4,000-foot, 12-inch Borehole } & \$ 445,808\end{array}$

$\begin{array}{ll}\text { Standard Suite Borehole Geophysics } & \$ 44,590\end{array}$

Additional Borehole Geophysics (Combinable Magnetic Resonance) $\quad \$ 14,000$

IT Oversight of Drilling and Geophysical Logging (Assume 28 Days) $\$ \$ 74,200$

Drilling Subtotal

$\$ 630,098$

Construction of 5-inch Well (Filter Pack and Seals Emplaced via Tremie)

$\$ 168,150$

Development of Well

$\$ 36,000$

IT Oversight of Well Construction and Development (Assume 8 Days)

$\$ 21,200$

Well Construction and Development Subtotal

$\$ 225,350$

Total Well Costs

$\$ 855,448$

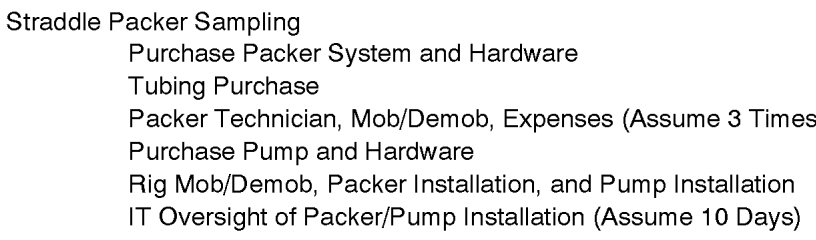

Grand Total for Drilling, Well Construction and Development, and Sampling $\$ 1,082,948$ 


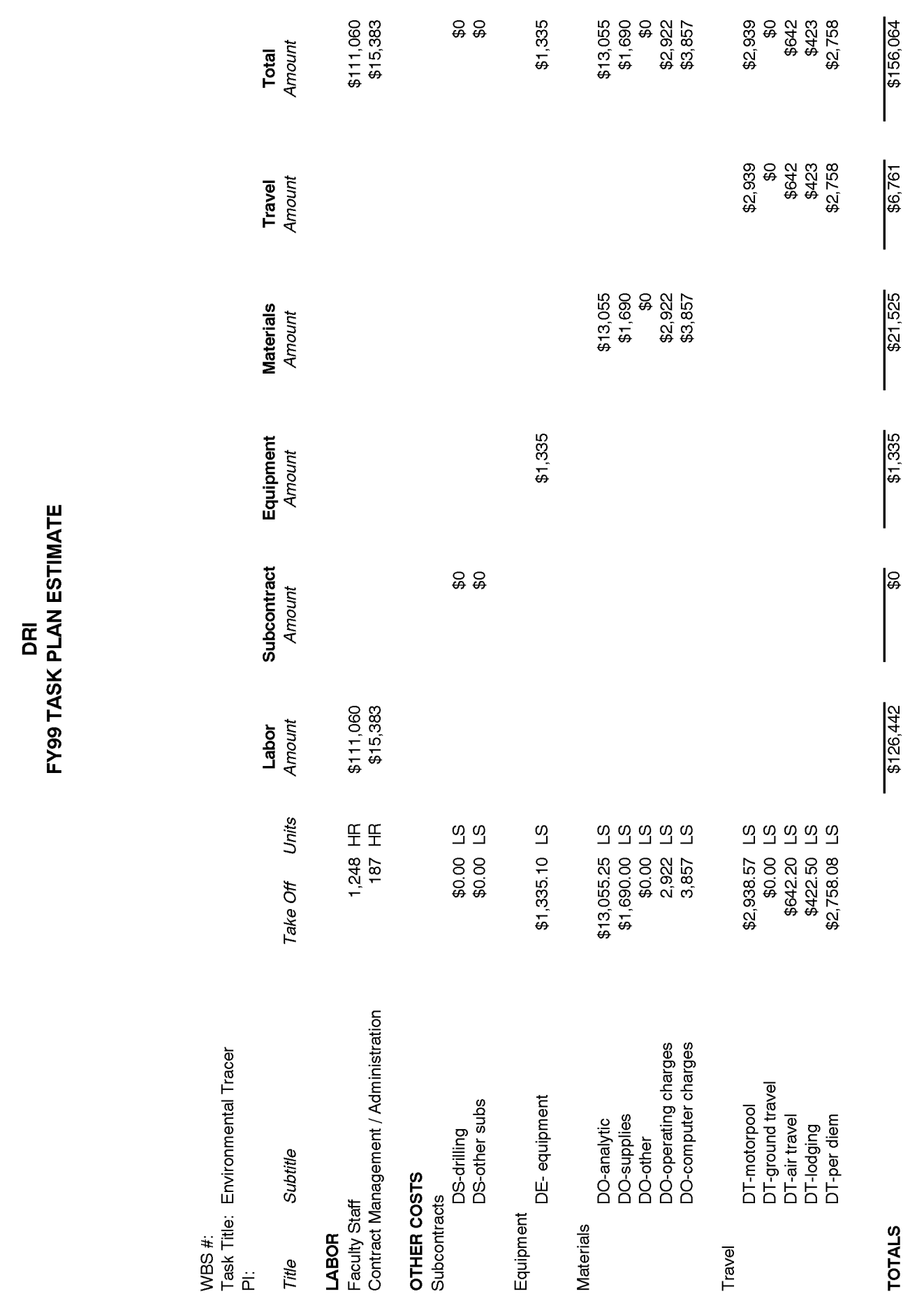




\section{IT COST ESTIMATE}

\section{Estimated Costs for Natural-Gradient Tracer Testing Program}

Preparation of Road and Two Pads

$\$ 3,000$

Drill Two 1,500-foot Wells

$\$ 357,460$

Standard Suite Borehole Geophysics (Two Boreholes)

$\$ 37,180$

Additional Borehole Geophysics (3 Hole Cross-Hole Tomography)

IT Oversight of Drilling and Geophysical Logging (Assume 6 Days)

$\$ 15,900$

Drilling Subtotal

$\$ 413,540$

Construction of Two Wells (No Filter Pack or Seals Emplaced)

$\$ 50,175$

Development of Two Wells

$\$ 18,000$

IT Oversight of Well Construction and Development (Assume 5 Days)

$\$ 13,250$

Well Construction and Development Subtotal

$\$ 81,425$

Grand Total for Drilling, Well Construction, and Development

$\$ 494,965$

E-10 


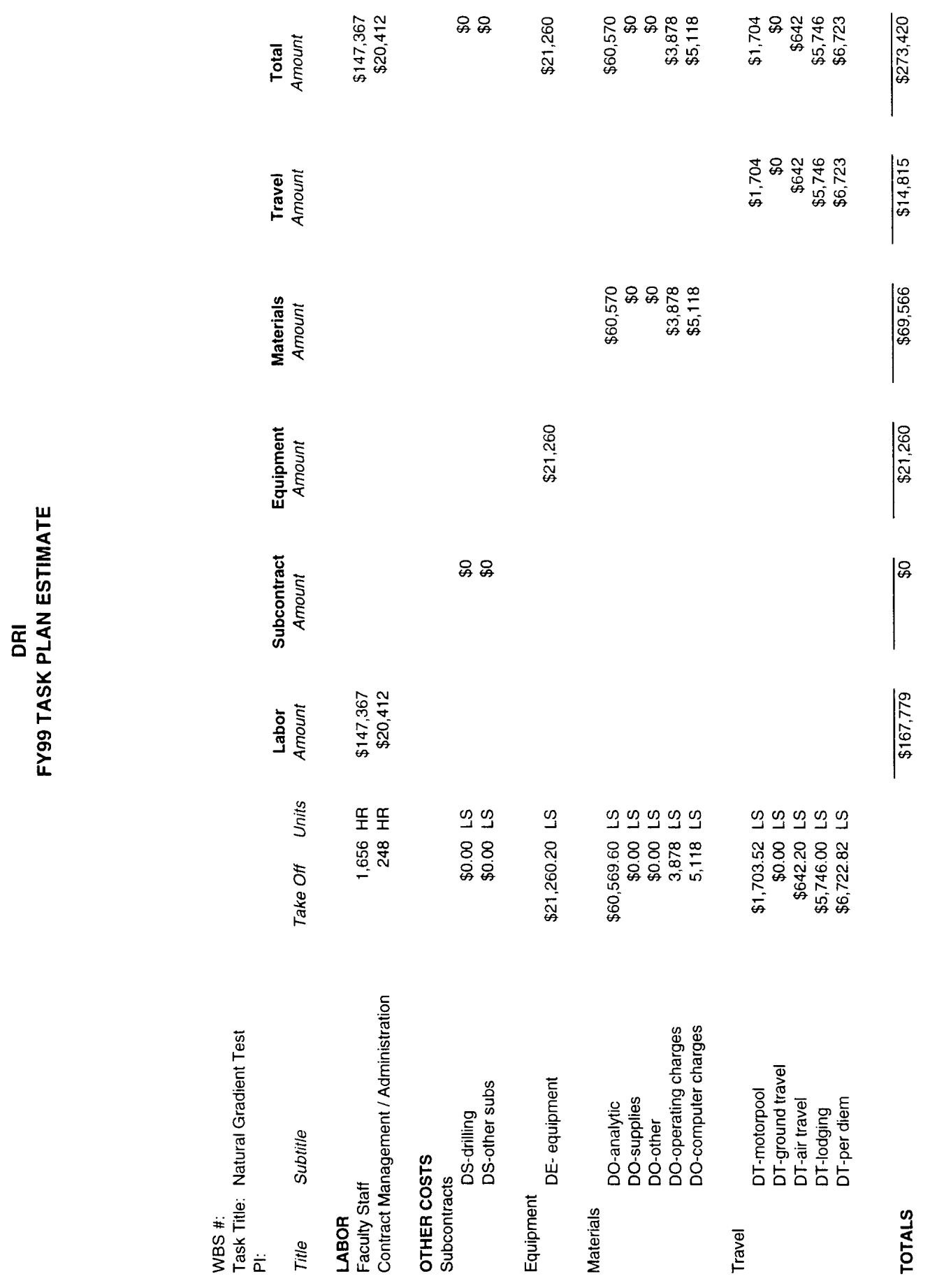

E-11 


\section{IT COST ESTIMATE}

\section{Estimated Costs for Single-Hole Packer Testing Program}

Road and Pad Preparation

Open Borehole Packer Testing Preparation and Setup Fees

Mobilization/Demobilization

$\$ 7,000$

Daily Charge for Truck, Equipment, and Crew (6 Days)

$\$ 78,000$

Data Interpretation, Analysis, and Reporting

$\$ 15,000$

Drill Rig Standby (144 Hours)

$\$ 54,000$

IT Oversight of Testing (Assume 6 Days)

$\$ 15,900$

\section{Drilling and Testing Subtotal}

Construction of One Well (Filter Pack and Seals Emplaced via Tremie)

$\$ 45,500$

Development of One Well

$\$ 18,000$

IT Oversight of Well Construction and Development (Assume 3 Days)

$\$ 7,950$

Well Construction and Development Subtotal

Grand Total for Drilling, Testing, Well Construction, and Development

Alternate Open Borehole Packer Testing

Subtotal

Alternate Well Construction

External Casing Packers

Minus Cost of Filter Pack and Grout Seals

$\$ 235,000$

$\$ 4,700$

Subtotal $\$ 230,300$

Port Collars

$\$ 65,000$

$\$ 4,800$

Subtotal $\$ 60,200$ 


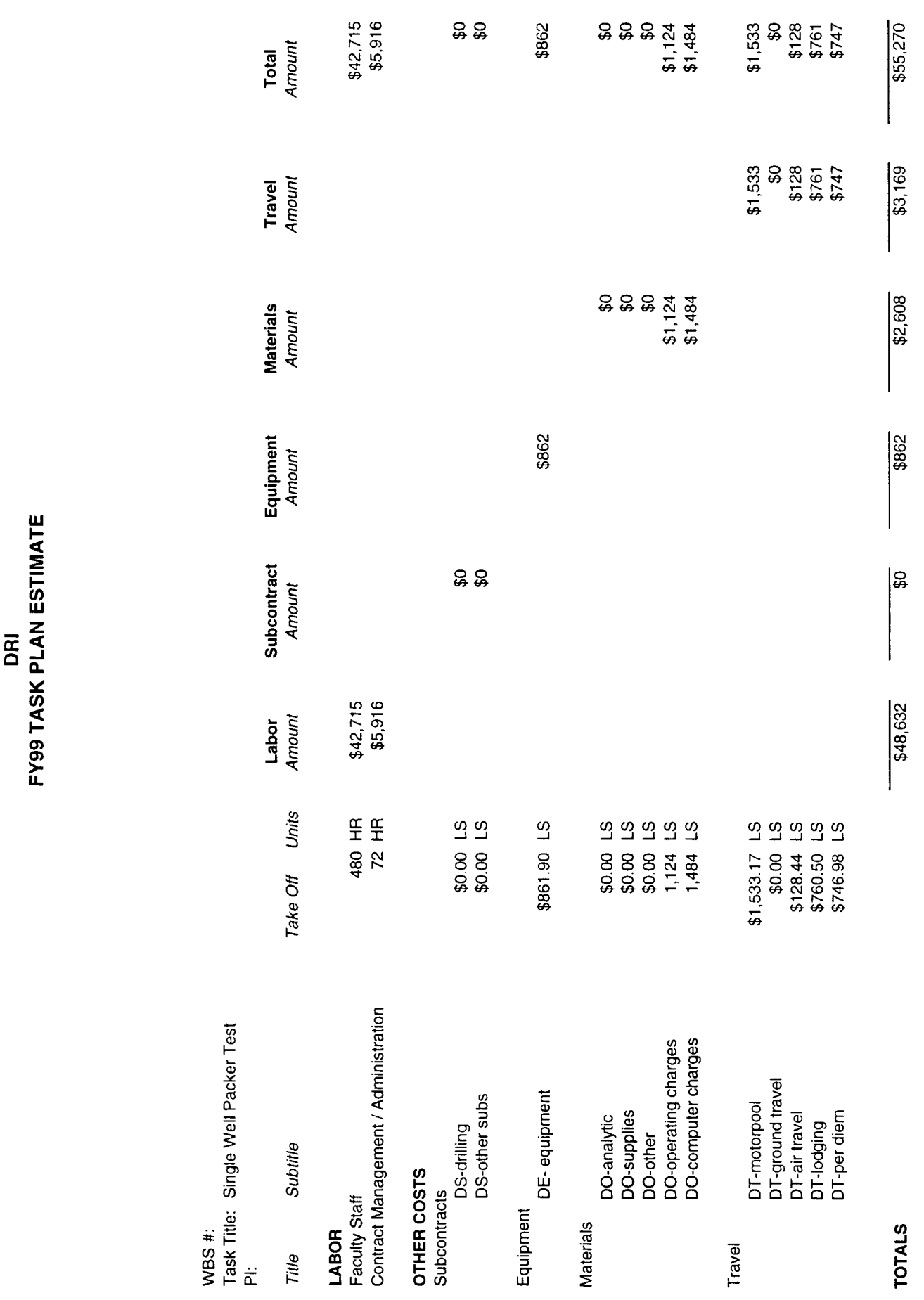

E-13 


\section{IT COST ESTIMATE}

\section{Estimated Costs for Two-well Tracer Testing Program}

\begin{tabular}{|c|c|c|}
\hline Road and Pad Preparation & $\$ 1,500$ & \\
\hline Drill One 1,500-foot Well & $\$ 178,730$ & \\
\hline Standard Suite Borehole Geophysics (One Borehole) & $\$ 18,590$ & \\
\hline Additional Borehole Geophysics (2 Hole Cross-Hole Tomography) & & \\
\hline IT Oversight of Drilling and Geophysical Logging (Assume 3 Days) & $\$ 7,950$ & \\
\hline & Drilting Subtotal & $\$ 206,770$ \\
\hline Construction of One Well (No Filter Pack or Seals Emplaced) & $\$ 25,088$ & \\
\hline Development of One Well & $\$ 9,000$ & \\
\hline IT Oversight of Well Construction and Development (Assume 2 Days) & $\$ 5,300$ & \\
\hline Well Construction and Dev & Iopment Subtotal & $\$ 39,388$ \\
\hline Pull Pump from HC-4, Set Pump in New Well, Reinstall in HC-4 & $\$ 23,800$ & \\
\hline Test Setup and Plumbing & $\$ 1,500$ & \\
\hline IT Oversight of Pump Installation and Test Setup (Assume 5 Days) & $\$ 13,250$ & \\
\hline Pump Installation and $T$ & st Setup Subtotal & $\$ 38,550$ \\
\hline Grand Total for Drilling, Construction, Development & and Test Setup & $\$ 284,708$ \\
\hline
\end{tabular}




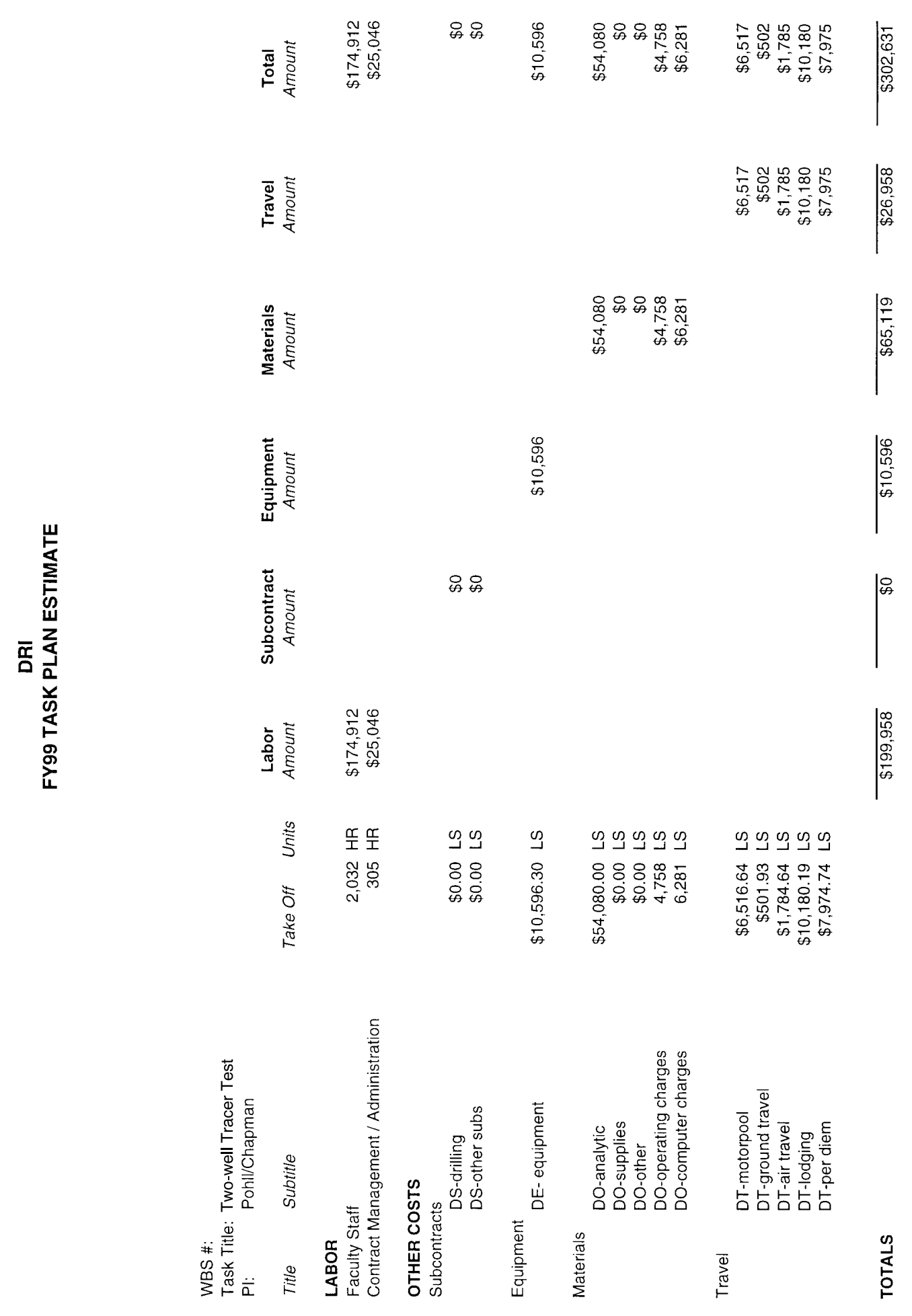

E-15 


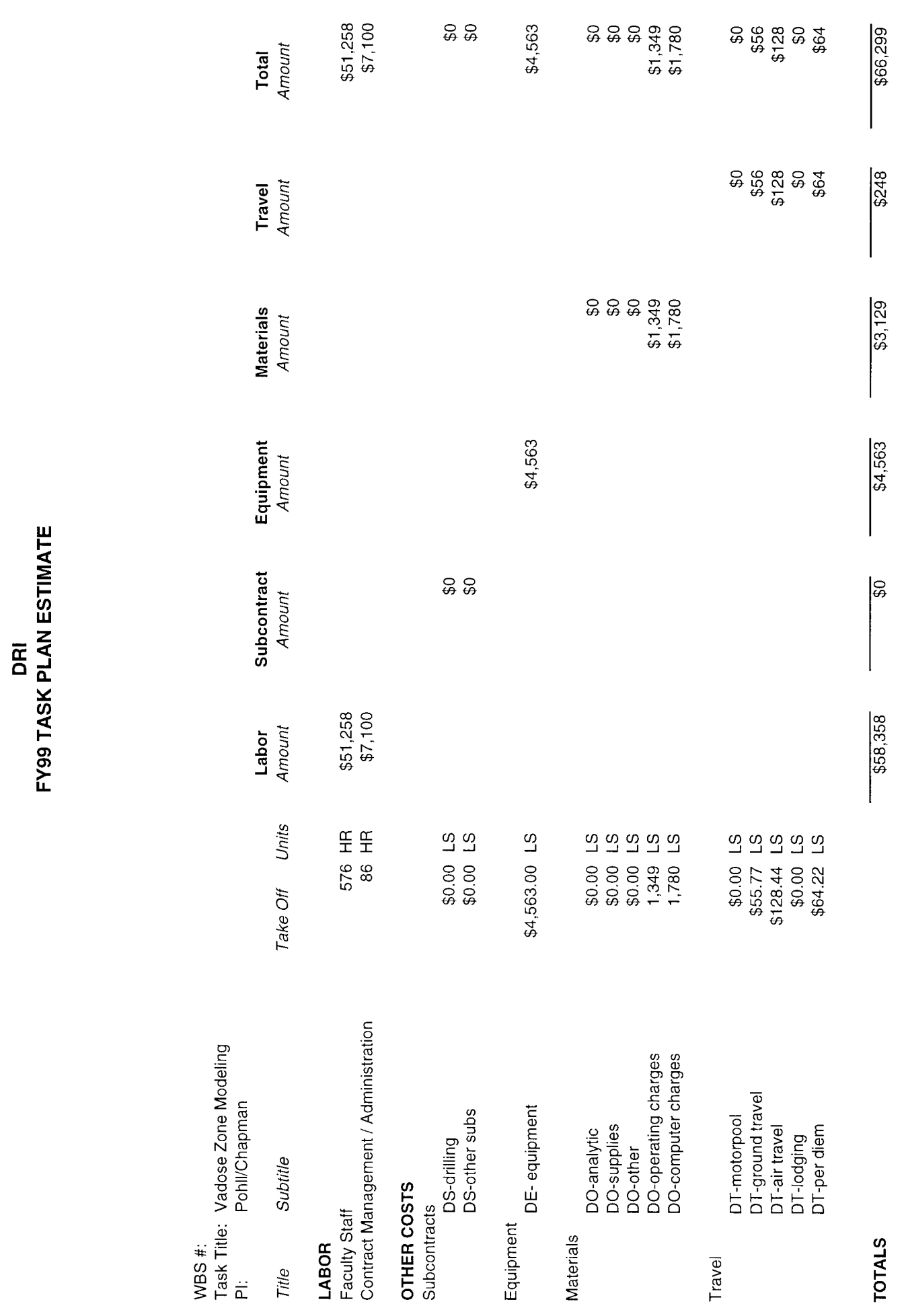

E-16 


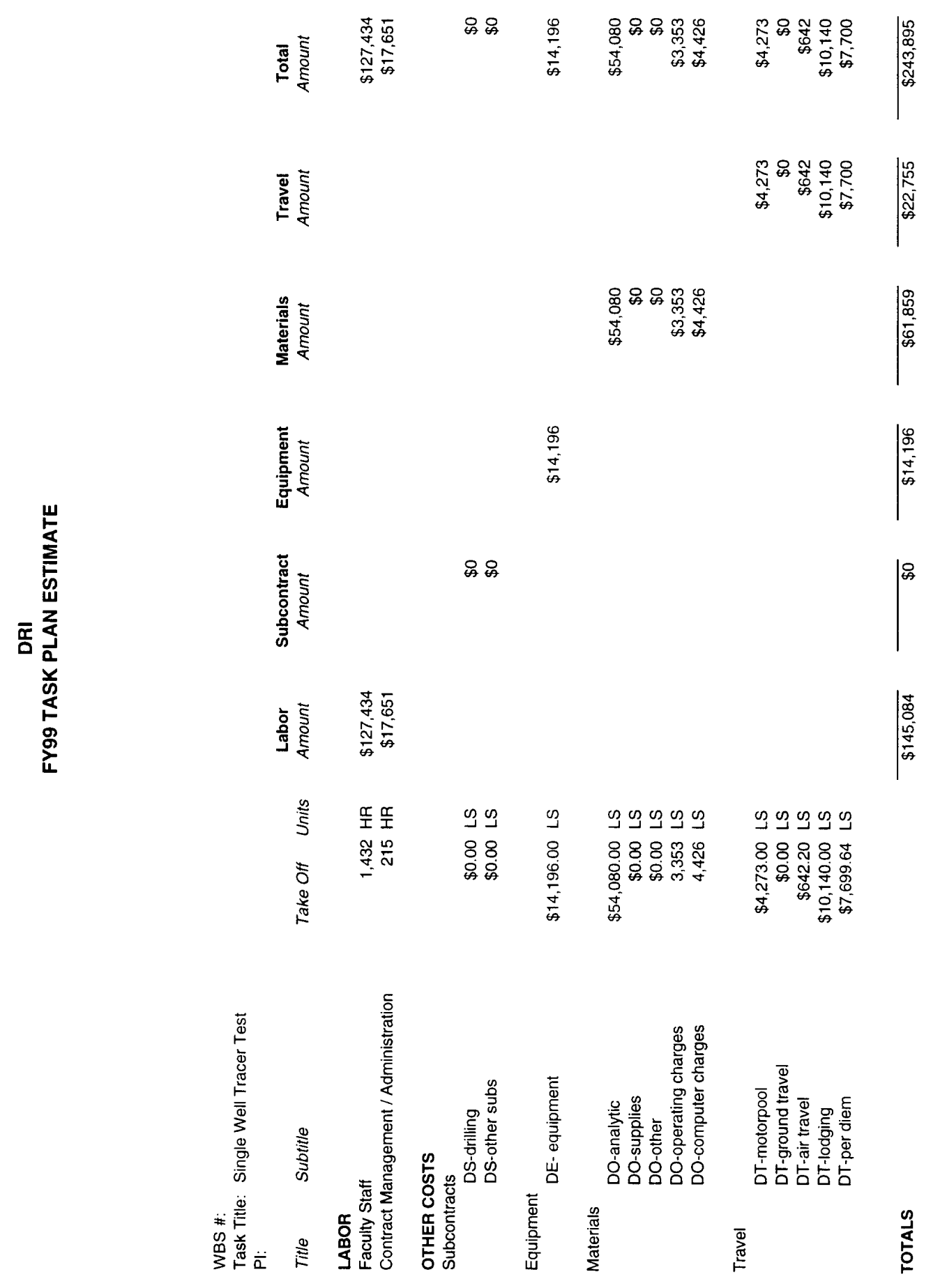




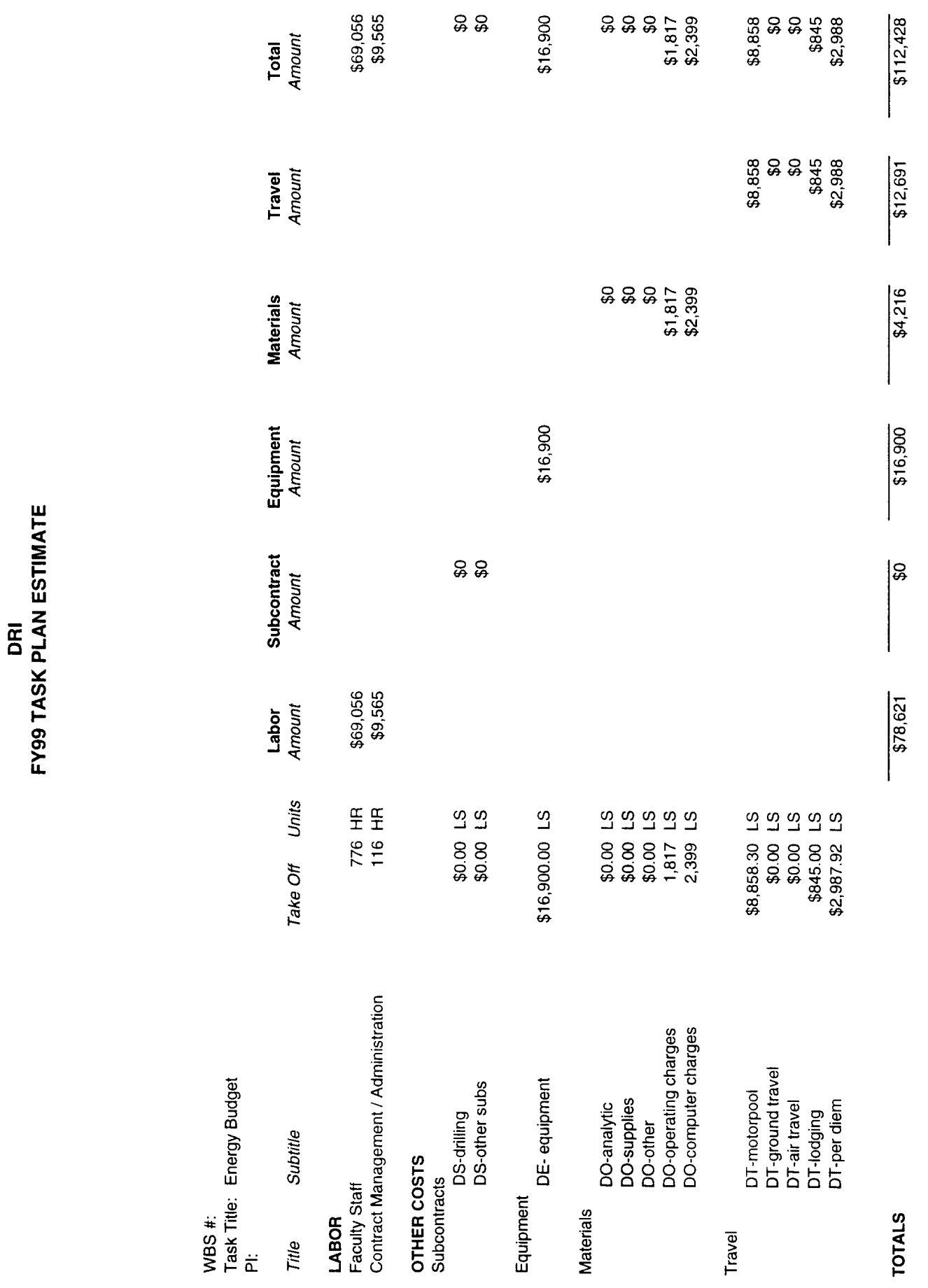

E-18 


\section{DISTRIBUTION}

Raymon D. Cox, Acting, Director

Contract Management Division

Nevada Operations Office

U.S. Department of Energy

P.O. Box 98518

Las Vegas, NV 89193-8518

Beverly Colbert

Contract Management Division

Nevada Operations Office

U.S. Department of Energy

P.O. Box 98518

Las Vegas, NV 89193-8518

Doug Duncan

Hydrology Program Manager

Environment, Safety \& Health Division

Nevada Operations Office

U.S. Department of Energy

P.O. Box 98518

Las Vegas, NV 89193-8518

Kenneth A. Hoar, Director

Environment, Safety \& Health Division

Nevada Operations Office

U.S. Department of Energy

P.O. Box 98518

Las Vegas, NV 89193-8518

Marjory Jones

Desert Research Institute

Water Resources Center

2215 Raggio Parkway

Reno, NV 89512-1095

Randy Laczniak

U.S. Geological Survey

Water Resources Division

6770 S. Paradise Rd.

Las Vegas, NV 89119
Leslie A. Monroe

Environment, Safety \& Health Division

Nevada Operations Office

U.S. Department of Energy

P.O. Box 98518

Las Vegas, NV 89193-8518

Mike Sabbe

Bechtel Nevada

P.O. Box 98521

Las Vegas, NV 89193-8521

Monica Sanchez

Environmental Restoration Division

Nevada Operations Office

U.S. Department of Energy

P.O. Box 98518

Las Vegas, NV 89193-8518

Peter Sanders

Environmental Restoration Division

Nevada Operations Office

U.S. Department of Energy

P.O. Box 98518

Las Vegas, NV 89193-8518

David Shafer

Water Resources Center

Desert Research Institute

755 E. Flamingo Road

Las Vegas, NV 89119-7363

David K. Smith

Isotopes Sciences Division

Lawrence Livermore National Laboratory

P.O. Box 808, M/S L231

Livermore, CA 94550

Doug Trudeau

U.S. Geological Survey

Water Resources Division

6770 S. Paradise Rd.

Las Vegas, NV 89119

Tim White

International Technology Corporation

P.O. Box 93838, M/S 439

Las Vegas, NV 89193-3838 
Runore C. Wycoff, Director

Environmental Restoration Division

Nevada Operations Office

U.S. Department of Energy

P.O. Box 98518

Las Vegas, NV 89193-8518

Nevada State Library and Archives

State Publications

100 North Stewart Street

Carson City, NV 89710-4285

Archives

Getchell Library

University of Nevada, Reno

Beverly Carter

MacKay School of Mines Library

University of Nevada, Reno

Document Section, Library

University of Nevada, Las Vegas

4505 Maryland Parkway

Las Vegas, NV 89154

Library

Desert Research Institute

2215 Raggio Parkway

Reno, Nevada 89512-1095
Library

IT Corporation

Bldg. B-1

P.O. Box 93838, M/S 439

Las Vegas, NV 89193-3838

ATTN: Toni Miller, M/S 439

Library

Southern Nevada Science Center

Desert Research Institute

755 E. Flamingo Road

Las Vegas, NV 89119-7363

Technical Information Resource Center

Nevada Operations Office

U.S. Department of Energy

P.O. Box 98518

Las Vegas, NV 89193-8518

Public Reading Facility

Nevada Operations Office

U.S. Department of Energy

P.O. Box 98521

Las Vegas, NV 89193-8521

Office of Scientific and Technical Information

U.S. Department of Energy

P.O. Box 62

Oak Ridge, TN 37831-9939 